\title{
Die Brown'sche Bewegung und die wahre Existenz der Moleküle.
}

\author{
Von Jean Perrin. \\ (Deutsch von Dr. Julius Donau, Graz.) \\ I. TEIL.
}

1. Erste Anzeichen des Phănomens.

Beim Betrachten einer im Gleichgewicht befindlichen Flüssigkeit, z. B. von Wasser in einem Glase, arscheinen alle Teile dieser Masse in vollkominener Ruhe. Wenn man einen spezifisch schwereren Gegenstand darauf legt, so fällt dieser Körper, und er fällt genau senkrecht, wenn er vollständig rund ist. Das Fallen ist zwar um so langsamer, je kleiner das fallende Objekt ist; aber solange es noch mit freiem Auge gesehen werden kann, fällt es und kommt immer aur Ruhz, wenn es den Boden des GefäBes erreicht hat. Man weiß endlich, daß es nicht mehr zurücksteigt, wenn es am Boden angelangt ist (Prinzip von A. Carnot).

Diese bekannten Pegriffe gelten jedoch nur für Größenordnungen, an welche unser Organismus angepaft ist, und der einfache Gebrauch des Mikroskops genügt, um uns Tatsachen aufzudrängen, welche an Stelle der alten statischen Auffassung des flüssigen Zustandes die kinetische treten lassen.

Es wäre in der Tat schwer, die Vorgănge in der Flüssigken mittels des Mikroskops lange zu studieren, ohne zu bemerken, daB jedes in der Flüssigkeit befindliche Teilchen, anstatt je nach seiner Dichte zu fallen oder zu steigen, ganz und gar unregelmäBige Bewegungen ausführt. Es geht und kommt, bleibt stehen, geht wieder weiter, wirbelt durcheinander, steigt, fallt, steigt wieder, ohne jemals zum gänzlichen Stillstand zu kommen. Das ist die Brown'sche Bèwegung, so genannt zu Ehren des Naturforschers Brown, welcher sie im Jahre 1827 (kurz nach der Erfindung der achromatischen Objektive) entdeckte, dann in der Folge bewies, dab diese Bewegung keineswegs von Lebewesen herrühre und erkannte, daB die suspendierten Teilchen sich um so schneller bewegen, je kleiner sie sind. 


\section{Projektion der Brown'schen Bewegung.}

Man kann dieses Phänomen einem ganzen Auditorium sichtbar machen, aber diese Projektion ist schwierig, und ich glaube nicht, daB es unnütz ist, die VorsichtsmaBregeln auseinanderzusetzen, welche mich zu annehmbaren Resultaten führten. Man bedient sich des clektrischen Lichtbogens (oder besser des Sonnenlichtes) und hält durch einen Wasserkasten den gröBten Teil der nicht leuchienden Warmestrahlen zurück. Die von den suspendierten Teilchen reflektierten Strahlen gehen, wie für die direkte Beobachtung, durch ein Immersionsobjektiv und ein Okular mit sehr starker Vergrößerung, und werden dann durch ein Prisma mit totaler Reflexion so zurückgeworfen, daß das Bild der Körner auf einem matten Glasschirm (zur leichtcren Orientierung in Felder geteilt) entsteht, hinter welchem sich das Auditorium befindet. Auf diese Weise wird das Licht besser ausgenützt, während bei einem gewöhnlichen Lichtschırm eın groBer Teıl der Strahlen in Richtungen zerstreut wird, in denen sich kein Beobachter befindet. Die Vergrößerung kann das 8000 bis 10000 fache erreichen.

Besonders wichtig ist die Anwendung einer geeigneten Suspension. Bei den wenigen Versuchen, welche bisher gemacht wurden, war der Durchmesser der benützten Körner von der Größenordnung des Mikrons (:=:1/1000 mm), und ihr Bild war, bei Anwendung von Immersions- oder seitlicher Beleuchtung, in einer Entfernung von drei Metern (wenigstens beim Bogenlicht) schwer wahrnehmbar. Kleinere Körner sind noch weniger sichtbar, und man wird zu der im ersten Augenblick widersinnig scheinenden Ansicht geleitet, dạh es vorteilhafter ist, große Korner zu projizieren als kleine. Freilich ist ihre Bewegung eine minder lebhafte, doch ist sie genügend stark, um ihre wesentlichen Merkmale leicht erkennen zu lassen.

Man muB also Teilchen wählen, deren Durchmesser mehrere Mikrons (Mikromillimeter) beträgt, was, wie wir bald sehen werden, gleich wünschenswert ist beim eigentlichen experimentellen Studium gewisser Punkte der Brown'schen Bewegung. Ich werde weiter unten (Abschnitı 32) angeben, wie ich zu groken vollkommen runden Gummigutt- oder Mastixkörnern gelangt bin. Mit solchen Kügelchen kann man in einem vollständig verdunkeltem Raum die Brown'sche Bewegung auf eine Entfernung von acht bis zehn Meter zur Wahrnehmung bringen. 


\section{Andauern des Phanomens bei Abwesenheit irgendeiner auBeren Ursache. Erklärung desselben durch die Bewegung der Moleküle.}

Dieses eigenartige von B rown entdeckte Phänomen hat anfangs zunachst nicht viel Aufmerksamkeit auf sich gezogen. Es blieb vielmehr lange Zeit unbeacntet von der Mehrzahl der Physiker, und man kann annehmen, daß diejenigen, welche davon hatten sprechen hören, diese Bewegung für eine derartige hielten, wie sie die Staubteilchen ausführen, dic wir im Sonnenstrahl unter dem Einflub schwacher, durch geringe Druck- und Temperaturunterschiede hervorgebrachter Luftströmungen tanzen sehen. Wenn man hedenkt, daß diese scheinbare Erklärung selbst überlegenen Geistern genügt hat, dann muB man um so mehr den Scharfsinn jener bewundern, welche in dieser für unbedeutend gehaltenen Erscheinung eine Grundeigenschaft der Materie erkannt haben.

Im übrigen ist es, wie fast immer, wenn man nach dem Ursprung einer großen grundlegenden Idee forscht, schwer, festzustellen, welchen Entwicklungsgang die Hypothese von der Molekülbewegung als Ursache des Brown'schen Phänomens genommen hat. Der erste Name, welcher in dieser Hinsicht zu nennen wäre, ist vielleicht derjenige Wi e n e r's, welcher, gestützt auf seine Beobachtungen, bestätigte, daB die Ursache dieser Bewegungserscheinung nicht die Wirkung von Konvektionsstrőmen ist, sondern in der Flüssigkeit selbst zu suchen sei, und welcher endlich, zur Zeit der Entwicklung der kinetischen Wärmetheorie, den Gedanken aussprach, $\mathrm{daB}$ die Molekülbewegungen eine Erklärung des Phänomens abgeben könnten 1).

Einige Jahre später veröffentlichten Delsaulx und P. Carbonnelle in der Royal Microscopical Society und in der Revue des Questions scientifiques (1877 bis 1880 ) verschiedene Notizen überden thermodynamischen Ursprungder Brown'schen Bewegung?). Man kann z. B. in einer Notiz von P. Delsaulx lesen, daB "les trépidations des petits corpuscules en suspension dans les liquides forment véritablement un phénomène général" ; daB "il est dès lors naturel de rattacher un phénomène ayant cette universalité à quel que propriété générale de la matière " und dab „dans cet ordre d'idées, les mouvements intestins de translation qui constituent l'état calorifique

1) Erklărung des atomistischen Wesens des flüssigen Körpcrzusłandes und Bestăligung desselben durch die sogenannten Molckularbewegungen (Pogg. Ann. $118,79,1863)$.

2) Vgl. auch einen im Januar 1909 in der Revue des Questions scientifiques erschienenen Arikel von M. Thirion, welcher auf die Ansichten dieset beiden Forscher, deren Mitarbeiter er war, aufmerksam macht. 
des gaz, des vapeurs et des liquides peuvent très bien rendre raison des faits constatés par l'expérience ${ }^{a}$.

In einer andern Notiz, der von P. Carbonnelle, liest man noch dieses: „Dans le cas d'une surface ayant une certaine étendue, les chocs moleculaires du liquide, cause de la pression, ne produiront aucun ébranlement du corps suspendu, parce que leur ensemble sollicite également ce corps dans toutes les directions. Mais, si la surface est inférieure à l'étendue capable d'assurer la compensation des irrégularités, il n'y a plus lieu de considérer la pression moyenne, il faut reconnaitre des pressions inégales variables de place en place, que le loi des grands nombres ne ramène plus à l'uniformité, et dont l'intensité changera et continuellement d'intensitẻ et de direction. De plus, les inégalités deviendront de plus en plus apparentes à mesure qu'on supposera le corps plus petit, et par suite les oscillations deviendront en même temps de plus en plus vives...."

Diese wichtigen Betrachtungen wurden gleich denen von Wiener nur sehr wenig bekannt. Im übrigen scheint das ihnen zugrunde liegende Versuchsmaterial nicht ausreichend gewesen zu sein, um die oberflächliche Erklärung des Phänomens, von der ich schon oben sprach, zu entwerten, so dab die neue Theorie von denjenigen, welche davon Kenntuis erhielten, nicht anerkannt wurde.

Durch die Arbeiten M. Gou y's ${ }^{1}$ ) endlich wurde festgestellt, dab die Annahme der Molekularbewegung nicht nur eine gute Erklärung des Brown'schen Phänomens ist, sondern daß letzteres überhaupt nicht leicht auf eine andere Ursache zurückgeführt werden kann. Dies brachte die Hypothese in die Höhe. Die Arbeiten Gouy's erregten sofort großes Aufsehen und erst seit dieser Zeit nahm din Brown'sche Bewegung einen Rang unter den hervorragenden Problemen der theoretischen Physik ein.

M. Gouy vor allen übrigen beobachtete, daß die Brown'sche Bewegung nicht durch Schwingungen von auBen erregt wird, indem sie bei Nacht, in einem Stollen, auf dem Felde draußen, wie am Tage in der belebien Strafe andauert. Sie wird auch nicht hervorgerufen durch die Konvektionsströne, welche in Flüssigkeiten entstehen, die nicht an allen Stellen die gleiche Temperatur besitzen, denn sie ändert sich kaum, wenn man sich noch so sehr Mühe gibt, das thermische Gleichgewicht in der Flüssigkeit zu erhalten. Es ist also jeder Vergleich zwischen der Brown'schen Bewegung und den

i) Journal de Physique, 2. Serie, 7, 561 (1888); Compt. rend. 109, 102 (1889); Revue général des Sciences 1895, I. 
im Sonnenstrahl tanzenden Staubteilchen unrichtig. Im letzteren Falle kסnnen wir leicht beobachten, das sich benachbarte Staubteilchen im allgemeinen im selben Sinne bewegen, wie die sie forttreibende Strömung, wăhrend bei der Brown'schen Bewegung eines der auffallendsten Merkmale die vollständige Unabìängigkeit der Verschiebungen zweier einander noch so nahe benachbarter Teilchen ist. Ebensowenig kann die unvermeidliche Belichtung zur Verantwortung gezogen werden, denn M. Gouy konnte weder bei fast vollständigem Ausschlub derselben noch bei Aenderung der Farbe des Lichtes irgendeine nennenswerte Aenderung des beobachteten Phänomens hervorrufen. Alle anderen nach und nach heraufbeschworenen scheinbaren Ursachen kommen ebensowenig in Betracht; die Natur. der Teilchen selbst scheint keine wichtige Rolle zu spielen, und so ist es schwer, nicht daran zu denken, daB dies. Teilchen einen inneren Bewegungszustand der Plüssigkeit verraten, und dies um so ausgesprochener, je kleiner sie sind, gleich wie ein Korkstöpsel besser den Bewegungen der Meereswellen folgt als ein großer Stock.

In diesem Lichte zeigt sich deutlich, was man das Gleichgewicht einer Flüssigkeit nennt. Dieses Gleichgewicht gilt nur für die ganze Masse als solche: es ist ein statistisches Gleichgewicht. In Wirklichkeit bewegt sich jede Flüssigkeit immerwährend und von selbst um so heftiger und rascher, je kleinere Teilchen in Betracht kommen. Der statische Begriff vom Gleichgewicht ist also vollkommen illusorisch.

\section{Die Brown'sche Bewegung and das Prinzip von Carnot.}

Wir haben also eine Bewegung vor uns, welche ohne äubere Ursache andauert. Es ist klar, daß diese Bewegung nicht im Widerspruch steht mit dem Prinzip von der Erhaltung der Kraft. Es genügt, daB jede Steigerung der Geschwindigkeit eines Teilchens von einer Abkühlung der Flüssigkeit in seiner Nachbarschaft begleitet ist und daB jede Verminderung der Geschwindigkeit eine örtliche Erwärmung zur Folge hat, ohne dab dabei auch nur eine Spur Energie verloren geht. Wir nehmen einfach wahr, daB das thermische Gleichgewicht auch selbst nur ein statistisches ist. Aber man muB beobachten, und dieser wichtige Gedanke rührt auch von $M$. Gouy her, daB die Brown'sche Bewegung keineswegs vereinbar ist mit den zu scharfen Formen, welche man oft dem Carnot'schen Prinzip gibt; man kanr : a für einen beliebigen dieser Ausdrücke prüfen. Man braucht 2. im Wasser, das sich im thermischen Gleichgewicht be- 
findet, nur ein Tèilchen, das schwerer wie Wasser ist, mit den Augen zu verfolgen, um zu sehen, wie es sich in bestimmten Augenblicken von selbst erhebt, wobei es Arbeit auf Kosten der Wärme des umgebenden Mittels verzehrt. Man kann also nicht mehr sagen, dab das Perpetuum mobile der zweiten Art unmöglich ist, sondern man muß sagen: „Für die Größenordnung, welche uns praktisch interessiert, ist das Perpetuum mobile der zweiten Art so, unbedeutend, daB es vernunftgemaß gar nicht in Betracht kommt." Im übrigen waren derartige Einschrănkungen schon seit langem gemacht worden: der Gesichtspunkt, nach welchem das $C$ arnot'sche Prinzip nur ein angenahertes Gesetz ausdrückt, wurde von Clausius, Maxwell, Helmboltz, Boltzmann, Gibbs verteidigt, und man erinnere sich im einzelnen an den "Damon" von $M a x w e l l$, der nach Belieben, ohne Arbeit Wärme von einer kalten Region in eine warme übergehen lieB. Solange man sich darauf beschränkte, die Moleküle als unsichtbar gelten zu lassen, war es, ihre Existenz leugnend, möglich, an die strenge Gültigkeit des $\mathrm{Ca}$ r n ot'schen Prinzipes zu glauben. Jetzt aber, wo sich diese Strenge im Widerspruch befindet mit einer sinnlich wahrnehmbaren Wirklichkeit, wăre dies nicht mehr vernünftig.

Die praktische Bedeutung des Carnot'schen !rinzipes wird dadurch nicht berührt, und ich glaube nicht erst lange versichern $2 u$ brauchen, daB es unbesonnen wăre, mittels der Brown'schen Bewegung Bausteine heben zu wollen. Aber das Verständnis dieses so wichtigen Prinzips wird dadurch ein tieferes; man sieht leichter ein, wie es an die Struktur der Materie gebunden ist, und man begreift es, wenn man sagt, dab die freiwillige Beiordnung der Molekularbewegung um so weniger wahrscheinlich wird, eine je größere Molekülanzahl sie umfaBt und je länger sie dauert ').

\section{Die kinetische Molekularhypothese.}

Ich habe gesagt, dab die Brown'sche Bewegung in der Theorie von $M$. Gouy und seiner Vorgánger ihre Erklärung in den unablăssigen Bewegungen der Flüssigkeitsmoleküle findet, welche, fortwährend an die beobachteten Teilchen stoBend, ohne dab sich ihre StoBe genau das Gleichgewicht halten, diese Teilchen in der Flüssigkeit unregelmaBig hin- und herführen. Man hat in der Tat, besonders

1) Was die allgemeine Bedeutung des Prinzipes anbelangt, so verweise tch auf die in sehr interessanter Weise entwickelten Belrachtungen. vön J. H. Rosny dem Aelteren in seinem Buche Sur le Pluralisme, S. 85 ‥ 91 (F. Alcan, 1909). 
zur Erklärung der Diffusionserscheinungen, wie auch der Umwandlung von Bewegung in Warme, schon seit langem angenommen, nicht nur daB die Körper trotz ihrer scheinbaren Homogenität eine diskontinuier. liche Struktur besitzen und aus verschiedenen Molekülen zusammengesetzt sind, sondern auch, daB diese Moleküle sich in steter Bewegung befinden, dab diese Bewegung mit steigender Temperatur lebhafter wird und erst beim absoluten Nullpunkt erlischt.

Anstatt diese fertige Hypothese herzunehmen und $z u$ sehen, ab sie Rechenschaft gibt von der Brown'schen Bewegung, scheint es mir vorteilhafter, zu zeigen, dab sie durch dieses einzige Phänomen logisch hergeleitet werden kann. und das will ich jetzt versuchen.

Das wirklich Befremdende und Neue in der Brownschen Bewegung ist ihre Beständigkeit. Das scheint in ersten Augenblick im Gegensatz mit unserer täglicien Erfahrung von der Reibung. Wenn wir zum Beispiel einen Eimer Wasser in einen Behälter hineinschütten. so wird es uns bald scheinen, als ob die Bewegung, welche zuerst die flüssige Masse beherrschte, in kurzer Zeit verschwunden sei. Betrachten wir einmal auf welche Art dieses scheinbare Gleichgewicht erreicht wird: sämtliche Wasserteilchen hatten zuerst nahezu gleiche Geschwindigkeiten und gleiche Richtung; diese Gleichsinnigkeit hört auf, sobald bestimmte Teilchen nach dem Anschlagen an den Gefäßwänden in verschiedenen Richtungen mit geänderter Geschwindigkeit zurückprallen, um neuerdings dürch ihre Stöße an andere Flüssigkeitspartien aus ihrer Richtung gebracht zu werden. Auch eine Weile nach dem Hineinschütten werden alle Teile des Wassers noch in Bewegung sein, aber man wird davon eine kleine Partie betrachten müssen, für welche die Geschwindigkeiten ihrer verschiedenen Punkte nahezu gleiche Richtung und dieselbe GröBe besitzen. Man würde die Bewegung leicht sehen, wenn man in die Flüssigkeit gefärbte Staubteilchen hineinmischen würde, welche dann gezwungen wăren, an den immer unregelmäBiger werdenden Bewegungen teilzunehmen.

Wir können als: demnach, so lange wir nochirgend etwas zu unterscheden vermögen, nicht beobachten, dab die Bewegungen aufhören, sondern dab sie mehr und mehr in Unordnung kommen, dab sie sich in immer unregelmåßigerer Weise in kleinere und kleinere Teile ausbreiten.

Geht dieses Entordnen (Dekoordination) ins Unendliche fort?

Um irgendeinen AufschluB darüber zu bekommen, um dieses Durcheinander wenigstens so weit als möglich zu verfolgen, wird man nicht mehr mit unbewaffnetem Auge beobachten, sondern sich des 
Mikroskops bedienen und als Anzeiger der Bewegung mikroskopischen Staub nehmen. Nun, das sind genau die Bedingungen, unter denen man die Brown'sche Bewegung wahrnimmt; wir sind also überzeugt, daB die Dekoordination der Bewegung, welche wir so ohne weiteres wahrnehmen, nicht immer andauert und mit Hilfe des Mikroskops stellen wir ein Gleichgewicht zwischen der Koordination und der Dekor dination fest. Und in der Tat, in jedem Augenblick, wenn bestimmte die Bewegung anzeigende Körner stillstehen, findet 24 gleicher Zeit in andern Regionen eine Bewegung statt, welche sich selbst wieder beiordnct (rekoordiniert) in der Weise, daß sie solchen in Ruhe befindlichen Teilchen eine Geschiwindigkeit erteilt. Man wird also zu folgendem Schlub geführt:

Da die Ausbreitung der Bewegung in einer Flüssigkeit nicht fortdauert und begrenzt wird durch eine spontane Rekoordination, sind die Flüssigkeiten selbst zusammengesetzt aus Teilchen, Molekülen, welche durch gege.ıseitige Vonittalung alle möglichen Bewegungen ausführen können, innerhaib welcher aber keine Zerstreuung der Bewegung möglich ist. Gäbe es keine solche Moleküle, so wäre eine Grenze der Dekoordination der Bewegungen auch nicht denkbar.

Andererseits, wenn sie existieren, werden stets teilweise Rekoordinationen stattfinden; diese Molkkuile gehen aneinander vorbei, beeinflussen einander (sei es durch Stoß oder sonstwie) und ändern fortwährend ihre Geschwindigkeiten an GröBe und Richtung, und durch Zufall wird es manchmal vorkommen, daB benachbarte Moleküle übereinstimmende Bewegungen ausführen. Endlich wird es, ohne daB dieșe vollständige Uebereinstimmung nötig wäre, wenigstens häufig v'rkommen, daß die Moleküle in der Gegend, wo sich ein anzeigendes Staubteilchen befindet, genügend Bewegungsenergie besitzen, um dasselbe in jene Richtung fortzustoßen.

Die Brown'sche Bewegung ist bei konstanter Temperatur andauernd: Das ist eine Erfahrungstatsache. Die Molekularbewegung, welche wir als Erklärung der Brown'schen annehmer, ist daher auch selbst andauernd.

Wenn diese Moleküle wie Billardkugeln aneinander stoßen, dann kann man sie als vollkommen elastisch betrachten und dieser Zustand kann als Erklärung dienen, warum bei den molekularen Zusammenstöben in einem thermisch isolierten System die Summe der Bewegungsenergien stets die -gleiche bleibt. 
Kurz und gut, die alleinige Betrachtung der Brownschen Bewegung kann schon zu der Annahme führen, dab jede Flüssigkeit aus elastischen durch immerwährende Bewegung belebten Molekülen geformt ist.

\section{Die Atome. Die Konstante von Avogadro.}

Seither nimmt man auf Grund verschiedener chemischer Betrachtungen und besonders der Substitutionserscheinungen die Existenz ven Atomen an. Wenn man zum Beispiel Kalzium in Wasser löst, so verdrängt ma:ı nur die Hâlfte des Wasserstoffs, welchen dieses ellthält. Der Wasserstoff dieses Wassers und somit jedes Wassermolekül besteht also aus zwei Teilen. Durch keine Erfahrung wird man gezwungen mehr anzunehmen, und man kann sich leicht denken, dats diese Teilchen durch kein chemisches Mittel sich weiter zerlegen lassen, oder mit einem Worte, daB dies die A to me sind. Andererseits wiegt jede Wassermenge und daher jedes Wassermolekül neun. mal soviel als der Wasserstoff, welcher darin enthalten ist; das Wassermulekül, welches zwei Wasserstoffatome enthält, wiegt also achtzehnmal mehr als das Wasserstoffatom. Auf ähnlichc Weise würde man feststellen, daß beispielsweise das Methanmolekül sechzehnmal schwerer ist als dasselbe Wasserstoffatom. Man gelangt auf diese Weise vom rein chemischen Gesichtspunkt durch den Atombegriff zu dem Verhältnis 10/18 der Molekulargewichte des Methanmoleküls und des Wassers. Nun koinmt man aber zu ganz demselben Verhältnis, wenn man Methanund Wasserdampfmassen vergleicht, welche unter gleichen Druck- und Temperaturverhältnissen denselben Raum einnehmen. Diese beiden Massen, welche in demselben Verhältnis stehen als die Moleküle beider, enthalten also gleichviel Moleküle. Dieses Ergebnis wiederholt sich bei den verschiedenen Gasen und wir kommen schlieblich auf experimentellem Weg auf die berühmt gewordene Annahme zurück, welche vor ungefähr einem Jahrhundert als "Hypothese von Avogadro*

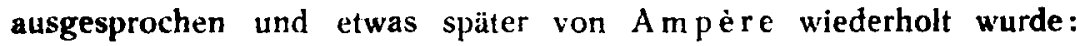
"Zwei beliebige Gase enthalten bei gleichen Druckund Temperaturverhältuissen in gleichen Räumen gleichviel Moleküle."

Wenn man unter einem Gramm-Molekül eines Stoffes, wie es jetzt gebräuchlich ist, die Masse dieses Körpers versteht, welche im Gaszustand das gleiche Volimen (gleiche Druck- und Temperaturverhältnisse vorausgesetzt) einnimmt, als zwei Gramme Wasserstoff, so lautet die Regel von Avogadro wie folgt: 
Zwei Gramm-Moleküle eines Stoffes enthalten die gleiche Anzahl Moleküle.

Diese unveränderliche Zahl, $\mathrm{N}$, ist eine allgemeine Konstante, und man nennt sie die Konstante von Avogadro. Wăre diese Konstante bekannt, so würde man die Masse cines beliebigen Moleküls kennen lernen; man würde selbst die Masse der Atome berechnen können, da uns aus den chemischen Formeln, zu denen wir auf verschiedenen Wegen gelangen, bekannt ist, wieviel Atome jeder Art in jedem Molekïl enthalten sind.

Das Gewicht des Wassermoleküls ist at n Beispiel 18 , das des Sauerstoffs $\frac{32}{N}$ und so für jedes Molekül. Ebenso ist das Gewicht des Sauerstoffatomes gleich $\frac{16}{N}$, das des Wasserstoffatoms $\frac{1,008}{N}$ und so für jides Atom.

\section{Die Konstante der Moleku!arenergie.}

Es ist leicht einzusehen, dah, wenn die Konstante von Avogadro bekannt wäre, man die mittlere kinetische Entagie der Bewegung der verschiedanen Moleküle berechnen könnte, und dab umsekehrt das Mab dieser Energie uns $N$ geben würde. Fassen wir diesen wichtigen Punkt etwas näher ins Auge.

Weun die Flüssigkeiten aus sich bewegenden Molekülen zusammengesetzt sind, dann erklärt sich der Druck, den sie auf die Gefäßwände, welch ihrer Ausbreikung sich entgegensetzen, ausüben, durch die StoBe ihrer Moleküle gegen diese Wände, und bei de" Gasen (wo die Molekïle sehr weit voneinander entfernt sind) h\% man, dank der rach und nach geschaffenen und verbesserten Sätze von Joule, Clausius und Maxwell, zeigen können, dab diese Annahme sich gena?! ausdrücken läßt durch die Gleichung

$$
\mathrm{pv}=\frac{2}{3} \mathrm{nw},
$$

wobei $p$ den Druck bezeichnet, welchen n-Moleküle mit der mittleren kinetischen Energie $w$ in einem Volumen $v$ ausüben.

Wenn die betrachtete Gasmasse ein Gramm-Molekül darstellt, dann wird $\mathrm{n}=-\cdots \mathrm{N}$ und $\mathrm{pv}=\mathrm{RT}$, wo $\mathrm{T}$ die absolute Temperatur und $R$ die Konstante der Gase $\left(=83,2 \times 10^{6}\right.$ in Einheiten des C. G. S. $)$ bezeichnen; die vorstehende Gleichung schreibt sich dann

$$
\frac{2}{3} \mathrm{Nw}=\mathrm{RT} \quad \text { oder } \quad \mathrm{w}=\frac{3 \mathrm{R}}{2 \mathrm{~N}} \mathrm{~T} .
$$


Nun ist die Konstante $\mathbf{N}$ für alle Stoffe die gleiche. Die kinetische Bewegungsenergie der Moleküle hat also für alle Gase denselben mittleren Wert, welcher proportional, ist der absoluten Temperatur

$$
w=-\alpha T \text {. }
$$

Die Konstante $\alpha$, welche man die Konstante der Molekular energic nennen könnte und gleich ist $\frac{3 R}{2 N^{\prime}}$, ist wie $N$ cine allgemeine Konstante.

Es ist klar, daß beide Konstanten bekannt w'erden, wenn ein: davon es wird.

\section{Die Atome der Elektrizităt.}

Zugleich mit $\mathbf{N}$ oder $\alpha$ wird endlich noch ein dritte allgemeinc Konstante gefunden, die sich beim Studium der elektrolytischen Ers hein ungen ergibt. Man weiB, daB die Elektrolyse des Gramm-Moleküls eine; gegebenen Elektrolyten von dem Durchgang stets gleicher Elektrizitätsmengen begleitet ist; bekanntlich erklärt man sich dies so, dah man annimmt, dal\$ in jedem Elektrolyten ein Teil der Moleküle in Ionen gespalten ist, welche eine bestimmte elektrische Ladung besitzen und daher im elektrischen Felde beeinflubt werden; endlich weit man, wenn man die Elektrizitätsmenge $F(96550$ Coulombs $)$, welche bei der Elektrolyse von einem Gramm-Molekül Salzsäure hindurchgeht, ein Faraday neunt, dab die Zerlegung irgendeines andem GrammMoleküls von dem Durchgang einer ganzen Anzahl Farada , begleitet ist, und dab also irgendein lon eine ganze Arzahl mal die Ladıng eines Wasserstoffions trägt. Diese Ladung e zeigt sich also als unteibar und bildet das elektrische Atom oder ein Elektron (Helmholt $\%$ ).

Es ist leicht, diese allgemeine Konstante $z u$ erhalten, wenn man eine der Konstanten $\mathrm{N}$ oder $\alpha$ kennt. $\mathrm{Da}$ in der Tat ein GranmAtom Wasserstoff, das heiBt $\mathrm{N}$-Atome Wasserstoff, im ionisierten Zustand ein Faraday mit sich führt, so hat man

$$
\mathrm{Ne} \ldots \mathrm{P}
$$

das heiBt, in elektrostatischen Einheiten des C. G. S.,

$$
\mathrm{Ne}=96550 \cdot 3 \cdot 10^{9}=29 \cdot 10^{13} \text {; }
$$

man erhält also mit einem Schlag die drei allgemeinen Konstanten $\mathbf{N}$, e, a.

\section{Molekulargeschwindigkeiten. Das Unregelmäigkeitsgesetz von Maxwell. Mittlere Wegstrecken.}

Man hat begonnen auf diese Frage $z u$ antworten, und disnit hat man, dank der bewunderungswürdigen Anstrengungen von 
Clausius, Maxwell und van derWaals, die angenaherte Grobe der Moleküle bestimmt. Ohne mich in Einzelheiten einzulassen, will ich den Weg angeben, welchen diese Forscher gegangen sind:

Zunächst rechnet man für jedes Gas das mittlere Quadrat $\mathbf{U}^{2}$ der Molekulargeschwindigkeit, indem man von der vorhin aufgeschriebenen. Gleichung

$$
\frac{2}{3} \mathrm{Nw}=\mathrm{RT}
$$

ausgehi. Es genügt, zu bemerken, daß man für $2 \mathrm{Nw}=\mathrm{MU}^{2}$ schreiben kaun, wobei $M$ das Gramm-Molekül des betreffenden Gases bedeutet. Man findet so, daB $U$ von der Größenordnung von einigen Hundert Metern pro Sekunde ist ( $43 \overline{5}$ Meter für Sauerstoff bei $0^{\circ}$ ).

Wohl verstanden, die Molekulargeschwindigkeiten sind sehr veranderlich und ungleich; aber in einer bestimmten Gasmasse bleibt das Verhältnis der Zahl der Moleküle, welche eine bestimmte Geschwindigkeit haben, fest. In der Annahme, daB die Wahrscheinlichkeit einer Komponente $\mathrm{x}$ unabhängig ist von den Werten der Komponenten $\mathrm{y}$ und $\mathrm{z}$ hat Maxwell das Verteilungsgesetz der Molekulargeschwindigkeiten abgeleitet. Der Ausdruck für dieses Gesetz

$$
\frac{1}{U} \sqrt{\frac{3}{2 \pi}} e^{-\frac{3}{2} U^{2}} \mathrm{dx}
$$

kennzeichnet die Unregelmä日igkeit der Molekularbewegungen. Man erhält ihn auch, wenn man annimmt, daB die Komponenten nach $0 x$ um den Wert Null herum nach dem von $G a u B$ und Laplace ausgesprochenen "Gesetz des Zufalls" zerstreut sind.

Dieses Gesetz von der Verteilung der Geschwindigkeiten gestattet die mittlere Geschwindigkeit $\Omega$ zu rechnen, welche nicht identisch ist mit $U$ (wie auch $\frac{a+b}{2}$ nicht die Quadratwurzel von $\frac{a^{2}+b^{2}}{2}$ ist), aber welche in der Tat sehr wenig davon abweicht $\left(\Omega=U \sqrt{\frac{8}{3 \pi}}\right)$. Andererseits erlaubt dieses Verteilungsgesetz die Hypothese zu prüfen, nach welcher die innere Reibung zwischen zwei parallelen mit verschiedener Geschwindigkeit sich bewegcnden Gasschichten durch das fortwăhrende Eintreffen der Moleküle von einer Schichte in die andre zustande kommt. So fand $M$ axwell, daB der Koeffizient der inneren Reibung $(\xi)$ oder Viskosität, welcher experimental bestimmbar ist, nahezu gleich ist dem dritten Teil des Produktes aus folgenden drei Größen: der absoluten Dichte des Gases $\delta$ (welche uns durch Wägung 
zugänglich ist), der mittleren Geschwindigkeit $\Omega$ der Moleküle (welche welche wir berechnen können) und der mittleren Weglănge der Moleküle L, das ist dem mittleren Wert des Weges, den ein Molekül zwischen zwei aufeinanderfolgenden Stößen in gerader Richtung durchläuft. In Wirklichkeit fand er

$$
\xi=0,31 \delta \Omega \mathrm{L} \text {. }
$$

Die mittlere Weglänge ist also bestimmbar; zum Beispiel beträgt sie für Sauerstoff oder Stickstoff bei gewöhnlicher Temperatur und bei Atmosphărendruck ungefähr $1 / 10$ Mikromillimeter. Bei den niedern Drucken der Crookes'schen Röhren kann sie mehrere Zentimeter erreichen.

\section{Beziehung zwischen der mittleren Weglănge des Molektuls und seinem Durchmesser.}

Andererseits zeigt ein Satz, den wir Cla u si u s verdanken, daB sich dieselbe mittlere Weglünge auch auf eine andere Art berechnen läBt, und zwar als eine Funktion der Annäherung der Moleküle und ihrer Dimensionen 1). Es ist in der Tat leicht einzusehen, daB die mittlere Weglänge um so kleiner wird, je mehr sich die Moleküle einander nähern und je grober sie sind.

Aber es hängt viel von der Form ab und ein Molekül von Stäbchenform wird z. B. nicht in gleicher Weise hindernd wirken, als wenn es Kugelgestalt hätte. Da man jedoch nichts sicheres über die Form der Moleküle weiß, hat man gedacht, keinen großen Irrtum zu begehen, wenn man ihnen die Gestalt einer Kugel zuspricht, deren Durchmesser gleich ist der mittleren Entfernung der Zentren zweier aufeinanderstoßender Moleküle. Diese Annahme kann gut sein für den Fall, dab es sich um einatomige Moleküle handelt (Quecksilber, Argon usw.), aber sie ist sicher falsch für die anderen Moleküle, kann aber doch noch dazu dienen, um angenäherte Folgerungen aus ihr zu ziehen, wenn es sich um nicht sehr komplizierte Moleküle handelt, wie z. B. beim Sauerstoff oder Stickstoff.

Betrachten wir also die Moleküle als Kugeln. Die angenäherte Rechnung von Clausius, die seither von Maxwell verbessert wurde, zeigt annähernd, daß

$$
L=\frac{1}{\pi \sqrt{2}} \cdot \frac{1}{n D^{2}},
$$

eine Gleichung, in welcher $D$ den Durchmesser eines Moleküls und n die Anzahl der in einem Kubikzentimeter enthaltenen Moleküle bedeuten.

1) Pogg. Ann. 1858. 
Da wir L. die mittlere Weglänge nennen können, so würde uns eine zweite Beziehung zwischen $\mathrm{n}$ und $\mathrm{D}$ den Durchmesser der Moleküle und ihre Anzahl $\mathrm{n}$ im Kubikzentimeter bestimmen lassen. In diesem Fall würden wir durch Multiplikation dieser Zahl n mit den bekannten Volumen des Gramm-Moleküls unter den gleichen Druck- und Temperaturbedingungen die Zahl der Moleküle in einem Gramm-Molekül, $\mathbf{N}$, d. h. die drei gesuchten allgemeinen Konstanten erhalten.

Nur ist diese zweite Berichung zwischen $n$ und $D$ nicht sehr leicht aufzufinden.

\section{Erste Bestimmungen der Konstante von Avogadro.}

Man kann mit der Beobachtung beginnen, dab im flüssigen $\mathrm{Zu-}$ stand die Moleküle nicht mehr aneinander gedrängt sein können, als es Kugeln in cinem Haufen von Kugeln sind \%. Nun kann man leicht feststellen, daB das Volumen der Kugeln 100 ist vom Volumen des Haufens im ganzen. Man hat also $1 / 6 \pi n D^{3}<0,73 q$, wo $\varphi$ das bekannte Volumen bedeutet, das in f!üisigen Zustand und bei tiefer Temperatur die Masse eines Kubikzentimeters des betrachteten Gases einnimmt. Diese Ungleichung kombiniert mit der vorangegangenen Gleichung, welche das Produkt $" \mathrm{D}^{2}$ gibt, führt zu einem großen (aber sehr angenăherten) Wert des Durchmessers der Moleküle, jedoch zu sehr unsicheren (und zu kicinen) Werten für $\mathrm{n}$ und $\mathrm{N}$. Man macht im allgemeinen diese Bestimmung für den Sauerstoff, welcher ein $\mathrm{N}>9.10^{22}$ gibt; es ist jedoch besser, sie für ein einatomiges Gas durchzuführen, dessen Moleküle wirklich Kugeln sein können, und in der Tat habe ich beim Wiederholen dieser Rechnung für das Quecksilber, dessen mittlere Weglänge bei $370^{\circ} \mathrm{C} 21.10^{-6}$ beträgt (Tabellen von Landolt), als untere Grenze für $\mathrm{N}$ höhere und daher günstigere Werte erhalten, und zwar $\mathrm{N}>45.10^{22}$. Was den molekularen Durchmesser anbelangt, so findet man denselben für alle in Betracht gezogénen Gase kleiner als ein Milliontel Millimeter (für den besonderen Fall des Quecksilbers $\mathrm{D}<3.10^{-8}$ ).

Diese Angabe versetut uns in die Lage eines Astronomen, welcher gern die Entfernung eines Sternes von der Sonne kennen würde, aber vorläufig nur weiB, daB er entfernter ist als der Neptun. Mangels

1) In Wirklichkeit beschränkt sich der ursprüngliche von Loschmidt herrührende Satz auf die Feststeliung, daB das Volumen der Molekule kleiner ist als das der Fldissigkeit, jedoch nicht zehnmal kleiner sein kann als letzteres. 
einer genauen Messung wird er diesen Stern wenigstens einztischlieben trachten zwischen zwei Grenzwerte, und z. B. erfahren, daß er năher der Sonne ist, als der Sirius.

Man kann sich in unserem Fall diese zweite Grenze mittels einer von Clausius und Mossotti aufgestellten Theorie über die Dielektrika verschaffen; in dieser Theorie hängt die dielektrische Kraft eines Gases davon ab, daß sich jedes Molekül durch Influenz, durch Umsetzung der innern elektrischen Ladungen, polarisiert. Indem wir diese Theorie weiter entwickeln, werden wir schreiben, dab das wahre Volumen von $\mathrm{n}$-Molekülen nicht gleich (wie dies öfter geschehen ist); sondern bestimmt größer ist, als das Volumen u von $n$-Kugein, vollkommenen Leitern, welche an Stelle der Moleküle gelegt werden können, ohne die Dielektrizitätskonstante $K$ des Mitteis zu ändern. Eine elektrostatische Rechnung liefert für u den Wert $\begin{aligned} & \mathrm{K}-1 \\ & \mathrm{~K}+2\end{aligned}$ also schreiben $1 / 6 \pi n D^{3}>\frac{K}{K}+\frac{1}{2}$.

Die Konstante K, nahezu gleich dem Quadrat des Refraktionskoeffizienten ( $\mathrm{Maxwe}$ ll), kann auch direkt gemessen werden.

Angewendet auf den Fall des Argons, erbält man mit Hilfe der Gleichung von $\mathrm{Clausius}$ durch Bildung von $\mathrm{n}^{2} \mathrm{~N}<200.10^{22}$. Was den Durchmesser der Moleküle betrifft, so findet man ihn für alle so untersuchten Gase größer als ein zehnmilliontel Millimeter (für den speziellen Fall des Argons $D>1,6 \cdot 10^{-8}$ ).

Die verschiedenen Molekulargrößen sind nun zwischen zwei Grenzen eingeschlossen, welche sich, wenn man das Gewicht jedes Moleküls in Betracht zieht, zueinander verhalten wie 45 zu 200. Der Grund, daB die Annïherung keine bessere ist, liegt besonders in der nur rohen Bestimmung des wahren Volumens der $\mathrm{n}$-Moleküle, die sich in der Volumeinheit des Gases befinden. Eine genauere, sehr sinnreiche Untersuchung verdanken wir van der Waals, welcher aus der Berechnung der mittleren Weglänge scheinbar alle Aufschlüsse herausholte, die man über die Molekulargrößen darin überhaupt suchen kann ). Die Gasgleichung ist unter der Voraussetzung erhalten worden, dab die Moleküle genug weit voneinander entfernt sind, als dab ihr Volumen gegen dasjenige des von ihnen durchlaufenen Raumes in Betracht käme und dabs irgendeines von ihnen eine nennenswerte Beeinflussung durch die Kohäsion erleidet. Van der Waals hat, diesen beiden vernachlässigten Größen Rechnung tragend, die berühmte

1) Continuité des états liquides et gazeux, 1873. 
Gleichung $\left(\mathrm{p}+\frac{\mathfrak{a}}{\mathrm{v}^{2}}\right)(\mathrm{v}-\mathrm{b})=\mathrm{RT}^{\mathrm{T}} \mathrm{T}$ konstruiert, welche annähernd gültig ist für jeden flüssigen Zustand; die besondere Natur des untersuchten Stoffes kommt in den beiden Parametern a und b zum Ausdruck, von denen der eine den Einfluß durch die Kohäsion ausdrückt und der andere das Vierfache des wahren Volumens der Moleküle der gegebenen Masse darstellt. Ist also einmal b bekannt, so wird die Gleichung $1 / 6 \pi n D^{3}=\frac{b}{4}$, im Verein mit der von $\mathrm{Clausius}$ und Maxwell $\pi n D^{2}=\frac{1}{L / 2}$, die Berechnung der Unbekannten $n$ und $D$ gestatten. --. Man hat diese Rechnung für Sauerstoff oder Stickstoff gemacht und für $\mathrm{N}$ einen Wert von nahe $45.10^{22}$ erhalten; die Wahl dieser Stoffe mub ich als eine seinr unglückliche bezeichnen, da in der Rechnung der Durchmesser von Molekülen, die sicher keine Kügeln sind, vorkommt. Wenn ich in die beiden Gleichungen, die für Argon nahe bei seinem kritischen Punkt erst seit kurzem bekannten bezüglichen Gröben einführe, so finde ich $\mathrm{N}=62.10^{22}$; ich muB hinzufügen, daB es nicht leicht wäre, den Fehler zu schätzen, mit dem diese Zalıl möglicherweise behaftct ist, da ja die Gleichungen von $\mathrm{Cla}$ usius, Maxwell und van der Waals nicht strenge gelten. Ein Sprung von 30 auf 100 würde uns nicht überraschen. - Mit der Bestimmung von van der Waals erreichen wir das Ende einer ersten Versuchsreihe. Wir wollen nun daran gehen; um auf ganz andern Wegen zu ählichen, vielleicht genaueren Resultaten zu gelangen.

\section{Die gleiche Verteilung der Energie.}

Wir haben geschen, dal bei derselben Temperatur die mittlere molekulare Energie für alle Gase die gleiche ist. Das gilt auch, wenn die Gase gemischt sind. Es ist bekannt, dab dann jedes Gas den gleichen Druck nach auben ausübt, als ob es allein da wäre, mit anderu Worten, daß $\mathrm{n}$-Moleküle dieses Gases in dem Raum v den gleichen Partialdruck ausüben, als ob kein anderes Gas vorhanden wäre, so daß der Ausdruck $\frac{3}{2} \frac{p v}{n}$ seinen Wert behält. Andererseits, wenn man den Ausdrụck $\mathrm{p} v=\frac{2}{3} \mathrm{r}, \mathrm{w}$ auf diesen Fall untersucht, so findet man, daß er anwendbar bleibt. És muB also w seinen Wert behalten. So haben z. B. die Moleküle der Ķohlensäure und die des Wasserdampfes, welche in der Atmosphäre anwesend sind, trotz der 
Verschiedenheit ihrer Naturen und ihrer Massen, die gleiche mittlere kinetische Energie.

Diese Unverănderlichkeit der Molekularenergie gilt nicht nur für den gasformigen Zustand, sondern, wie va n't H of f's schöne Arbeiten gezeigt haben, auch für die Moleküle sämtlicher verdünnter Lősungen. Stellen wir uns eine halbdurchlässige Zelle vor, gefüllt mit einer verdünnten Lösung und umgeben vom reinen Lösungsmittel; wir setzen voraus, daß diese Zelle die Moleküle des Lösungsmittels leicht hindurchtreten läBt, ohne daB diese Moleküle irgendeinen Druck ausüben kőnnten, die Moleküle des gelösten Stoffes aber zurückhălt. Die Stoße dieser Moleküle gegen die Zellwände verursachen also einen "osmotischen Druck" $P$, und man findet bei genauerem Zusehen, daß man den durch diese Moleküle hervorgebrachten Druck noch wie bei den Gasen rechnen und daher $P v=\frac{2}{3} n W$ schreiben kann, wobei $W$ die mittlere kinetische Bewegungsmenge von $\mathfrak{n}$ in dem Raume $\mathbf{v}$ der Zelle eingeschlossenen Molekülen bedeutet.

Nun hat van't Hoff darauf hingewiesen, daB die Versuche von Pf effer für den osmotischen Druck den gleichen Wert ergeben, als es der Druck ist, welchen dieselbe Menge des gelösten Stoffes auf die Zellenwãnde ausüben würde, wenn er allein und im gasförmigen Zustand das Volumen der Zelle ausfüllen würde. $W$ ist also gleich $w$ : die Moleküle eines Stoffes haben im gelosten wie im gasformigen Zustande dieselbe mittlere Energie.

Ich will hier eine, wie mir scheint, für die Anschaulichkeit eines wichtigen Satzes der kinetischen Theorie beitragende Bemerkung machen. Das Gesetz von va n't $H$ off lehrt uns, dab ein Molekül Aethylalkohol in wăsseriger Lösung dieselbe Energie hat, als irgendeines der Moleküle, weiche aus der Lösung verdarapfen; es würde auch noch dieselbe Energie besitzen, wenn es sich in Chloroform befande (das heiBt, wenn es. von Chloroformmolekülen umgeben wäre) oder selbst in Methylalkohol oder Propylalkohol; es ist daher daran zu glauben, dab es auch noch dieselbe Energie in Aethylalkohol hat; oder mit andern Worten, daB es eines der Molekülc ist, welche den reinen Aethylalkohol bilden. Man sieht also ein, dah die Molekularenergie in einer Flüssigkeit oder einem Gas die gleiche ist und man jetzt sagen kann: Beiderselben Temperatur sind die mittleren kinetischen Energien aller Moleküle jeder Flüssigkeit gleich grob und proportionalderabsoluten Temperatur. 
Man kann aber diese schon so allgemeine Hypothese noch erweitern. Nach dem eben besprochenen haben die schweren Zuckermoleküle, die sich in einer Zuckerlösung bewegen, die gleiche mittlere Energie wie die beweglichen Wassermoleküle. Diese Zuckermoleküle enthalten bereits $\left.45^{1}\right)$ Atome; die Molekule des (Chininsulfats et.thalten deren mehr als 100 und man kann noch kompliziertere und schwerere aufzählen, auf die sich die Gesetze von van't Hoff (oder die von diesen abgeleiteten Gesetze von $R$ a oult) anwenden lassen. Die Masse des Moleküles scheint überhaupt nicht begrenzt zu sein.

Betrachten wir alsdann ein noch gröberes Tellchen, welches selbst zusammengesetzt ist aus mehreren Molekülen, mit einem Wort ein Staubteilchen. Wird es auf die Stöße der es umgebenden Moleküle nach einem andern Gesetze i ggieren? Wird es sich nicht einfach verhalten wie ein sehr großes $\Lambda$ ooekül, so dab seine mittlere Energie den gleichen Wert hat, wie die eines einzelnen Molekuls? Obgleich man dies nicht behaupten darf, ist diese Hypothese zum wenigsten interessant genug, da $B$ es sich der Mühe lohnt, die Folgerungen, die sich aus ihr ergeben, zu erörtern.

Wir sind also zurückgekommen auf die Beobachtung der Teilchen einer Emulsion und auf das Studium jener rătselhaften Bewegung, welche am unmittelbarsten zur Molekularhypothese führt. Gleichzeitig gelangen wir dazu, die Theorie dieser Bewegung genauer festzulegen, indem wir sagen, daB nicht nur jedes Teilchen seine Bewegung den Stoben der Moleküle der Flüssigkeit verdankt, sondern auch daß die durch diese StöBe erhaltene Energie im Mittel gleich ist derjenigen irgendeines dieser Moleküle.

Die Annahmen, deren Wahrscheinlichkeit ich zeigen will, könnten als spezielle Falle des berühmten Theorems über die gleiche Verteilung der Energie angesehen werden, welches mit dem Gesetze von der Verteilung der Geschwindigkeit von Maxwell den Hauptkern der mathematischen Theorie der Molekularbewegungen bildet. Dieses Theorem, welches nach und nach durch die zahlreichen Bemühungen von Maxwell, Gibbs, Boltzmann, Jeans, Langevin, Einstein $u$. a. aufgebaut wurde, führt uns zu der festen Annahme, dab die kinetischen Energien jeder form, die im Innern einer Flüssigkeit irgendwelche Molekülkomplexe besitzen, die gleichen sind. Dieses Theorem ist auch anderweitig von grobser Bedeutung, so kann man zum Beispiel mit seiner Hilfe nach der Anzahl der Atome eines Gas-

1) Vgl. Original, wo inforge eines Druckfehlers fälschlich 36 Atome steht. 
moleküls das Verhältnis der spezifischen Wărme dieses Gases voraussehen. Aber sein Beweis erfordert komplizierte Rechnungen, und mir erschien ein einfacherer, wenn auch weniger genauer Weg wünschenswert. Im übrigen soll hier das Wort Theorem zu keiner Täuschung Anlab geben, denn es wimmelt darin von Hypothesen, wie fast in jeder Theoric der mathematischen Physik.

Ich glaube es nicht nötig zu haben zu betonen, dab vorstehendes keine Herabsetzung der großen Bedeutung der mathematischen Physik sein soll; im Gegenteil glaube ich, dab letztere als Werkzeug zur Erforschung und Erfindung darin besteht, daB sie uns die Wahrscheinlichkeit von Tatsachen, an die wir auf Grund qualitativer Urteile nicht hätten denken können, auf rein logischem Wege vermittelt.

Kurz, wir werden, auf was immer für einem Wege es auch sei, zu der Annahme geleitet, daB die mittlere Bewegungsenergie eines Moleküls gleich ist derjenigen, welche die Teilchen einer Emulsion (Suspension) besitzen. Wenn wir demnach ein Mittel finden, die Energie dieser Teilchen von meBbaren GröBen zu rechnen, dann haben wir mit einem Schlag auch ein Mittel, unsere Theorie zu prüfen. Wern die Versuche einmal gemacht sind, werden sich in der Tat zwei Fălle ergeben: entweder werden die erreichten Zahlen von den aut Grund der oben zusammengefaBten kinetischen Ausdrücke gerechneten grundsätzlich abweichen; dann, und besonders wenn diese Zahlen auch noch verschieden sind bei den verschiedenen in Untersuchung gezogenen Teilchen, wird der Wert der kinetischen Theorien sinken und der Ursprung der Brown'schen Bewegung anderswo zu suchen sein; oder aber werden die experimentell gefundenen Zahlen von der Grobenordnung der vorausberechneten sein, dann werden wir nicht nur die Molekulartheorie dieser Bewegung als befestigt betrachten können, sondern wir werden in unsern Experimenten auch nach einem in diesem Fall vielleicht genauen Weg zur Bestimmung der MolekülgröBen suchen können. In hoffe zeigen zu können, daB der Versuch in diesem letzteren Sinne geantwortet hat ${ }^{1}$ ).

1) Die von mir erhaltenen Resultate sind von Mal 1908 bis September 1909 in den Comptes rendus veroffentlicht worden. 


\section{TEIL.}

13. Die Geschwindigkeit eines Suspensionsteilchens ist ilcht direkt meBbar.

Ein direktes Verfahren scheint folgendes zu sein: stellen wir uns vor, daB man die Masse eines mikroskopischen Teilchens hat feststellen können; kann man nun nicht hoffen, durch direkte Messungen wenigstens eine Ahnung seiner mittleren Geschwindigkeit und somit seiner Energie zu bekommen, sei es durch Tellung der Entfernung zweier Stellungen, die es am Anfang und am SchluB der Beobachtung einnimmt, durch die Zeitdauer dieser Beobachtung (scheinbare mittlere Geschwindigkeit), sei es durch Verfolgung seiner Bahn wăhrend einer gegebenen Zeit und Division der letzteren durch die Gesamtlange dieser Bahn?

Man hat in der Tat diesen Weg zuerst betreten (Wiener. Ramsay, Exner, Zsigmondy, The Svedberg und ich), und man kann in den verschiedenen Abhandlungen Schătzungen der mittleren Bewegungsgeschwindigkeit von Teilchen der Großenordnung eines Mikromillimeters finden, die stets einige Mikromillimeter pro Sekunde ausmachen. Dies würde aber jenen Teilchen eine mittlere Energie zumuten lassen, welche ungefăhr 100000 mal kleiner ist, als diejenlge, zu der wir durch die kinetische Theorie gelangen, und dies würde das Theorem von der gleichen Verteilung der Energie vollständig umstürzen.

Aber solche Schătzungen sind $\mathrm{g}$ a $\mathrm{z} \mathrm{f}$ al $\mathrm{s} \mathrm{ch}$. Die Bahnănderungen sind so zahireich und erfolgen so rasch, daB es unmïglich ist, sie zu verfolgen, ind die verzeichnete Bahn ist immer viel einfacher und kürzer als sie in Wirklichkeit ist. Desgleichen ändert die mittlere scheinbare Geschwindigkeit (Quotient aus der Größe der Verschiebung durch die Zeit) wăhrend einer gegebenen Zeit ihre Größe und Richtung ganz auberordentlich, ohne sich irgendwelchen Grenzen zu nahern, wenn man die Beobachtungszeit abkürzt; dies kann man leicht einsehen, wenn man die Stellungen des Teilchens von Minute zu Minute notiert, dann z. B. von fünf zu fünf Sekunden, und noch besser, wenn man sie von zwanzigstel zu zwanzigstel Sekunde photographiert, wie es jüngst Viktor Henri getan hat, um die Bewegung zu kinematographieren.

Wohlverstanden, man kann also in keinem der Bahnpunkte selbst in rohester Annäherung eine Tangente errichten.

Kurz, eine direkte Messung ist unmöglich. Ich will nun den Weg angeben, den ich gegangen bin. 


\section{Ausdehnung der Gasgesetze auf die verdünnten Emulsionen.}

Setzen wir voraus, daß man eine Emulsion mit ganz gleichen Teilchen, kurz ausgedrückt eine gleichförmige Emulsion, hat herstellen können. Es schien mir von vornherein einleuchtend, dab sich die Teilchen dieser Emulsion je nach der Höhe verteilen müssen, wie dies auch die Gasmoleküle unter dem Einfluß der Schwere tun. In gleicher Weise, wie die Luft dichter ist am Meeresniveau als an der Spitze eines Gebirges, erreichen auch die Suspensionsteilchen, wie ihre ursprüngliche Anordnung auch gewesen sein mag, einen Verteilungszustand, bei welchem die Konzentration als Funktion der Hohe von unten nach oben zu abnimmt und das Gesetz der Verdünnung dasselbe ist wie bei den Gasen. Eine aufmerksamere Prüfung bestätigt diese Annahme und liefert für das Verdünnungsgesetz einen genauen Ausdruck, weicher $\mathrm{dem}$ von Laplace zur barometrischen Hohenbestimmung benutzten schr ghnlich ist. Stellen wir uns eine gleichformige Emulsion vor, welche einen senkrechten Zylinder vom Querschnitt s erfüllt. Der Zustand der horizontalen Schicht zwischen den Hơhen $h$ und $h+d h$ würde sich nicht andern, wenn sie zwischen zwei für die Wassermoleküle durchlässigen, für die Teilchen aber undurchlässigen Wanden (z. B. Membranen aus Pergamentpapier oder Kollodium) eingeschlossen wăre. Jede dieser halbdurchlässigen Membranen ist durch die Stöbe der Teilchen, welche sie zurückhält, einem osmotischen Druck ausgesetzt. Ist die Emulsion verdünnt, so wird sich dieser Druck mittels der:elben Formel berechnen lassen, wie für ein Gas oder eine verdünnte Lösung, und zwar so, daB, wenn im Niveau $\mathbf{b}$ die Teilchenzahl in der Volumeinheit $\mathbf{n}$ beträgt, der osmotische Druck $P$ gleich ist $\frac{2}{3} \mathbf{n} W$, wo $W$ die mittlere Teilchenenergie bedeutet; im Niveau $h+d h$ wird der Druck $\frac{2}{3}(n+d n) W$ sein. Da nun die in Betracht gezogene Teilchenschicht nicht fatlt, so muB Gleichgewicht herrschen zwischen der Differenz der osmotischen Drucke, welche, nach oben zu drïcken, und dem Gesamtgewicht der Teilchen weniger dem Druck, den sie erleiden, und der nach unten drückt. Wenn wir also $\Psi$ das Volumen jedes Teilchens, $\Delta$ seine Dichte und $\delta$ diejenige der intergranulären Flüssigkeit nennen, dann haben wir $-\frac{2}{3} \mathrm{sWdn}=\mathrm{n} \mathrm{sd} \mathrm{h} \varphi(\Delta-\delta) \mathrm{g}$ oder $-\frac{2}{3} \mathrm{~W} \frac{\mathrm{dn}}{\mathrm{n}}=q(\Delta-\delta) \mathrm{gdh}$, Differenzialgleichungen, welche durch Integration zu folgender Beziehung zwischen den Konzentrationen $n_{0}$ und $n$ in zwei Punkten mit der 
Niveaudifferenz $\mathrm{h}$ führen: $\frac{2}{3} \mathrm{~W} \log \frac{\mathrm{n}_{0}}{\mathrm{n}}=\varphi(\Delta-\delta) \mathrm{g} \mathrm{h}$, welchen Ausdruck man die Verteilungsgleichung der Emulsion nennen könnte. Sie sagt aus, dab die Konzentration der Teilchen einer gleichformigen Emulsion als Exponentialfunktion der Höhe abnimmt, wie dies auch beim Luftdruck als Funktion der Erhebung vom Meeresspiegel der Fall ist ${ }^{1}$ ). Wenn es gelingt, in dieser Gleichung die GröBen bis auf $W$ zu messen, dann wird es sich zeigen, ob sie sich bewahrheitet und ob der Wert, den sie für $W$ anzeigt, wohl derjenige ist, welcher der Molekularenergie annăhernd zugeschrieben wurde. Wenn dies der Pall ist, dann ist der Ursprung der Brown'schen Bewegung festgestellt, dann können die Gasgesetze, welche von van't $H$ of $f$ bereits auf die Lösungen ausgedehnt wurden, auch auf die Emulsionen mit sichtbaren Teilchen übertragen werden.

\section{Fur die Versuche geeigaete Emulsionen.}

Die bisherigen Beobachtungen enthielten nichts über die Verteilung des Gleichgewichts der Teilchen einer Emulsion. Man wuBte nur, dab sich die obersten Partien einer großen Anzahl von kolloiden Losungen aufhellen, wenn man sie mehrere Wochen oder Monate ruhig stehen lust.

Ich habe an diesen kolloiden Losungen (Arsensulfid, Eisenhydroxyd, Kollargol usw.) mehrere erfolglose Versuche gemacht. Dagegen ist es mir nach einigem Herumsuchen gelungen, an Gummiguttiemulsionen, dann (mit Hilfe von M. Dabrowski) an Emulsionen von Mastix, Messungen vorzunehmen.

Das Gummiguttl, das als Wasserfarbe Verwendung findet, stammt von dem indorhinesischen Gummibaum Garcinia morella. Ein Stückchen dieser Substanz lost sich, mit der Hand mit wenig Wasser verrieben (wie man z. B. verfahrt, um mit einem Stïck Seife Seifenwasser zu machen), nach und nach auf und gibt eine schöne undurchsichtige Emulsion von lebhaft gelber Farbe, in der man mittels des Mikroskops

1) Ich habe diese Gleichung gelegentlich der Veroffentlichung meiner ersten Versuche (Comptes rendus, Mal 1908) auigestellt. Seit dieser Zeit ist mir bekannt geworden, daB Einste in und Smoluchowski, von deren schönen theoretischen Studien ich spiter sprechen werde, schon gewubt haben, dab die Verteilung nach dem Exponentialgesetz eine notwendige Folge der gieichen Vertellung der Energie ist: Sie scheinen im ubrigen nicht daran gedacht zu haben, dab man in diesem Sinne ein entscheidendes Experiment futr oder gegen die Molekulartheorie der Brown'schen Bewegung verwitklichen kann. 
einè Unzahl gelber, verschieden grober Körner von vollkommener Kugelgestalt entdeckt. Man kann diese gelben Teikchen von der Plüssigkeit, in der sie schweben, durch krăftiges Zentrifugieren (in der Art, wie man die roten Blutkorperchen vom Serum scheidet) trennen. Sie sammeln sich am Boden der zentrifugierten Eprouvette und bilden einen dichten gelben Schlamm, von dem man die darüberstehende trübe Flüssigkeit abgieBt. Dieser gelbe Brei liefert nach abermaliger Zerteilung in destilliertem Wasser die Ausgangsemulsion für die zu den Messungen bestimmten glejchförmigen Emulsionen.

Anstatt die natürlichen Körner so zu benutzen, kann man das Gummigutti mit Methylalkohol behandeln, weicher fast die ganze Masse ( ungefăhr 4/5) lost und einen schleimigen weiBen Rückstand hinterlaBt, auf dessen Eigenschaften ich vielleicht noch zurückkommen werde. Diese alkoholische, gut durchsichtige, einer Bichromatlosung nicht unahnliche Flüssigkeit, verwandelt sich beim Verdünnen mit viel Wasser in eine gelbe undurchsichtige Emulsion, welche das Aussehen der natürlichen Emulsion besitzt und gleich dieser aus kugelrunden Körnern zusammengesetzt ist. Man kann letztere von dem schwach alkoholischen Wasser, das sie enthalten, wieder durch Zentrifugieren trennen und durch Zerteilung in reinem Wasser, wie oben, eine Mutteremulsion erhalten, in der sich Teilchen von sehr verschiedener GröBe befinden, deren Durchmesser jedoch, im Falle die alkoholische Lösung sehr rasch mit einem genügenden UeberschuB vermischt wurde, kleiner ist als $1 \mu(1 / 1 \mathrm{cos} \mathrm{mm})$.

lch bin der Ansicht, daB der durch Wasser so gefallte Körper ein definiertes chemisches Individuum darstellt und nicht ein Gemenge');

1) Eine rasch durchgefuhrte physikalisch-chemische Untersuchung hat mir folgtnde Resultate geliefert:

Die gelbe, In Alkohol und ebenso leicht in Schwefelkohlenstoff und Essigsüure Iösliche Masse besitzt eine saure Natur, denn sie wird von selbat sehr verdannten Alkalien gelost. Man kann diese Saure tiltieren, indem man jene Sodamenge feststellt, welche eine gegebene Emulsion eben noch durchsichtig macht.

Es ist bekennt, dab Methylalkohol und Schwefelkohlenstoff unvollstindig mischbar sind und beim Zusammenschütten zwei ubereinanderliegende Schichten bilden. Diese färben sich durch die gelbe in ihnen geloste Masse sehr ungleichformig, und würden wahrscheinlicli die Bestandteile ungleich losen, wenn letztere ein Gemenge repräsentieren würden. Nun aber erfordern die aus den belden Losungen durch Wasserzusatz ertaltenen Emulsionen zu ihrer Klartung stets dieselbe Sodamenge pro Gramm gelöster Substanz; noch genauer, ein Oramm-Molekul Soda loste in einem Fall 537, in einem andern 542 Gramme der emulgierten Masse; ebenso fuhrte die kryoskopische Prufung der Essigsäure als Losungsmittel zu der Zahl 555. - Es ist demnach sehr wahrscheinlich, daB der gelbe Bestandtell des Gummiguttis ein einheltlicher Stoff mit dem angenaherten Molekulargewicht von 540 ist, und wetchen man Guttis a u re (Acide Guttique) nennen konnte. Ich habe welter beobachtet, das diese Guttisłure, welche bei der Sledehitze die 
aber das ist für das hier verfolgte Ziel gleichgültig, und es genügt, daß die Teilchen einer Emulsion dieselbe Dichte besitzen, damit man sich daraus auf die noch zu besprechende Art gleichförmige, für die Messungen geeignete Emulsionen verschaffen kann. Ich bemerke nebenbei, daß man eine Emulsion als re in bezeichnen kann, weun die sich zusammensetzenden Teilchen dieselbe Zusammensetzung, also auch die gleiche Dichte besitzen.

Aehnliche Betrachtungen betreffen den Mastix, den man zur Bereitung von Firnis verwendet, stammt aus Einschnitten in die Rinde von Pistacia leutiscus (Insel Chios). Er gibt durch direkte Behandlung mit Wasser keine Emulsion; wenn man ihn jedoch in Berührung mit Methylalkohol låbt, so erhălt man über einem klebrigen vollkommen unlöslichen Rückstand eine anscheinend reine Lơsung, welche bei hinreichender Verdünnung mit Wasser eine weiße wie Milch aussehende Emulsion gibt. Die Teilchen dieser Emulsion sind rund und von sehr verschiedener Größe. Die Substanz, welche diese Körner bildet, würde nach Johnston ein Molekulargewicht von ungefähr 606, entsprechend der Formel $\mathrm{C}_{40} \mathrm{H}_{62} \mathrm{O}_{4}$, besitzen.

Da haben wir nun zwei Stoffe, welche kugelrunde Kömer geben (und dies ist ohne Zweifel bei allen harzigen Emulsionen der Fall); in allen diesen Fällen wird die Gleichung von der Verteilung der Teilchen mit dem Radius a, $\frac{2}{3} W \log \frac{n_{0}}{n}=\frac{4}{3} \pi a^{3}(\Delta-\delta) g h$, gelten, oder, da ein Neper'scher Logarithmus gleich dem mit 2,303 multiplizierten gewöhnlichen Logarithmus ist, $W 2,303 \log _{10} \frac{n_{0}}{n}=2 \pi a^{3}(\Delta-\delta) \mathrm{g}$ h. Ich habe nach und nach sămtliche in dieser Gleichung vorkommende Großen gemessen.

\section{Das fraktionierte Zentrifugieren. Herstellung einer gleich- fơrmigen Emulsion.}

Man muB zunāchst eine Emulsion herzustellen verstehen; deren såmtliche Teilchen nahezu gleiche Radien haben. Das von mir angewendete Verfahiren läbt sich mit der fraktionierten Destillation eines Flüssigkeitsgemisches vergleichen. Wie nămlich während der Destillation die zuerst übergehenden Anteile verhältnismäBig reicher sind an

Kohlens:lure der Karbonate austrelbt, bel gewönnlicher Temperatur durch einen Kohlensauregasstrom, in eine Losung von Natriumguttat (guttate de Sodium), ausgetrieben wird, und alsdann eine Emulsion von gelben Kornem wiedergibt. Es ist moglich, daB sich die Korrierbildung in der Gummipflanze auf analoge Art erklaren laBt. 
flüchtigeren Bestandteilen, so sind die beim Zentrifugieren einer reinen') Emulsion zuerst sedimentierten Mengen verhältismäßig reicher an großen Körnern; man hat also im Zentrifugieren ein Mittel in der Hand, die Teilchen nach ihrer Größe zu scheiden. Am einfachsten verfăhrt man in folgender Weise:

Man füllt die zu zentrifugierende Eprouvette bis zu einer bestimmten Höhe, $10 \mathrm{~cm}$ zum Beispiel, mit einer reinen Emulsion; man läßt die Maschine mit einer bestimmten Winkelgeschwindigkeit, z. B. 30 Touren pro Sekunde-(was in einer Entfernung von $15 \mathrm{~cm}$ von der Achse eine Zentrifugalkraft gibt, welche ungefähr $500 \mathrm{mal}$ größer ist als die Schwerkraft), laufen; man unterbricht den Gang der Maschine nach einer bestimmten Zeit, 60 Minuten zum Beispiel; man labt' sie von selbst zur Ruhe kommen, was-einige Minuten dauern soll; man zieht mit Vorsicht die Eprouvette wieder heraus.

Ein ziemlich fester Schlamm bedeckt den Boden dieser Eprouvette, und zwar in einer Höhe, welche im Verhältnis zur Höhe der Flüssigkeit im allgemeinen verschwindend klein ist; der Bodensatz enthält alle Teilchen, die während der Zentrifugierung am Grunde der Eprouvette angelangt sind; die Teilchen liegen so dicht aneinander geprebt wie Sandkörner in einem Sack.

Bezeichnen wir den Radius, den ein am Anfang der Zentrifugierung an der Oberfläche der Flüssigkeit befindliches Teilchen haben muB, um am Ende des Zentrifugierens am Grunde der Eprouvette anzukommen, mit $a_{1}$; alle größeren Körner haben sich schon früher abgesetzt, doch sind in dem Schlamm auch noch kleinere Teilchen enthalten, welche Zeit gehabt hatten; den Boden zu erreichen, da sie sich schon von Anfang an in den tieferen Lagen der Emulsion befanden. Sodann hebert man die über dem Bodensatz befindliche Flüssigkeit vorsichtig ab; man füllt die Eprouvette von neuem bis zur ursprünglichen Höhe mit destilliertem Wasser auf; man schüttelt heftig, wobei sich der Schlamm vollständig zerteilt, und wiederholt nun die vorhergegangene Operation bei derselben Winkelgeschwindigkeit und der gleichen Dauer des Zentrifugierens. Dabei werden alle Teilchen, deren Radius grober ist als $a_{1}$, noch den Boden erreichen, manches kleine Teilchen aber, welches vorhin sich sogleich absetzte, da es sich schon nahe befand, wird diesmal keine Zeit mehr dazu finden, wenn es

1) Enthielte die ursprüngliche Emulsion Teilchen von verschìedener Dichte, so könnte man durch das Zentrifugieren stets nur die Teilchen absondern, welche in der gleichen Zeit aus der gleichen Hohe fallen, die aber nicht gleich groB sein whirden. 
sich zufällig nahe an der Oberfläche befindet. Kurz, der zweite Bodensatz. enthält wie der erste alle Teilchen mit gröBerem Radius als $a_{1}$, enthält aber viel weniger noch kleinere Teilchen.

Man giebt die darüberstehende Emulsion, welche schon viel heller ist, als das erste Dekantat es war, ab und wiederholt die gleichen Operationen, bis die am Ende einer jeden Zentrifugierung über dem Bodensatz befindliche Flüssigkeit aussieht wie klares Wasser. Sodann enthălt der Niederschlag alle Teilchen der ursprünglichen Emulsion, deren Halbmesser $a_{1}$ überschreiten, und er enthalt nur solche; alle kleineren Körner sir:d ausgeschaltet.

Beginnen wir dieselben Operationen mit dem zuletzt erhaltenen Bodensatz, setzen aber die Zentrifugierungsdauer herab! Bezeichnen wir den Halbmesser, den ein an der Oberfläche befindliches Teilchen husen muB, um am Ende der Zentrifugierung am Boden der Eproustte anzukommen, mit $a_{2}$; dann werden sich in der über dem Bodensatz befindlichen Flüssigkeit nur Teilchen finden, deren Radius kieiner ist als $a_{2}$; nach ihrem Ursprung kann aber diese Flüssigkeit nur Teilchen enthalten, die größer sind als $a_{1}$; wenn nun $a_{1}$ und $a_{2}$ nicht viel voneinander verschieden sind, dann ist diese Flüssigkeit praktisch eine gleichförmige Emulsion, und man braucht sie bloB abzugieben.

Ich halte es für überflüssig auseinanderzusetzen, wie man auf ähnliche Art nach Wunsch gleichförmige Emulsionen von kleineren oder aus dem dabei erhaltenen Rückstand Emulsionen von größeren Teilchen erhalten kann.

\section{Bestimmung der Dichte der Tellchen.}

Es ist notwendig, daB wir die Dichte der Körner der zu untersuchenden gleichförmigen Emulsion kennen lernen. Ich habe zwel Methoden benützt, welche beide übereinstimmende Resultate liefern. Beide Verfahren benützen die Tatsache, daB man die in einer gegebenen Emulsionsprobe vorhandene Harzmenge durch einfaches Austrocknen im Trockenschrank genau dosieren kann. Wenn die Temperatur ein wenig über $100^{\circ}$ beträgt, wird bald ein konstantes Gewicht erreicht, welches sich (ohne Rücksicht auf die Zeitdauer der Erhitzung) nicht merklich ändert, wenn man sie auf $130^{\circ}$ oder selbst $140^{\circ}$ steigert. Bei dieser Temperatur ist das Harz eine sehr zähe Flüssigkeit geworden, welche beim Abkühlen ein klares Glas gibt, welches wahrscheinlich die gleiche Dichte besitzt, wie die Teilchen der Emulsion. Wir werden also dazu geführt, das spezifische Gewicht dieses Glases zu bestimmen. 
Dies geschieht einfach und $\boldsymbol{E}^{*}$ au, indem man Bruchteile der glasigen Masse in destilliertes Wasser wirft, dem man nach und nach Bromkalium hinzufügt, bis die Glasteile in der Losung weder zu Boden fallen noch sich zur Oberflache zu erheben suchen, also schweben. Die gesuchte Dichte ist folglich gleich der Dichte dieser Lösung, die man ohne Schwierigkeit messen kann (Methode von Retgers, anwendbar selbst für sehr kleine Partikel).

Die zweite Methode ist vielleicht genauer, hat aber den Nachteil, daB man bei ihrer Anwendung viel von der Emulsion braucht. Man miBt bei einer gegebenen Temperatur (nahe bei $20^{\circ}$ ) die Massen $m$ tes Wassers und $\mathbf{m}^{\prime}$ der Emulsion, mit welcher ein und dieselbe Flasche angefüllt werden kann. In der Masse $\mathbf{m}^{\prime}$ bestimmt man durch Austrocknung die Menge $\mu$ des in der Emulsion enthaltenen Harzes, woraus sich die Masse des in der Suspension befindlichen Wassers $z \mathbf{u}\left(\mathbf{m}^{\prime}-\mu\right)$ ergibt. Ist nun d die Dichte des Wassers, dann ist $\frac{m}{d}$ das Volumen des Gefabes, $\frac{m^{\prime}}{d}$ das Volumen des intergranulären Wassers, die Differenz $\left(\frac{m}{d}-\frac{m^{\prime}-\mu}{d}\right)$ das Volumen der Korner, und der Quotient aus ihrer Masse $\boldsymbol{F}$ und diesem Volumen die gesuchte Dichte.

Wie bereits gesagt, geben diese beiden Methoden annuhernd gleiche Resultate; so wurde zum Beispiel die Dichte der Teilchen einer bestimmten Gummiguttiemulsion zu 1,205 nach der ersten und zu 1,207 nach der zweiten Methode gefunden. Ebenso ist die Dichte det Körner einer Mastixemulsion gleich 1,063 nach der ersten und 1,064 nach der 2weiten Methode. - Es ist zu beachten, dab sich diese Zahlen auf jene Falle beziehen, wo die intergranuläre Flüssigkeit praktisch reines Wasser ist. - Ich habe in der Tat gefunden, daB die Tellchendichte $z u$ steigen scheint, wenn die Zwischenflüssigkeit Salze enthalt und führe dies unmittelbar auf eine Adsorptionserscheinung des Salzes an der Oberfläche der Teilchen zurück.

Das gleiche gilt, wenn die Zwischenflüssigkeit ein Kolloid mit unsichtbaren Teilchen enthält, welche sich an die großen Harzkörner anlagern und so. ihre. Dichte beeinflussen können. - Das ist der Fall bei den natürlichen Emulsionen des Gummiguttis, welches bis auf nahezu $1 / 8$ ein ungefarbtes im Ultramikroskop unauflosbares Kolloid enthält. Man kann davon die gelben Körner durch Zentrifugieren und Aufschlimmen trennen und erhält dann für sie die gleiche Dichte, wie we für die Teilchen aus den alkoholischen Losungen gefunden wurden. 
Daher findet man schlecht dewaschene natürliche Kömer schwerer als gutgewaschene. $\mathrm{Da}$ ich diese Fehlerquelle früher nicht kannte, sind meine ersten Bestimmungen ein wenig entstellt').

\section{Anordnung der Beobachtung.}

Wenn man die Verteilung des Gleichgewichtes in Emulsionen studiert, so beobachtet man nicht, wie man leicht glauben könnte, Schichten von einigen Zentimetern oder Millimetern Höhe, sondern nur ganz dünne Lagen, von der Hơhe eines für die mikroskopische

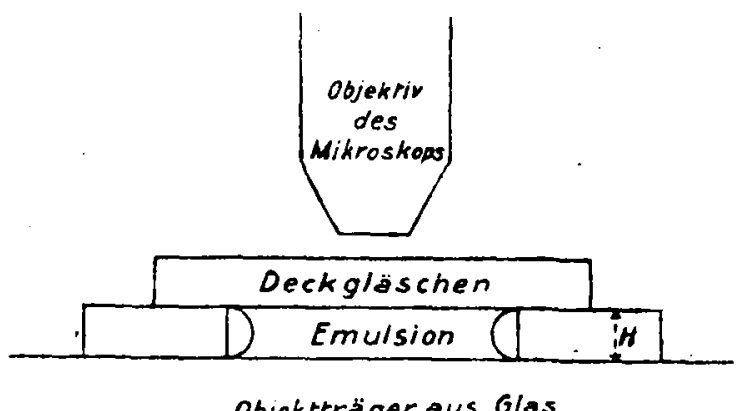

Fig. 1

Beobachtung bestimmten Präparates (wie sie die vorstehende Fig. 1 anzeigt).

Stellen wir uns vor, daß man auf einem glăsernen Objekttrăger eine ganz dünne, breit durchlochte Glasscheibe aufgekittet hat. Man hat sich auf diese Art ein flaches zylindrisches GefäB geschaffen, dessen Hohe $\mathrm{H}$ zum Beispiel $100 \mu$ (=1/10 Millimeter) betrăgt $\left.{ }^{2}\right)$. In die Mitte dieser Kammer bringt man einen Tropfen der Emulsion und bedeckt ihn sogleich mit dem Deckglăschen, welches sich genau an die obere Flache der durchbrochenen Scheibe anlegt und so die Kammer vollstänđig abschlieBt. Um jede Verdunstung zu vermeiden, tuberzieht man die Ränder des Deckgläschens mit Paraffin oder Firnis und kann dann ein Prăparat mehrere Tage oder selbst wochenlang beobachten.

Das Präparat wird sodann auf die sorgsam horizontalgestellte Platte eines guten Mikroskopes gebracht. Das benützte Objektiv mit sehr starker Vergroberung besitzt eine geringe Feldtiefe, und man

J) Compt. rend., Mai 1908.

ๆ) Diese Anordnung findet sich bei den zur Zahlung der Blutkörperchen bestimmten Zellen ( $Z \mathrm{el} B)$, welche ich benutzt habe. 
kann gleichzeitig nur die Teilchen genau sehen, welche sich in einer sehr dünnen (GröBenordnung des $\mu$ ) Horizontalschicht befinden. Durch Senken oder Heben des Mikroskops bekommt man die Teilchen anderer Hohenlagen in das Gesichtsfeld.

Die senkrechte Entfernung dieser beiden Schnitte sei h, und wir müssen sie, da sie in der Verteilungsgleichung vorkommt, genau kennen lernen. Wir erhalten sie durch Multiplikation der Verschiebung des Mikroskops, h', mit dem Brechungsexponenten der beiden Mittel, welche das Deckgläschen trennt. $\mathrm{Da}$ die $Z$ wischenflüssigkeit Wasser ist, so wird h gleich sein ${ }_{3}^{4} h^{\prime}$, wenn man mit geworhnlichem Objektiv arbeitet und einfach $h^{\prime}$, wenn man ein Wasserimmersionsobjektiv verwendet, wie ich es oft getan habe. Was die Verschiebung $h^{\prime}$ anbelangt, so kann man diese direkt an der graduierten Trommel der Mikrometerschraube ablesen, welche die.Bewegungen des Mikroskopes vermittelt (die Zei $\theta^{\prime}$ 'schen Schrauben geben wenigstens Viertel Mikromillimeter an).

\section{Zăhlung der Teilchen.}

Wir müssen jetzt das Verhältnis ${ }_{n}^{n_{0}}$ der Konzentrationen der Teilchen in den beiden verschiedenen Niveaus feststellen. Dieses Verhăltnis ist offenbar dem mittleren Verhältnis der Teilchenzahlen gleich, welche man im Mikroskop bei den zwei Oberflächen beobachtet. Diese Zahlep bleiben uns zu finden übrig.

Dies scheint im ersten Anblick nicht so leicht; es handelt sich nicht darum, ruhige Objekte zählen, und man braucht nur ins Mikroskop zu blicken, um im Gesichtsfeld einige Hundert Körner zu bemerken, welche sich nach allen Richtungen bewegen, welche übrigens fortwährend verschwinden, wăhrend doch neue Teilchen auftauchen, und man ist rasch von der Nutzlosigkeit der Anstrengungen überzeugt, welche man machen kann, um die mittlere Anzahl der in dem beobachteten Niveau enthaltenen Teilchen auch nur annähernd zu bestimmen.

Am einfachsten scheint es alsdann, eine Momentphotographie dieses Horizontalschnittes anzufertigen, die scharfen Bilder der Teilchen zu verzeichnen und, wenn die Emulsion schon genügend verdünnt ist und diese Zahl klein ist, wieder anzufangen, bis die mittlere Anzahl der auf einer Tafel verzeichneten Teilchen mit der gewünschten Annăherung als bekannt betrachtet werden kann. Ich selbst habe, wie man weiter unten sehen wird, für'verhältnismäßig dicke Körner dieses Verfahren benützt. Bei Teilchen, deren Durchmesser weniger als 
$0,5 \mu$ betrug, erhielt ich keine guten Bilder und da habe ich folgenden Kunstgriff angewandt:

Ich stellte in die Brennpunktebene des Okulars eine undurchsichtige Scheibe von unechtem Blattgold, welche mittels eines Nadelstiches fein durchlocht war. Das Sehfeld wurde dadurch auBerordentlich verkleinert, und das Auge konnte mit einem einzigen Blick die genaue Anzahl der Teilchen feststellen, welche in einem durch ein kurzes Signal gegebenen Moment, oder wăhrend der sehr kurzen Beleuchtungsdauer, welche ein photographischer Verschlu日 gestattet, erblickt wurden. Es genügt, wenn diese Zahl geringer als 5 oder 6 ist.

Wenn man diese Bestimmungen in regelmaBigen Zwischenrăumen, zum Beispiel von $15 \mathrm{zu} 15$ Sekunden, macht, so erhält man eine Reihe von Zablen, deren mittlerer Wert sich melir und mehr einer Grenzzahl nazhert, welche die mittlere Anzahl der Teilchen vorstellt, die sich im beobachteten Niveau, in der kleinen zylindrischen Schicht, auf welche das Mikroskop eingestellt ist, befinden. Wenn man in einem anderen Niveau die mittlere Anzahl der in dem gleichen Volumen enthaltenen Teilchen bestimmt hat, so ert : man in dem Quotienten dieser beiden Zahlen das gesuchte Konzentr: : sonsverhaltnis. Wohlverstanden, anstatt alle bezüglichen Abzählungen der Reihe nach in einem einzigen Niveau zu machen, ist es besser, sie zu wechseln, so daB man zum Beispiel 100 Abzählungen in einem Niveau macht, dann 100 in einem andern, sodann wieder von neuem $100 \mathrm{im}$ ersten und so fort. Wenn man einigermaBen genaue Zahlen erhalten will, so muB man mehrere Tausend Abzăhlungen machen. Ich will als Beispiel im folgenden die Zahlen wiedergeben, welche $\mathbf{5 0}$ nacheinander vorgenommene Abzählungen in zwei $30 \mu$ voneinander entfernten Niveaus einer von mir benutzten Emulsion gaben:

$\begin{array}{llllllllll}3 & 2 & 0 & 3 & 2 & 2 & 5 & 3 & 1 & 2 \\ 3 & 1 & 1 & 0 & 3 & 3 & 4 & 3 & 4 & 4 \\ 0 & 3 & 1 & 3 & 1 & 4 & 2 & 2 & 1 & 3 \\ 1 & 1 & 2 & 2 & 3 & 0 & 1 & 3 & 4 & 3 \\ 0 & 2 & 2 & 1 & 0 & 2 & 1 & 3 & 2 & 4\end{array}$

für das niedrigere Niveau und

für das höhere.

$\begin{array}{llllllllll}2 & 1 & 0 & 0 & 1 & 1 & 3 & 1 & 0 & 0 \\ 0 & 2 & 0 & 0 & 0 & 0 & 1 & 2 & 2 & 0 \\ 2 & 1 & 3 & 3 & 1 & 0 & 0 & 0 & 3 & 0 \\ 1 & 0 & 2 & 1 & 0 & 0 & 1 & 0 & 1 & 0 \\ 1 & 1 & 0 & 2 & 4 & 1 & 0 & 1 & 0 & 1\end{array}$




\section{Bestimmung des Radius der Korner.}

Um die Verteilungsgleichung anwenden zu kőnnen, brauchen wir nur noch eine einzige Bestimmung, die des Halbmessers der Teilchen der untersuchten gleichförmigen Emulsion. Ich habe diesen nach drei verschiedenen Verfahren erhalten:

Erstes Verfahren. Ich habe zunächst nach dem Beispiele von J. J. Thomson, Langevin und aller derer, welche die Dimensionen kleiner Tropfen oder von Staubteilchen in einem Gas zu bestimmen gehabt haben, die Gültigkeit einer Berechnung von Stokes, die sich auf die Bewegung einer Kugel in einer zăhen Flüssigkeit bezieht, als bestehend angenommen. Nach dieser Rechnung ist die Reibungskraft, welche sich der Bewegung der Kugel entgegenstellt, in jedem Augenblick gegeben durch $6 \pi \zeta$ a v, was: 5 dic Zahighciii uct Flüssigkeit, a den Kugelhalbmesser und $\mathbf{v}$ die Geschwindigkeit der Kugel bezeichnen. Wenn die Kugel unter dem alleinigen EinfluB der Schwere in gleichförmiger Bewegungsart fallt, dann muB die Reibung dem scheinbaren Gewichte der Kugel in der Flüssigkeit gleich sein; es ist also $6 \pi \xi \mathrm{a} v=\frac{4}{3} \pi \mathrm{a}^{3}(\Delta-d) \mathrm{g}$, aus welcher Gleichung sich nach. der Messung der Geschwindigkeit, v, das a bestimmen labt.

Angenommen, man konnte eine auBerordentlich hohe vertikale Săule der gleichförmigen in Betracht gezogenen Emulsion verwirklichen. Es wird darn von einer endgültigen Verteilung des Gleichgewichtes gar keine Rede sein und die Körner der obersten Schichten werden niederfallen

Fig. 2 wie die Tröpfchen einer Wolke, ohne daß ein Zurūcksteigen aus den tieferen Lagen, wo sich die Teilchen anhăufen, zu befürchten wäre. Die Flüssigkeit klärt sich also in ihrem oberen Teil, und die Dicke der aufgehellten Schicht, geteilt durch die Zeit, während welcher die Emulsion sich selbst überlassen blieb, gibt die Fallgeschwindigkeit, auf welche sich das Gesetz von Stokes anwenden labt.

Man findet bei den von mir untersuchten Emulsionen diese $E_{r}$ scheinung in der Tat bestätigt. Man braucht nur ein kapillares Rohr von einigen Zentimetern Höhe (Fig. 2) mit der Emulsion zu pillen, beide Enden zu verschlieBen und in einem Thermostaten senkserists 
einzustellen, um zu sehen, wie die Emulsion allmählich die oberen Schichten der Flüssigkeit verlät, indem sie wie eine Wolke mit deutlicher Oberflache fällt und dabei jeden Tag ein gleiches Stück zurïcklegt. Man nimmt eine kapillare Röhre, um Konvektionsströme (die sich in breiten Rohren auBerordentlich leicht bilden) zu vermeiden, welche die Oberflache der Wolke verwischen würden.

Die Bestimmung des Halbmessers der Teilchen ist nun mit Hilfe des Stokes'schen Gesetzes möglich. Die Anwendung des letzteren auf so kleine Kugeln gibt jedoch AnłaB zu Einwänden, die ich später untersuchen werde. Es war also wünschenswert den Halbmesser der Tellchen auf einem andern, wenn moglich direkterem Weg zu etreichen.

$Z$ weites Verfahren. Man würde diesen Halbmesser sehr genau bekommen, wenn man die Anzahl der in einem bekannten Volumen der titrierten Eraulsion (gleich nąch dem Durchschütteln) enthaltenen Teilchen wüBte. Das gabe die Masse eines Teilchens und, da man sein spezifisches Gewicht kennt, auch seinen Halbmesser. Zu diesem Behufe genügt es, sämtliche Körner zu zählen, die in einem Zylinder der Emulsion anwesend sind, dessen Hohe gleich ist der Höhe des Präparates (ungefăhr $100 \mu$ ) und dessen Grundflăche bekannt ist, wie dies bei den Blutkörperchen-Zahlzellen der Fall ist, deren Boden in Quadrate von $50 \mu$ Seiteniange geteilt ist. Aber die schichtenweise Abzahlung (oder Integration) aller im Praparat enthaltenen Teilchen enthalt viel Unsicherheit. Man müBte in der Tat, von andern Schwierigkeiten abgesehen, die Tiefe jeder Schicht von der Grobenordnung eines $\left.\mu^{2}\right)$ genau kennen.

Glicklicherweise hatte ich bei anderer Gelegenheit wahrgenommen, daB die Gummigutti- oder Mastixteilchen, wenn sie sich in einem schwach sauren Mittel (z. B. 0,01 Gramm-Moleküle im Liter) befinden, an den Glaswănden, die das Prăparat einschlieBen, ankleben. In merklicher Entfernung von diesen Wanden hat sich das Brown'sche Phănomen in keiserlei Weise verăndert; wenn aber infolge dieser Bewegung ein Teilchen durch Zufall zur Berührung mit dem Objekttrăget oder dem Deckgläschen kommt, dann wird es unbeweglich und verlåBt nicht mehr die Wand. Die Emulsion wird immer schwalcher und schwächer, bis sich naçh einigen Stunden sămtliche Teilchen, die

1) Wir brauchen diese Dicke nicht kennen zu lernen, da wir, um das Konzentrationsverhaltnis in zwel verschiedenen Niveaus zu erhalten, das Verhalltnis der in diesen beiden Hơhen gefundenen Teilchenzahlen nehmen; es genugt uns, dab die Feldtiefe, wie immer sie auch sei, in jenen beiden Niveaus den gleichen Wert habe. 
sir enthielt, an den Wänden angelilebt haben. Sie können doch $\therefore$ gezăhlt werden, wenn sie an verschiedenen $\mathrm{Pu}$ iten festsitzen keineswegs krümelige Anhäufungen bilden (partielle Koagulation dv' Kolloides). Ohne darauf näher eingehen zu können, begnüge ich mici damit, zu sagen, dab sehr geringe Mengen eines im natürlichen Saft des Gummigutti gegenwärtigen $\mathrm{Schutzkolloids,} \mathrm{der} \mathrm{unter-}$ suchten Emulsion zugesetzt, genügen um die Koagulation der Teitchen aus der mit reiner Salzsăure angesäuerten Emulsion zu verhindern. Man kann nun so vorgehen:

Man schüttelt die gleichförmige zu untersuchende, vorher titrierte Emulsion; man entnimmt ihr ein bekanntes Volumen und vermischt es mit einem ebenfalls bekannten Volumen schwach angesäuerten Wassers; man schüttelt wieder; man nimmt sich ein Tröpfchen der Mischung heraus, gibt es auf den Objektträger und bedeckt es rasch mit dem Deckglıschen, dessen Ränder man paraffiniert, wobei jede Verschiebung sorgfältig zu vermeiden ist.

Wenn dies geschehen ist, lä日t man das Präparat auf der Platte des Mikroskopes liegen, bis sich alle Teilchen an den Wänden abgesetzt haben. Man fügt jetzt in das Mikroskop eine Hellkammer ein, bringt den Boden des Präparates in das Gesichtsfeld und zeichnet die Kontur eines der auf den Objektträger eingeritzten Quadrate; in diesem wird das Bild eines jeden in diesem Viereck enthaltenen Teilchens durch einen Punkt angedeutet; hierauf hebt man das Mikroskop, bis man die an der oberen Fläche niedergeschlagenen Teilchen scharf sieht, und merkt sich auf die gleiche Weise die Teilchenbilder an, die sich im Innern desselben Umrisses befinden und somit von demselben geraden Prisma der Emulsion herrühren. Man kann dann auf der erhaltenen Zeichnung die Punkte mit Muße abzählen und erhält so die gesuchte Teilchenzahl.

Man wiederholt die gleiche Arbeit für eine andere Partie des Präparates und setzt das so fort, bis der inittlere Wert der in jedem Quadrat gefundenen Teilchenzahl als gut bekannt betrachtet werden kann. Durch eine einfache Rechnung erhält man endlich die Teilchenzahl, welche dem Gesamtvolumen der titrierten ursprünglichen Emulsion entspricht, also auch den gesuchten' Radius, und zwar nach einer zweiten Methode, die nichts mit dem Gesetz von Stokes zu tun hat. Dic Fig. 3 ist die Wiedergabe der Photographie einer der von mir gemachten Zeichnungen; der Halbmesser der Teilchen Itc: betreffencien Emulsion betrug $0,212 \mu$. 
Man hätte den übrigens ermüdenden Gebrauch der Hellkammer durch einfaches Photographieren der an den Wänden fixierten Tèllchen vermeiden können. Das Auge ist jedoch, was die Sichtbarkeit sehr kleiner klarer Körner auf fast ebenso klarem Grunde (man darf nicht

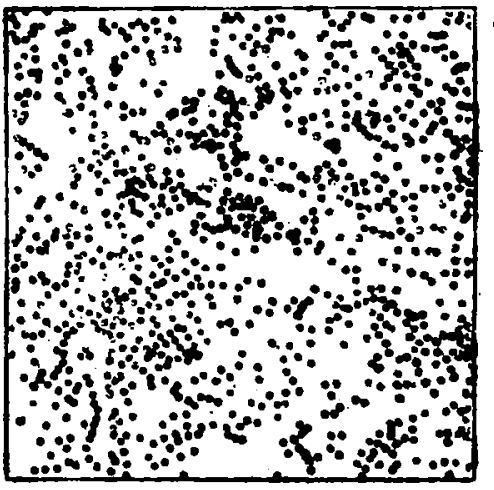

Fig. 3 vergessen, $\mathrm{daB}$ die Teilchen durchsichtige Kugeln sind) anbelangt, empfindlicher als die photographische Platte, und ich habe die Photographie nur dann benützen konnen, wenn der Teilchendurchmesser gröBer war als ein halbes $\mu$.

Drittes Verfahren. Manchmal kommt es vor, daB sich die Teilchen unter dem Einflusse der Säure zu 3, 4 oder 5 zu einem geradlinigen Stabbchen zusammensetzen, welches man noch einige Augenblicke sich bewegen sieht, bevor es sich an der festen Flăche ansetzt. Die Lange dieser Stabbchen kann man in der Hellkammer wie auch auf photographischem Wege leicht bestimmen, wenn auch der Durchmesser eines einzelnen Teilchens auf diese Art wohl nur sehr grob geschătzt werden kann (Verlängerung durch die Diffraktionl). Und dies gibt ein drittes wenn auch nicht sehr genaues, so doch sehr unmittelbares Verfahren ab, den Durchmesser der Teilchen einer gleichförmigen Emulsion' zu bestimmen.

Bei noch gröberen Körnern (Großenordnung eines $\mu$ ) werden die Anhlufungen noch regelmäBiger, und die Teilchen legen sich aneinander an und nicht thereinander; die tirekte Messung des Halbmessers ist dann sebr ieicht.

\section{Erwelterung des Gesetzes von Stokes.}

Die drei vorstehenden Methoden führen zu übereinsțimmenden Resultaten. In der folgenden Tabelle will ich in Hundertsteln eines $\mu$ die Halbmesser anführen, welche ich nach jenen Verfahren für verschiedene gleichförmige Emulsionen erhalten habe. Die auf ein und dieselbe Emulsion bezüglichen Zahlen befinden sich in der gleichen Zeile; die mittlere Kolumne gibt die durch Anwendung des Stokes'schen Gesetzes erhaltenen Zahlen; links davon sind die durch Zahlung der Teilchen mit bekannter Gesamtmasse gewonnenen Zahlen und rechts endlich die durch unmittelbate Messung der Lange der durch die aneinandergereihten Körner gebildeten Stăbchen. 


\begin{tabular}{|c|c|c|c|}
\hline \multirow[t]{3}{*}{ Mastix } & Zahlang & $\begin{array}{l}\text { Stokes } \\
5 ?\end{array}$ & $\begin{array}{c}\text { Messung der Sidbchen } \\
54\end{array}$ \\
\hline & - & 40 & 50 \\
\hline & 46 & 15 & 455 \\
\hline \multirow[t]{3}{*}{ Gummigutti } & 30 & 29 & 30 \\
\hline & 21,2 & 21,3 & - \\
\hline & 14 & 15 & - \\
\hline
\end{tabular}

Die Zahlen auf der fünften Linie, die sich auf eine gleichfơrmigere Emulsion beziehen, als es die übrigen sind, konnten mit der größten Genauigkeit bestimmt werden. Ich habe in verschiedenen Regionen verschiedener Präparate an 11000 Körner gezăhlt, um die Ziffer 21,2 der ersten senkrechten Reihe zu erhalten.

Kurz, die drei angewandten Verfahren rechtfertigen sich durch die Uebereinstimmung ihrer Resultate. Und noch mehr, aus dieser Uebereinstimmung ergeben sich wichtige Folgerungen betreffs des S t o k e s'schen Gesetzes.

Dieses Gesetz ist durch Berechnung gefunden worden, und zwar unter der Annahme von Bedingungen, welche in dem Fall der Kugeln, welche eine sebr wirksame Brown'sche Bewegung besitzen, ganz und gar nicht erfüllt $z u$ sein scheinen. Ueberdies ist die dabei in Betracht gezogene Geschwindigkeit die wahre Geschwindigkeit der Kugel in bezug auf die Flüssigkeit. Nun hat aber diese wahre Geschwindigkeit, welche unter dem Einflub der Brown'schen Bewegung fort und fort ihre Richtung und Größe andert, nichts gemein mit der konstanten, an Grobe übrigens unvergleichbar geringeren Vertikalgeschwindigkeit, mit welcher die aus einer groben Kornerzahl gebildete Wolke in der Flüssigkeit fallt. Solange ịch den Radius der Körner nur mit Hilfe der S to k e s'schen Formel bestimmte, war es also vollkommen gerechtfertigt, sich gegen die Genauigkeit von auf so gewagtem Weg gefundenen Resultaten zu verwahren, wie dies Jacques Duclaux betreffs meiner ersten Veröffentlichung $\left.{ }^{1}\right)$ tat. Natürlich muB man dieselben Vorbehalte auf alle die Falle ausdehnen, wo man sich in der gleichen Weise der Stokes'schen Formel bediente; im besondern müssen sie geiten für die berühmten Resultate, welche die J. J. Thomso n'sche Schule durch Kondensation von Wassertropfchen auf lonen erhalten hatte, und namentlich auch für die Arbeiten von $L$ a ng e vin oder seiner Nuchfolger über die groBen lonen der Atmosphäre, Teilchen, deren Größe von der Ordnung eines Hunderstel $\mu$ ist.

2) J. Perrin, Comp. rend. 146, 967 (1908), und J. Ducla ux, Comp. rend. 147, 131 (1908). 
Die Uebereinstimmung der vorstehenden Messungen wird diese 7.weifel zerstreuen; aber gerade, weil diese Uebereinstimmung nicht von vornherein offenbar war, enthält sie etwas Neues und gibt uns das Recht, folgenden Satz, eine Extrapolation des S tokes'schen Gesetzes, :Is experimentell bewiesen zu betrachten:

Wenn eine in Gröbe und Richtung sich gleichbleibende Kraft in einer Flüssigkeit auf ein Teilchen wirkt, welches von der Brown'schen Bewegung getrieben wird, so erhalt dasselbe eine in der Richtung der konstanten Kraft liegende Komponente, welche mit der Zeit wächst und welche im Mittelgleichist $\underset{6 \pi}{6 \mathrm{~F}}$, wo F die Kraft, t die Zeit, 6 die Viskositat der Flüssigkeit und a den Radius des Teilchens bezeichnen.

Die vorangegangenen Versuche zeigen. dab dieses Gesetz in dem Bereich der mikroskopischen Grölen gültig ist, und die Bestätigung seiner Richtigkeit bis an die gröBten ultramikroskopischen Teilchen läbt keinen .Zweifel mehr darüber, daB dieses Gesetz auch wenigstens annähernd für die noch kleineren Teilehen der gewöhnlichen kolloiden Lösungen oder für die großen in den Gasen gefundenen lonen gilt.

Es gilt noch, wie ich vermute, für grolie Moleküle, wie die von Chininsulfat, aber waltrscheinlich nicht mehr streng für solche Moleküle, deren Halbmesser kleiner oder nur unbedeutend größer ist, als derjenige der Moleküle des Lösungsmittels. Ich werde später (Nŕ. 36) einen experimentellen Beweis hierfür bringen; aber man kann schon jetzt sehen, daß die Formel für die Reibung den Wert Null anzeigt, wenn der Radius Null ist, während die wirkliche Reibung, weiche von der Wahrscteinlichkeit der Zusammenstöße zwischen dem in Betracht gezogenen Teilchen und der Moleküle des Lösungsmittels abhängt, nur dann Null werden kann, wenn diese letztern selbst gleichzeitig unendlich klein werden.

Im übrigen hat die äußerste Grenze, für welche das Stokes'sche Gesetz noch gilt, nichts zu tun mit dem hier verfolgten Ziel, und nachdem wir jetzt im Besitze aller Mittel sind, welche wir zur Beglaubigung und Anwendung der Verteilungsgleichung auf gleichförmige Emulsionen nötig hatten, wollen wir sehen, was wir damit erreichen und auf welche Art wir die Frage nach dem Ursprung der B row n'schen Bewegung zur Entscheidung bringen können. 


\section{Die fortschreitende Verdännung als Funktion der Hơhe.}

Betrachten wir einen senkrechten Emulsionszylinder, welcher für die mikroskopische Beobachtung in der Art angecrdnet ist, wie dies in Nr. 18 naher bezeichnet wurde. Gleich nach dem kraftigen Durchschütteln sind die Teilchen nahezu gleichföra:g verteilt. Alier lins.r. Verteilungszustand wird sich, wenn unsere kine theorse ricifig ist, beim ruhigen Stehen der Emulsion andern wist wird emen Grenzwert erreichen, wo die Konzentration als Exponentialfunktion der Hohe abnehmen wird.

Dies wird durch den Versuch vollauf bestătigt. Am Anfang sieht man ungefăhr soviele Korner in einer oberen oder tieferen Schicht einer Emulsion. Nach einigen Minuten schon werden die unteren Partien auf Kosten der Körner der oberen Lagen tellchenreicher. Wenn man dann anfangt, die Teilchen in zwei bestimenten Niveaus (Nr. 19) auszuzăhlen, so findet man als Verhaltnis $\frac{n_{0}}{n}$ der Konzentrationen in diesen Lagen einen Wert, welcher eimige Zeit noch, aber immer langsamer und langsamer wăchst und endlich konstant wird, ohne irgendwelcher geordneter Verănderung mehr zu unterliegen.

Bei den Emulsionen, mit denen ich arbeitete, genügten drei Stunden, bis 'sich jener Grenzzustand der Verteilung eingestellt hatte, denn man fand nach dieser Zeit oder nach 15 Tagen fast die gleichen Werte.

Diejenigen von den Emulsionen, welche nicht aseptisch gemacht wurden, werden manchmal von langgestreckten und sehr lebhaften Protozoen heimgesucht, wetche gleich Fischen die Emulsion durchwühlen und so die Ungleichheiten der Verteilung zwischen den unteren und oberen Schichten stark vermindern. Wenn man aber die Geduld gehabt hat, zu warten, bis diese Mikroben mangels an Nahrung endlich abstarben und trăge zu Boden fielen, was zwei bis drei Tage dauerte, dann fand man wieder den früheren Verteilungszustand mit all den Eigenschaften einer dauernd geordneten Verteilung.

Wenn einmal bleibende Ordnung eingetreten ist, so ist es leicht festzustellen, ob die Konzentration als Exponentialfunktion der Hobe abnimmt. Die folgenden Messungen zeigen, daß dies in der Tat der Fall ist.

Ich habe zunächst mit Gummiguttiteilchen mit einem Rauilus von beiläufig $0,14 \mu$ gearbeitet. Die Küvette, in der sie untersucht wurden, besaß eine Höhe von $110 \mu$. Die Konzentration der Körner wurde in fünf gleichweit voneinander entfernten Ebenen festgestellt. 
Die unterste derselben war $5 \mu$ über dem Boden des Präparates (um den möglichen Einfluß der Wand auszuschalten), und der Abstand von je zwei einander unmittelbar folgenden Ebenen betrug $25 \mu$, so daB sich die oberste $5 \mu$ unter der Oberfläche befand. Die gefundenen Zahlen verhielten sich zueinander wie $100,116,146,170,200$, so daB die Ziffern 100,119,142,169, 201, welche von den vorangegangenen nur innerhalb der Fehlergrenzen verschieden sind, eine geometrische Reihe bilden. Die Verteilung der Teilchen ist also dieselbe, wie bei einem unter dein Einfluß der Schwere im Gleichgewicht befindlichen Gase. Nur die Abnahme bis zur halben Konzentration, welche sich für die Atmosphäre bei einer Höhe von 6 Kilometern zeigt, ist hier bei einer Hohe von 1/10 Millimeter erreicht.

Dieser Konzentrationsfall ist aber noch $z u$ unbedeutend, als daB dadurch der Exponentialcharakter der Abnahme sichergestellt wäre. Ich habe daher mit groberen Kormern versucht, eine raschere Konzentrationsverminderung $2 \mathrm{u}$ verwirklichen.

Meine sorgfăltigste Versuchsreihe wurde mit Gummiguttikornern gemacht, deren Halbmesser $0,212 \mu$ betrug. Die Zăhlungen sind in einem GefäB von $100 \mu$ Hohe in vier Horizontalebenen gemacht worden, welche das Gefab in einer Entfernung von 5, 35, 65, $95 \mu$ vom Boden desselben durchschnitten.

Die Zhhlung wurde direkt durch ein Nadelloch hindurch (Nr. 19) vorgenommen und lieferte 13000 Teilchen; auf die genannten Niveaus verteilt, verhalten sich die Konzentrationen wie die Zahlen 100, 47, $22,6,12$, fast gleich den Zahlen $100,48,23,11,1$, die eine geometrische Reihe bilden.

Also ist die exponentielle Verteilung der Teilchen auBer Zweifel gesetzt, jeder Erhebung um $30 \mu$ entspricht hier eine Verminderung der Konzentration um die Hălfte ihres jeweiligen Wertes.

Eine -dritte, weniger genaue Versuchsreihe, welche sich aul 3000 Teilchen eines unreinen Gummigutti bezog, das dichter isf als das reine, wurde nach einem anderen Verfahren (Zahlung der Körner auf photographischem Wege) gewonnen. Der Radius der Teilchen war wenig von $0,29 \mu$ verschieden. Diesmal genügte eine Erhebung von $30 \mu$, um die Konzentration auf den zehnten Teil ihres Wertes zu verringern; in Zahlen ausgedrückt, verhielten sich die Konzentrationen in den Niveaus $5,15,25,35 \mu$ wie die Zahlen $100,43,22,10$, von denen die Zahlen 100, 45, 21, 9,4, die eine geometrische Progression bilden, nur in den Grenzen der Versuchsfehler abweichen. 
In der Figur 4 sieht man übereinanderliegend die Wiedergabe der Photographien, aus welchen sich die vorstehenden Zahlen ergeben; die progressive Verdünnung ist augenscheinlich. Sie wirkt über-

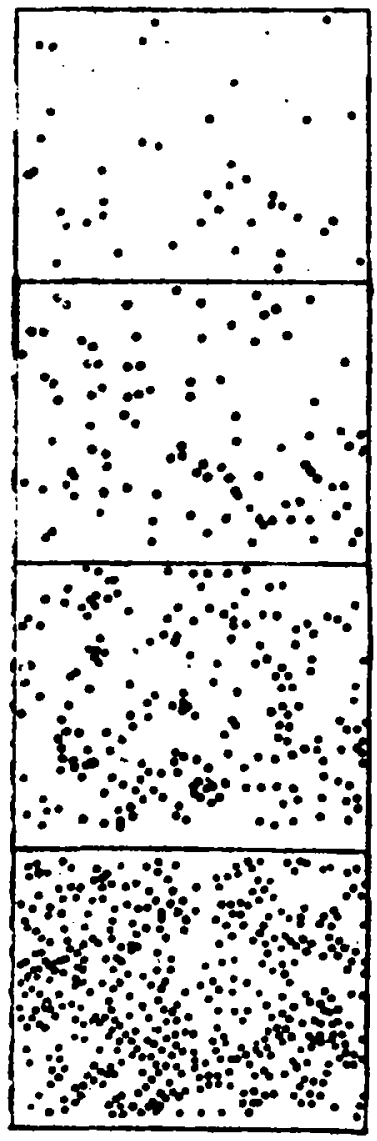

Fig. 4

Verteilung des Gleichgewichtes von Gummigutti - Teilchen $(0,6 \mu$ Durchmesser, 4 Niveaus, genommen von $10 \mathrm{zu} 10 \mu$ ).

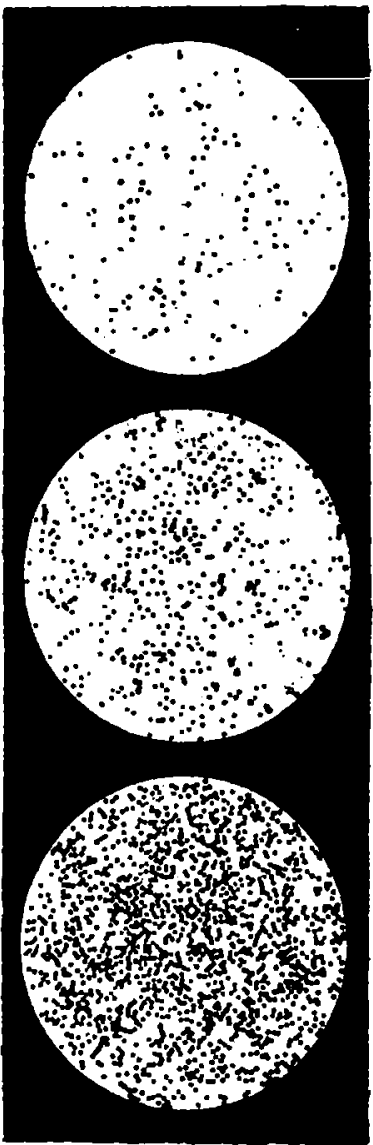

Fig. 5

Gleichgewichtsverteilung in einer Mastixemulsion (1 $\mu$ Durchmesser, 3 Niveaus, genommen von 12 zu $12 \mu$ ).

raschend, wenn man, dos Auge auf das Präparat gerichtet, das Mikroskop durch Drehen an der Mikrometerschraube rasch hebt. Man sieht dann, daB die Teilchen schnell abnehmen, wie auch die Luft um den steigenden Ballon herum dünner und dünner wird, nur mit der Beschränkung, daB $10 \mu$ in der Emulsion dasselbe bedeuten, wie 6 Kilometer in der Luft. 
Ich habe Gummigutti-Emulsionen mit noch schwereren Körnern untersucht. Bei einer derselben, in welcher die untersten Regionen ausgezählt wurden, fiel bei einer Erhebung um $6 \mu$ die Konzentration auf ein Viertel ihres Wertes. Sie würde demnach in $60 \mu$ Höhe zweimillionenmal schwächer sein als an Boden.

Man bemerkt auch, nach dem Eintreten der endgültigen Verteilung, bei Emulsionen der letzterwähnten Art in den obersten Schichten des benützten Giefäßes, nahe bei $100 \mu$ Höhe, kein einziges Teilchen mehr.

Ich habe endlich gemeinsam mit $M$. Dabrowski die exponentielle Verteilung auch für die Emulsionen des Mastix festgestellt. So zeigten zum Beispiel für eine Emulsion, deren Körner einen Durchmesser von ungefähr $1 \mu(\mathrm{a}=0,52 \mu)$ hatten, vier in übereinanderliegenden Abständen von $6 \mu$ gemachte Photographien im Verhältnis zueinander 1880, 940,530 und 305 Bildchen von Körnern, Zahlen, die wenig verschieden sind von $1880,995,528$ und 280, die in geometrischer Reihenfolge abnehmen.

Die Figur 5 veranschaulicht die Verteilung der Körner bei dieser Emulsion in drei je $12 \mu$ übereinanderliegenden Horizontalschichten. Die Abnahme nach dem Exponentialgesetz ist also feststehend.

\section{Die Molekularbewegung als Ursache des Brown'schen Phănomens').}

Sobald das Verhältnis der Konzentrationen an zwei Stellen nur abhängig ist von dem senkrechten Abstand der zwei Punkte, gibt die in Nr. 14 und 15 aufgestellte Verteilungsgleichung

$$
2,303 W \log _{10} \frac{n_{0}}{n}=2 \pi a^{3}(\Delta-\delta) g h
$$

für jede Emulsion einen wohldefinierten Wert für die Energie der Teilchen W. Wenn unsere kinetische Theorie ganz exakt ist, dann wird dieser Wert unabhängig sein von der gewăhlten Emulsion, er wird bei derselben Temperatur gleich sein der mittleren Energie w irgendeines Moleküls, oder, was auf das gleiche hinauskommt, der Wert w des Ausdruckes $\frac{3}{2} \frac{\mathrm{KT}}{\mathrm{W}}$ wird, unabhangig vom Halbmesser und der Dichte der studierten Teilchen, dem Ausdruck $\begin{array}{ll}3 & \mathrm{RT} \\ 2 & \mathrm{w}\end{array}$ gleich sein, das ist der Konstanten von Avogadro ( $\mathrm{Nr} .7$ ), deren angenäherten Wert wir bereits kennen (Nr. 11). Man will also mit einem Wort wissen, ob sich bei verschiedenen Emulsionen der Wert $\mathrm{N}^{\prime}$ der durch

1) Compt. rend. 146, 167, und 147, 530 (1908). 
die van der Wa al'sche gefundene Zahl 60.1022 annähert. Die Versuchsreihen, mit deren Hilfe das Gesetz der exponentialen Verdũnnung festgestelit wurde und noch mehrere andere Untersuchungen, von denen ich jetzt reden will, antworten darauf.

Die erste bereits veroffentlichte Versuchsserie bezieht sich auf nicht vollkommen gereinigte und gewaschene Gummiguttiteilchen mit einem Halbmesser von beilăufig $0,14 \mu$; eine Korrektion der dabei gewonnenen Resultate konnte ich spater nicht mehr vornehmen, da mir keine Probe dieser Emulsion mehr zur Verfügung stand. Da die Beobachtung bei Immersionsbeleuchtung nur schwer oder gar nicht möglich war, wurde sie bei seitlicher Beleuchtung gemacht und lieferte bei der direkten Zählung durch ein Nadelloch ungefähr 3000 Körner. Dem erlaubten Spielraum für diese Versuchsreihe Rechnung tragend, ergab sich für $\mathrm{N}^{\prime}$ ein Wert zwischen $50.10^{22}$ und $80.10^{22}$.

Eine zweite Klasse von Versucheu erstreckte sich auf Teilchen von ungefahr dęm doppelten Halbmesser (ungefăhr $0,3 \mu$ ); die Korner waren gut gewaschen $(\Delta-\delta=0,21)$ und ziemlich gleichformig. Die Zăhlung ergab auch ca. 3000 Körner und der Wert $\mathrm{N}^{\prime}$ wurdé zu $75.10^{22}$ : anden.

Eine irtte Versuchsreihe von vergleichbarer Genauigkeit, welche mit fast hgro $u$ Teilchen $(a=0,29 \mu)$ eines unreinen Gummiguttis $(\triangle \cdot \dot{0} \quad 0,3)$ angestellt wurde, ergab nach einem anderen Verfahren (ZählL $x$ d $\cdot$ Teilchen auf den photographischen Platten) $65.10^{22}$.

Die viert. Scrie umfaBt deutlich grobere Teilchen $(a=0,45 \mu)$, die fast $30 \mathrm{mal}$ chw: die gut geneinigt zaren $\wedge-\delta=0,21$ ). Diese Teilchen waren so schwer, daB ihre Konzentration bei einer Erhebung um $6 \mu$ auf ein Viertel ihres Wertes sank. Die direkte Auszăhlung von beiläufig 4000 Körnern gab für $\mathrm{N}^{\prime} 72 \cdot 10^{22}$.

Es war wünschenswert, aufer dem Gummigutti noch einen anderen Stoff in den Bereich der Untersuchung zu ziehen. Es wurde daher eine fänfte Reihe von Versuchen mit Mastixteilchen vorgenommen; an diesen Arbeiten hat sich auch $M$. Dabrowski beteiligt. Die zur Untersuchung verwendeten Körner haben bei gleichem Voluminhalt im Wasser ein dreimal geringeres scheinbares Gewicht als die Teilchen des reinen Gummiguttis $(\triangle \cdot \delta=0,063)$. Wir haben mit Körnem gearbeitet, deren Durchmesser etwas grober war als ein Mikromillimeter $(a=0,52 \mu)$ und die sich leicht photographieren ließen.

Die Aufnahmen der sechs voneinander um $6 \mu$ abstehenden horizontalen Schnitte wurden einmal von der untersten zur obersten Schichte, 
dann durch Abwärtsbewegung des Mikroskopes auf umgekehrtem Wege gemacht. Die so erhaltenen zwölf Photographien lassen die Bilder von beilăufig 7500 Körnern entnehmen, woraus sich für $N^{\prime}$ der Wert $70.10^{22}$ ergibt.

Es stimmen also die Werte der Teilchenenergie, welche den vorstehenden Reihen entsprechen, innerhalb der Genauigkeitsgrenzen der Versuche überein; dabei variierte die Masse der Korner von 1 bis 40, der Dichteunterschied der Teilchen und des Mittels von 1 bis 4,7 und die Raschheit der Verdünnung als Funktion der Höhe von 1 bis 30. Wir haben hier innerhalb eines später noch zu erweiternden Bereiches gleichsam eine experimentelle Bestătigung der. gleichen Energieverteilung der verschiedenen Massen vor uns. - Aber es steht auch fest, daB diese Werte mit dem für die Molekularenergie von uns Vorbergesehenen übereinstimmen.

Der mittlere Unterschied erreicht nicht 15 Proz., und die mittels der van der Waals'schen Gleichung erreichte Zahl ist nicht von dieser Genauigkeit. - Ich glaube nicht, daB diese Uebereinstimmung noch einen Zweifel über den Ursprung der B rown'schen Bewegung übrig läbt.

So kann also die Molekulartheorie des Brown'schen Phănomens als experimentell befestigt angesehen werden, und ebenso ist die wahre Existenz der Moleküle nicht leicht abzuleugnen. Zu gleicher Zeit sehen wir die von van't $H$ of $f$ bereits auf die verdannten Losungen ausgedehnten Gesetze der vollkommenen Gase nun auch für die gleichformigen Emulsionen gelten.

Die B rown'sche Bewegung stelit uns in einer anderen Grőßenklasse ein getreues Bild dèr Bewegungen dar, welche zum Beispiel die im Wasser eines Sees gelősten Sauerstoffmoleküle ausführen, welche, da sie gegenseitig selten aneinanderprallen, ihre Richtungen und Geschwindigkeiten nach ihren ZusammenstöBen mit den Molekülen des Losungsmittels ändern.

Es kann interessant sein, zu beobachten, daB die gröBten der Teilchen, bei welchen ich die Gesetze der vollkommenen Gase als geltend gefunden habe, schon mittels einer starken Lupe im Sonnenlicht sichtbar sind. Sie verhalten sich wie die Moleküle eines idealen Gases, dessen Gramm-Molekăl 200000 Tonnen wiegen würde.

Ich füge noch hinzu, daB die in diesem Paragraphen zusammengefaBten Mess!ngen mit verdünnten Emulsionen gemacht worden sind, welche in ihrem an Teilchen reichsten Teil nicht ein Tausendstel an 
Harz enthielten und wo der osmotische Druck nicht den milliardsten Teil einer Atmosphäre erreichte.

Diese letzte Ziffer zeigt, in welchem Punkte ich von den Bedingungen abyewichen, unter welchen man ċe osmotis :zen Drucke von kolloider Lossungen mit sehr kleinen und $e$ ' lander sehr genăherten Körnern hat entdecken (Malfitano) und messen (J. Duclaux) kőnnen. Es kann sein, daB einmal eine der van der Wa als'schen mehr oder minder analoge Verallgemeinerung $\mathrm{zu}$ einem theoretischkinetischen Ausdruck führen wird, der eine Berechnung des osmotischen Druckes solcher Lösungen zulä日t.

\section{Genaue Bestimmung der Konstante von Avogadro.}

Kurz, gleiche Körnchen verteilen sich in einer verdünnten Emulsion wie schwere Molekulle, gehorchen den Gasgesetzen, und ihre Verteilungsgleichung, in welcher man jetzt für $W$ den Ausdruck $\frac{3}{2}-\frac{R T}{N}$ setzen kann, lautet nun $2,303 \frac{R T}{N} \log _{10} \frac{n_{0}}{n}=\frac{4}{3} \times a^{3} g(\Delta-\delta) h$. Einmal richtig aufgestellt, bietet diese Gleichung selbst ein Mittel von scheinbar unbegrenzter Genauigkeit zur Bestimmung von $N$ und der davon abhăngigen Konstanten. Die Bereitung einer gleichformigen Emulsion und die Bestimmung der auBer $\mathrm{N}$ in der Gleichung figurierenden Groben können in der Tat bis zu jedem beliebigen Grad der Vollkommenheit getrieben werden. Das ist nur eine einfache Prage der Geduld und der Zeit. - Die in den vorhin zusammengefaBten fünf Versuchsreihen für $\mathrm{N}$ erhaltenen Werte haben 69.1022 zum Mittel; die sorgfältigste dieser Serien ist jene, die ich mit Mastix vorgenommen habe (Zählung auf photographischen Platten); und die für N 70.1022 ergibt.

Ich habe ferner mit Gummigutti weitere Versuche gemacht (die Resultate habe ich bereits oben angeführt), von denen ich glaube, daB sie noch genauer sind. Der mittlere Halbmesser der Körner der verwendeten Emulsion wurde durch Zăhlung von 11000 Teilchen einer titrierten Emulsion zu 0,21:2 $\mu$ und durch Anwendung des Gesetzes von Stokes zu $0,213 \mu$ gefunden. Der Dichteunterschied zwischen der Masse der Teilchen und des dazwischen befindlichen Wassers betrug bei $20^{\circ}$, der Temperatur, bei welcher die Messungen vorgenommen wurden, 0,2067. In den verschiedenen Höhen wurden (direkte Zahlung durch ein Nadelloch hindurch) 13000 Teilchen gezăhlt, deren Verteilung nach dem Exponentialgesetz erwiesen war, indem jeder Erhebung um $30 \mu$ ein Konzentrationsabfall um die Halfte 
des jeweiligen Wertes (die genauen Zahlen siehe Nr. 22) folgte. Der aus diesen Messungen für $\mathrm{N}$ sich ergebende Wert ist gleich 70,5.1022.

\section{Numerische Werte der Konstante von Avogadro und der davon abhăngigen Konstanten.}

Man wird also dazu geführt, für die Konstante von Avogadro den Wert $\mathrm{N}=70,5.10^{22}$ festzulegen. Die Anzahl $\mathrm{n}$ der bei gleichen Druck- und Temperaturbedingungen in einem Kubikzentimeter Gas enthaltenen Moleküle, erhalten durch Division der vorstehenden Zahl durch das Volumen 22400 des Grammoleküls, ist demnach $n=3,15$. $10^{19}$. Die Konstante der Molekularenergie (Nr. 6), gleich $\frac{3 R}{2 N}$, ist in Einheiten des C. G. S. sumit gleich $\alpha=1,77 \cdot 10^{-16}$, und folglich die mittlere kinetische Energie irgendeines Moleküls bei $0^{0} 273 \propto$ in Ergs, d. h. $w=0,48 \cdot 10^{-13}$. Endlich erhält man die Ladung eines Elektrons oder das Elektrizitătsatom durch Division eines Faraday durch $\mathbf{N}$ (Nr. 8), und sie beträgt in elektrostatischen Einheiten des C.G.S.

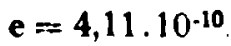

26. Cewichte und Dimensionen der Molekule oder der Atome.

Die Masse irgendeines Moleküls oder eines Atomes erhălt man offenbar mit derselben Präzision. So zum Beispiel wird jedes Sauerstoffmolekül, da es in $32 \mathrm{~g}$ Sauerstoff $\mathrm{N}$-Moleküle gibt, die Masse $0_{2}=\frac{32}{N}=45,4 \cdot 10^{-2}$ haben und das Atom Sauerstoff wird $0=\frac{16}{N}=22,7.10^{-24}$ Gramm wiegen.

In gleicher Weise wird man die Masse jedes Moleküls und Atoms erhalten; man dividiert einfach das Gramm-Molekül der betreffenden Verbindung durch N, oder, wenn es sich um das Atom handelt; des Grammatoms des bezugglichen einfachen Stoffes durch dieselbe Zahl. Das leichteste aller Atome, das ist das Wasserstoffatom, hat demnach die Masse $H=\frac{1,008}{N}=1,43 \cdot 10^{-24}$. Endlich ergibt sich auch die Masse eines der Korpuskel, welche die negative Elektrizitat der Kathodenstrahlen oder der $\boldsymbol{\rho}$-Strahlen fortführen, init der gleichen Genauigkeit, da man weiB, daB sie 1775 mal kleiner ist, als die des Wasserstoffatoms ( $\mathrm{Cl}$ a s s e $\mathrm{n}$ ). Diese Korpuskelmasse, das letzte Stoffelement, welches der Mensch entdecikt hat, ist also $C=0,805 \cdot 10^{-27}$. Was die Dimensionen der Molẹküle anbelangt, so kőnnen wir jetzt, da wir $n$ kennen, dieselben aus der Gleichung von Clausius-Maxwell 
(Nr. 10) $L=\frac{1}{\pi \sqrt{2}} \quad 1$ n $D^{2}$ für alle Gase berechnen, deren mittlere Wegstrecke L (mit Hilfe der Viskosität) bekannt ist.

So berechnet sich beispielsweise die mittlere Wegstrecke des Quecksilbermoleküls bei Atmosphärendruck und $370^{\circ}$ aus der Viskosităt $6.10^{-4}$ des Gases nach der Gleichung von $M$ axwe11, $\eta=0,31 \varrho \Omega \mathrm{L}$. welche für $\mathrm{L}$ den Wert $2,1 \cdot 10^{-5}$ liefert. Andererseits ist bei $379^{9} \mathrm{n}$ gleich $3,15 \cdot 10^{19} \frac{273}{273+370^{-}}$. Der gesuchte Durchmesser ist also gleich der Quadratwurzel aus $\frac{1}{\pi \sqrt{2}} \cdot \begin{array}{ccc}2 & 643 & 10^{5} \\ 3,15 \cdot 10^{19} & 273\end{array} \cdot 2,1^{-}$, das heiBt genau $2,8 \cdot 10^{-8}$.

So habe ich einige molekulare Durchmesser berechnet und die nachstehenden Zahlen erhalten:

$$
\begin{aligned}
& \text { Helium } \cdots 1,7 \cdot 10^{-8} \\
& \text { Argon . . 2, 2,7.10-8 } \\
& \text { Quecksilher . 2,8 } 10^{-8} \\
& \text { Wasserstoff } \cdot 2,0 \cdot 10^{-B} \\
& \text { Sauerstoff } \cdots 2,6 \cdot 10^{-8} \\
& \text { Stickstoff } \cdots 2,7 \cdot 10^{-8} \\
& \text { Chlor . . . 4,0 } 10^{-8} \\
& \text { Acther } \ldots 6,0 \cdot 10^{-8}
\end{aligned}
$$

Es ist klar, daß es sich in dem Falle ron mehratomigen Molekülen nur um einen schlecht definierten Durchmesser handelt, dessen Bestimmung natürlich nicht mit der Sicherheit erfolgen kann, wie dies für die Massen möglich ist.

Endlich kann man selbst den Durchmesser des Korpuskels bestimmen, wenn man mit J.-J. Thomson annimmt, daB der ganze passive Widerstand desselben elektromagnetischen Ursprunges ist, oin welchem Falle der Durchmesser durch die Gleichung 1) $D=\begin{array}{cc}4 & \mathbf{e}^{2} \\ 3 & \mathrm{mV}^{2}\end{array}$ bestimmt ist, wo $\mathrm{V}$ die Lichtgeschwindigkeit, $m$ die Masse des Korpuskels und e die Ladung des Korpuskels, d. i. 4,1 1.10-10 bedeuten. Für D ergibt sich dann der Wer̈t $1 / 31^{-12}$, also sehr viel kleiner als der Durchmesser der kleinsten Alome.

) Siehe Langevin, Thése 70 . 


\section{TEIL.}

\section{Die Formeln von Einstein.}

Die im vorigen Kapitel angeführten Versuche gestatten, wie wir gesehen haben, den Ursprung der Brown'schen Bewegung festzustellen und verschiedene molekulare GröBen zu bestimmen. Aber noch ein anderer Versuchsweg war moglich und ist von Einste in ") im Anschlub an sehr schone theoretische Arbeiten, von denen ich jetzt sprechen muB, vorgeschlagen worden ${ }^{2}$ ).

Wir haben bis jetzt noch keine genaue Charakteristik der Kraft der Brown'schen Bewegung gegeben, welche ein bestimmtes Teilchen in Bewegung setzt; wir haben nur bemerkt, dab seine wahre Geschwindigkeit nicht direkt meBbar ist. E in s $\mathrm{t}$ in betrachtet, ohne in Verwirrung um den unendlich verwickelten Weg zu geraten, den das Teilchen wahrend einer gegebenen Zeit durchläuft, einfach nur seine Ortsverănderung während dieser Zeit, die Verschiebung, welche durch die Laange des geradlinigen Segmentes, welches den Anfangspunkt und den Endpunkt trennt, definiert ist. Das Mittel der Verschiebungen, denen das Teilchen (oder eine groBe Zahl gleicher Teilchen) innerhalb gleicher Zeiten unterworfen ist, ist die mittlere Ortsverănderung in dieser Zeit.

Betrachten wir vorlăufig Körnchen, welche mit der Zwischenflüssigkeit die gleiche Dichte besitzen; dann ist ihre Bewegung nicht nur im rechten Winkel zur Vertikalen (wie unter den gewöhnlichen Bedingungen), sondern nach allen Richtungen vollkommen unregelmåBig.

Wegen dieser vollstãndigen UnregelmäBigkeit werden sich die aufeinanderfolgenden Verschiebungen un die mittlere Ortsverănderung w verteilen; diese Verteilung wird genau nach dem von Maxwell für die Verteilung der molekularen Geschwindigkeiten um die mittlere Geschwindigkeit (Nr. 9) angegebenen Gesetze erfolgen, und daher ist das mittlere Quadrat $\mathrm{E}^{2}$ der Verschiebung gleich $\frac{3 \pi}{8} \omega^{2}$.

Denken wir uns die Teilchen in der Flüssigkeit ungleich verteilt; sie werden gegen die Gebiete der geringeren Konzentrationen diffundieren, und das natürlich um so rascher, je lebhafter ihre Bewegung ist, d. h. mit anderen Worten, um so schneller, je größer ihre mittlere Verschiebung in einer gegebenen Zeit ist. Die mathematische

1) "Moge es bald einem Forscher gelingen, die hler aufgeworfene, flir-die Theorie der Warme wichtige Frage zu entscheldenl*

) Ann. d. Phys. 1905, 549, und 1906, 371. 
Behandlung dieses Gedankens ist nicht sehr schwierig'), erfordert keine neue Hypothese und führt $z u$ der sehr einfachen Gleichung $\mathrm{E}^{2}=6 \mathrm{D} \tau$, in welcher $r$ die Zeltdauer und $\mathrm{D}$ den Diffusionskoeffizienten bedeuten; diese Gleichung labt sich nach der Division threr beiden Teile durch 3 schreiben $\xi^{2}=2 \mathrm{D} \tau$, wo $\xi$ das mittlere Quadrat $\cdot d e r$ Projektion der Verschiebung auf eine Achse $O x$ bedeutet.

Nehmen wir jetzt an, daB die Teilchen einer an Grobe und Richtung konstanten Kraft unterworfen sind. Ihre in der Richtung dieser Kraft modifizierte Bewegung wird im rechten Winkel zu dieser Richtung nicht geândert; die vorstehende Gleichung bleibt also, was die Projektion der Verschiebungen auf eine horizontale Achse betrifft, noch anwendbar, wenn die Teilchen nicht die gleiche Dichte besitzen als die zwischen ihnen befindliche Flüssigkeit.

Es bleibt noch übrig, den Diffusionskoeffizienten als Punktion der experimentell zuganglichen Parameter auszudrücken. In dem Palle von runden Körnern vom Halbmesser $\alpha$ gelingt dies leicht (E in st e in), wenn man den bleibend geordneten Zustand in Betracht zieht, der sich ergibt, wenn eine konstante, auf die Teilchen wirkende Kraft?) trotz der. Diffusion die verschiedenen Konzentrationen in senkrecht zur Richtung der Kraft liegenden Schichten aufrecht erhät. Es passieren also (vgl. Einstein ${ }^{3}$ ) jede senkrecht zur Kraft liegende Ebene unter dem EinfluB dieser Kraft ebensoviele Teilchen in einem Sinne als durch die Wirkung der Diffusion in entgegengesetzter Richtung, und man erhălt die Gleichung von $\mathrm{E}$ instein $\mathrm{D}=\frac{\mathrm{RT}}{\mathrm{N}} \frac{1}{6 \pi \mathrm{a} \zeta^{\prime}}$ diesmal aber mit Hilfe von neuen Hypothesen.

Die eine dieser Hypothesen, durch welche die Viskosităt der Flüssigkeit eingeführt wird, besteht in der Annahme des Gesetzes von Stokes fir den Fall, wo eine konstante Kraft auf die durch die Brown'sche Bewegung getriebenen Teilchen wirkt. Ich habe bereits weiter oben (Nr. 21) gezeigt, daB diese Erweiterung experimentell begründet werden kann, was eine theoretische Beweisführung entbehrlich macht.

Die andre Hypothese, durch welche $N$, die Konstante von Avogadro, eingefahrt wird, ist uns bereits gelăufig und besteht in der Annahme, daB die mittlere Energìe eines Körnchens gleich ist der

1) Siehe Einstein, Ann. d. Phys. 1906, 557.

2) Welche nicht die Schwrre zu sein braucht.

") Ann. d. Phys. 1906, 554. 
Molekular-Energie. Gerade dadurch wird die Theorie Einstein's zu einem Prüfstein der Hypothese angemessen, welche den Ursprung der Brown'schen Bewegung in die Molekularbewegung versetzt.

Die Prüfung ist theoretisch leicht durchgeführt; man braucht bloB die beiden vorstehenden Gleichungen z.u nehmen und folgende

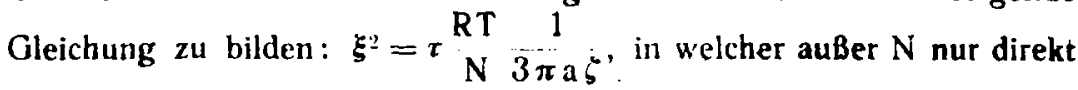
meBbare Grölien vorkommen. Man wird nur noch zu untersuchen laaben, ob die durch diese Formel für $\mathrm{N}$ gefundenen Werte mit den auf anderen Wegen gefundenen übereinstimmen ').

Einen Schritt weitergehend und sich des Umstandes bedienend, daf, wenn die gleiche Energieverteilung richtig ist, die mittlere Energie der Rotation um eine Achse gléich ist der mittleren Energie der Ueberführung parallel zu einer Áchse, hat $\mathrm{E}_{\text {inst }} \mathrm{in}^{2}$ ) eine Gleichung erhalten, welche, für eine gegebene Zeit, das mittlere Quadrat $\alpha^{2}$ der Rotation des Teilchens ur eine Achse ausdriickt: $\alpha^{2}=\tau \frac{R T}{N} 4 \pi \frac{1}{4 \zeta a^{3}}$, eine Gleichung, weiche, wie ich später zeigen werde (Nr. 32), zu einem schwierigeren, doch nicht unmöglichen experimentellen Nachweis dienen kann. Aber ich will mich vorerst mit derjenigen der Einste in'schen Formeln beschäftigen, welche sich auf die Verschiebungen bezieht.

\section{Experimentelle Prufung der Theoric von Einstein.}

\section{Erste Versuche.}

Man kann zunăchst bemerken, daß nicht die Masse der Teilchen, sondern ihr Volumen in dieser Formel vorkommt. Schwere Metallstäubchen, Oeltröpfchen und selbst Lufibläschen würden bei gleichem Volumen genau dieselbe Bewegung haben. Das haben in der Tat gute Beobachter schon seit langem versichert ${ }^{3}$ ). Es waren dies sicherlich nicht Eindrücke, die sich auf genaue Bestimmungen stützten, die aber bestimmt genügten, um zu zeigen, daß ein schweres und ein leichtes Körnchen von derselben Größe sich wider Erwarten gleich bewegen.

1) Es scheint unir gerechtierligt, daran zu etinnern, daß S moluchowski fast zu gleicher Zeit mit Einstein und von einem anderen Gesichtspunkt aus zu einer ganz ahnlichen Formel gekommen ist. Vgl. seine Arbeit uber ,Une théorie cinétique du mouvement brownien (Bulletin de l'Academie des Sciences de Crocovie, juillet 1906), wo man auBer sehr interessanten Betrachtungen auch eine vorzügliche historische Zusammenstellung älterer Arbeiten findet.

2) Ann. d. Phys. 1906, 371 380.

3) Jevons, Proc. Manch. Soc. 1869, 78. Carbonnelle et Thirion, Revue des Questions scientifiques 1880, 5. Gouy, Compt. rend. 109, 102 (1889). 
Die Theorie von A. Einste in enthält auch nichts von einem Elektrisierungszustand der Teilchen. Das Gegenteil hiervon war von verschiedenen Forschern angenommen wurden, welche, ohne übrigens die Gründe hierzu anzugeben, erklärten, daß die Elektrisierung der Teilchen eine wesentliche Bedingung ihrer Bewegung ist. Die Ungenauigkeit dieser Annahme ist von The Svedbergl) gezeigt worden, welcher durch allmähliches Hinzufügen von Spuren Aluminiumsulfats zu einer kolloiden Silberlösung den Sinn der elektrischen Ladung der Teilchen umkehrte, also den Wert Null dieser Ladung passierte, ohne auch nur einen Augenblick irgendeine Verminderung in der Lebhaftigkeit der Brown'schen Bewegung wahrzunehmen.

Im Hinblick auf den Einflua der Temperatur und der Viskosität kann man zunächst einige interessante Beobachtungen von Ex $n$ er anführen, welche, älter als die Theorie von A. Einstein, in keinerlei Weise von dieser beeinflu8t werden konnten ${ }^{2}$ ).

Exner hat mit Gummiguttikürnern gearbeitet, deren Radius er nach dem Aussehen des, wie man weiß, durch die Diffraktion verlängerten Bildes schătzte. Er verfolgte so gut als morglich in der Hellkammer die Bahn in einer gegebenen Zeit und dividierte in der Hoffnung, wenigstens annähernd die wahre Geschwindigkeit des Körnchens zu erhalten, den vollkommen krummlinigen Weg durch diese Zeit. Wir haben gesehen (Nr. 13), daß solche Schätzungen sehr falsch sind, und daB die wahre Geschwindigkeit viel grober ist als die scheinbare so erhaltene.

Aber das Verhaltnis der bei zwei Temperaturen während einer gegebenen Zeit gezeichneten Bahnlängen kann nicht sehr verschieden sein von dem Verhäitnis der die beiden äußersten Bahnpunkte verbindenden Strecken; mit anderen Worten, das Verhältnis der von Exner bei zwei verschiedenen Temperaturen beobachteten scheinbaren Geschwindigkeiten kann dem Verhältnis der Verschiebungen während derselben Zeit für diese zwei Temperaturen annähernd gleich sein.

Nun sagt Exner, daß die Geschwindigkeit eines Teilchens ungefăhr 1,6 mal gröber wird, wenn man von 20 auf $71^{\circ}$ steigt. Diese Zahl ist fast gleich der Quadratwurzel 1,7 des Ausdruckes

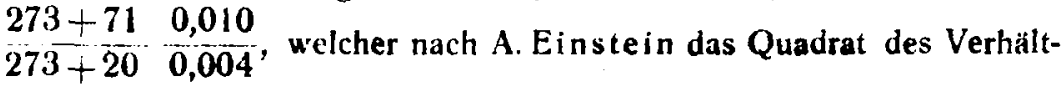
nisses der-mittleren Verschiebungen in der gleichen Zeit bei zwei ver-

1) Nova Acta Soc. Sc. 2 (Upsala 1907).

) E. Exner, Ann. d. Phys. 2, 843 (1900). 
schiedenen Temperaturen sein soll. Man kann hierin einen Vorläufer der teilweisen Bestătigung der in Frage stehenden Formel erblicken.

Man sieht in diesem Beispiel, daß die Lebhaftigkeit der Brownschen Bewegung auber von der Temperatur noch besonders von det mit dieser Hand in Hand gehenden Veränderung der Viskosität ab. hängig ist. Exner, welcher die wahren Geschwindigkeiten zu erreichen hoffte und der Meinung war, dab die kinetische Energie des Teilchens sich nicht proportional der absoluten Temperatur ändert, schlob daraus mit Unrecht, daB die Teilchen nicht als analog den Molekülen einer Flüssigkeit betrachtet werden können.

Einige Jahre später, und nach Verkündigung der Einstein'schen Formel, hat Svedberg eine experimentelle Prüfung vorgenommen und glaubte eine genügende Bestätigung erhalten $z u$ haben'). Aber ich muB sagen, daB dieser Teil seiner übrigens sehr interessanten Arbeit $\left.{ }^{2}\right)$ mir die optimistischen Folgerungen, die er daraus zieht, nicht zu rechtfertigen scheint und die gestellte Frage ohne Antwort la $\mathrm{Bt}^{3}$ ). Die Verschiebungen, welche er beobachtet hat sind vier- bis sechsmal gröBer als diejenigen, welche nach seinen Berechnungen der Formel genügen; im ersten Anblick ist man, den experimentellen Schwierig. keiten Rechnung tragend, versucht, hierin zum wenigsten eine grobe Uebereinstimmung zu erblicken, aber eine aufmerksame Prüfung ergibı eine wirklich große Verschiedenheit. In der Tat setzt eine vier-bis sechsmal zu große Verschiebung, wenn die Pormel genau ist, einen 25 mal kleineren Radius voraus, als es der von Svedberg an. genommene war, das heißt für das gleiche Gewicht Substanz ungefaht $12000 \mathrm{mal}$ mehr Teilchen in einem gegebenen Volumen. Nun bestehı ein von Svedberg angewendetes Mittel zur Bestimmung des Halbmessers in der Abzählung der in einem bekannten Volumen der titrierten Emulsion enthaltenen Teilchen, und es ist ganz unmöglich, daß er in diesem Volumen $12000 \mathrm{mal}$ weniger Teilchen gesehen hat, als darin wirklich vorhanden waren. Und weiter: Svedberg legt in seinen Berechnungen der Konstanten von Avogadro den Wert $4.10^{23}$ bei, welcher zu dieser Zeit zulässig war, aber sicher fasi

1) Studien zur Lehre von den kolloiden Lðsungen, Nova Acta Reg. Soc Sc. Upsaliensis, 4. Serie, 2 (Upsala 1907), und „Ion*, 1909.

7) Abwesenheit jeder Beziehung $z$ wischen der Berlihrungselektrizitat und der Brown'schen Bewegung; und Entdeckung von kolloiden Metallosungen ir nichtionisierten Flissigkeilen.

3) Anm. d. Red. Siehe indessen hierzu die Rechtfertigung von The Svedberg Zeitschr. f. physik. Chem. 71, 571 (1910). - Wo. Ostwald. 
sm die Hälfte zu klein ist. Wenn man $\mathrm{N}$ einen genaueren Wert beilegt, so sieht man, dab die mittleren Verschiebungen, welche sie anzeigt, fast $7 \mathrm{mal} \mathrm{zu}$ grob sind, und man müßte in dem untersuchten Volumen der Emulsion ungefăhr $100000 \mathrm{mal}$ zu wenig Teilchen gefunden haben. Der augenischeinliche Schlub aus den Svedberg'schen Versuchen wäre also, entgegen seiner eigenen Behauptung, daB die Formel von $E$ instein sicher falsch ist.

Glücklicherweise ist $z$ wischen den Größen $\xi$ und $\tau$, welche in der Gleichung vorkommen, und den von Svedberg dafür eingesetzten schlecht definierten Größen keine Aehnlichkeit. Durch einen passenden Ausflub erkilte Svedberg der beobachteter Emulsion eine gleichmäbige Bewegung, die genug rasch war, dab jedes Teilchen infolge der Fortdauer der Lichteindrücke für das Auge eine glänzende Bahnlinie lieferte. Infolge der Brown'schen Bewegung ist diese Kurve senkrecht zur allgemeinen Verschiebung ausgezackt. Wer aber die vollkommene U:rregelmäBigkeit der B row n'schen Bewegung kennt, wird es für unmöglich halten, daß diese Bahnen, wie Svedberg, der sich offerbar in einem Irrtum befand; sagt, regelmäBige Wellenlinien von wohl definierter Amplitüde und Wellenlänge sein können. S vedberg bestimmte durch Vergleichung mit einem Okularmikrometer die Beträge der (in Wirklichkeit nicht existierenden) Gröben, w'elche er Wellenlänge und Amplitüde der Oszillation nennt. Die Ausflubgeschwindigkeit der Flüssigkeit berücksichtigend, berechnete er sodanv die Schwingungsdauer, worunter die Zeit zu verstehen wăre, während welcher ein Teilchen senkrecht zur allgemeinen Verschiebung eine Ortsverănderung gleich der doppelten Amplitüde erleidet. Ich glaube nicht, $\mathrm{daB}$ es notig ist, auf der Unsicherheit länger $z u$ beharren, welche aus einer cben so fraglichen Methode als gewagten Schätzungen hervorgeht.

Im Gegenteil, es ist von allem Anfang an ganz korrekt, daB man sich, um die inittlere Verschiebung eines Teilchens während einer bestimmten Zeit $z \mathfrak{u}$ erhalten, die aufeinanderfolgenden Stellungen des Bildes dieses Teilchens auf in gleichen Zeitintervallen aufgenommenen Photographien bezeichnet. Viktor Hen $\mathrm{r}$ hat in diesem Sinne eine kinematographische Studie der Brown'schen Bewegung von natürlichen Körnern von Kautschukmilch gemacht. Es handelte sich um verhältnısmäßig große Teilchen, deren Durchmesser zu ungẹähr $1 \mu$ geschätzt wurde ${ }^{l}$ ).

1) Comp. rend., 18. Mai und 6. Juli 1908. 
Abgesehen davon, daß die mittlere Verschiebung in einer gegebenen Zeit sich nahezu so änderte wie die Quadratwurzel aus der Zeit, schien die Gesamtheit dieser Messungen für die Theorie von Einste in ungünstig. Die mittlere Verschiebung, welche in neutralem Wasser fast dreimal größer ist als es die Formel verlangt, würde dieser erst dann genügen, wenn der auf $1 \mu$ geschätzte Durchmesser des Teilchens achtmal kleiner wäre; dies ist aber unmöglich (Teilchen von diesem Durchmesser wären selbst bei direkter Beleuchtung nicht mehr wahrnehmbar).

Aber es schien, was von viel größerer Bedeutung wäre, daß Spuren von Säure oder Alkali, welche nicht nennenswert die Viskosität beeinflussen und übrigens nicht instande sind, die Kautschukteilchen zu agglutinieren, ihre Bewegung außerordentlich verlangsamten. So wurde zum Beispiel in schwach angesäuertem Wasser die mittlere Verschiebung neunmal kleiner als im neutralen Wasser, was für Teilchen von gleichem åuBeren Aussehen einen 80 mal größeren Durchmesser als im neutralen Wasser gefordert hătte. Diese ungeheuere Verschiedenheit ist ganz unvereinbar mit der Theorie von A. Einstein und übrigens mit jeder Theorie, welche die Natur der intergranulossen Flüssigkeit vernachlassigt und dieselbe nur durch ihre Viskositat vertreten läßt.

Soviel ich weiB, entwickelte sich damals unter den franzosischen Physikern, welche diese Fragen genau verfolgten, ein reger Meinungsaustausch, der auf mich einen groBen Eindruck machte, da ich daraus ersah, wie sehr das Vertrauen, das wir in unsere Theorien setzen, begrenzt ist. Man nahm ohne zu zögern einfach an, daB die Theorie von Einste in unvollstāndig oder ungenau sei.- Andererseits gab man es nicht auf, in die Molekularbewegung den Ursprung des B rown'schen Phănomens zil versetzen, da ich durch Versuche nachgewiesen hatte 1 ), daB sich eine verdünnte Emulsion so verbalt wie ein sehr dichtes Gas, dessen Moleküle ein Gewicht, gleich dem der Emulsionskorner, haben. Man begnügte sich also mit der Annahme, daB sich in die Ausdrücke Einstein's irgendeine ergänzende ungerechtfertigte Hypothese eingeschlichen habe.

\section{Experimentelle Bestatigung der Theorie von Einstein.}

lch dachte mir indessen, da Vikt or Henri allein den Durchmesser seiner Körner schätzte und sich die Allgemeinheit seiner

1) Comp. rend. 146, 967 (Mai 1908). 
Resultate vorbehielt, daß es noch nützlich sein könnte, die mittlere Verschiebung von Teilchen mit genau bekanntem Durchmesser, die ich herstellen konnte, zu messen. Mit diesen Messungen betraute ich Herrn $\mathrm{Ch}$ a udesaigues. Mangels eines chronophotographischen Apparates bezeichnete er die Stellung eines Körnchens in der Hellkanmer von $1 / 2$ Minute zu $1 / 2$ Minute, begann wieder mit einem anderen Teilchen und das so fort, wobei er im allgemeinen vier $\mathrm{Ab}$ lesungen pro Teilchen vornahm.

Gleich mit den ersten Versuchen stand es schon fest, dab die Verschiebungen, trotz anderer Erwartung, die Ein st e in 'sche Gleichung wenigstens annahernd bestätigten. Gleichzeitig ïberzeugte ich mich auch, daß das Hinzufügen von Säurespuren die Bewegung der Körner nicht nemrensweri beeinfluBte, wenn sich diese Teilchen weit von den Gefäbwänden befanden $)$. Kurz, man mub annehmen, dab irgendwelche unbekannte Komplikationen oder systematische Fehlerquellen die Resultate von Viktor Henri beeinflußt háben, denn die Messungen, die ich nun zusammenfassen werde, lassen keinen Zweifel über die strenge Gültigkeit der von Ein st $\mathrm{e}$ in aufgestellten Formel zu.

Wie ich soeben bemerkte, wurden die Korner, die ich bereitet hatte, in der Hellkammer bei senkrechtem Mikroskop angezeichnet, wodurch man die Horizontalprojektionen der Verschiebungen erhielt. Wenn man auf quadriltiertem Papier arbeitet, so bekommt man die Projektionen der verschiedenen so erhaltenen Segmente auf zwei rechtwinkeligen Achsen direkt, doch ist es überflüssig sie zu messen, da die Summe der Quadrate dieser Projektionen gieich ist der Summe der Quadrate der Segmente, so dab man, um das mittlere Quadrat der Projektion auf eine Achse zu bekommen, nur die einzelnen dieser Segmente zu messen, ihre Quadrate zu berechnen und die Halfte des Mittels dieser Quadrate zu nehmen braucht. Man hat dann nur mehr nachzusehen, ob der durch die Gleichung von Einstein

$$
\xi^{2}=\tau \frac{R T}{N} \frac{1}{3 \pi a \zeta}
$$

für $\mathbf{N}$ gegebene Wert innerhalb der Fehlergrenzen mit dem schon bestimmten Wert übereinstimmt.

M. Chaudesaigues studierte zunächst verhältnismäBig grobe, untereinander ziemlich gleiche Gummiguttikörnchen mit einem Radius von fast $0,45 \mu$. Er notierte die Verschiebung von 40 dieser Teilchen

1) Trotzdem, daB diese Zugabe die Elektrizität, welche die Teilchen bei der Beruhrung annahmen, zuerst neutralisierte und dann ihren Sinn umkehrte. 
während 1 Minute und 25 während 2 Minuten; diese Aufzeichnungen gaben für $\mathrm{N}$ den Wert $94.10^{22}$. Anderers its lieferten mir 30 fast gleiche Körnchen mit etwas gröBerem Radius (gleich 0,5 $\mu$ ) $66.10^{22}$, was für diese Gruppe ein Mittel von $80.10^{22}$ gibt.

M. Chaudesaigues studierte sodann die Körner vom Radius 0,212 , welche mir die genaueste Bestimumung von $\mathrm{N}$ (Nr. 24) gestattet hatten. Die folgenden zwei Tabellen fassen die Messungen zusammen, die mit zwei Gruppen von 50 Kömern gemacht wurden, von deneı jedes von 30 zu 30 Sekunden durch 2 Minuten hindurch verfolgt wurde; die Viskosität für die erste Serie (Wassertemperatur $17^{\circ}$ ) betrug 0,011 , für die zweite 0,012 :

\begin{tabular}{|c|c|c|c|c|}
\hline $\begin{array}{r}\text { Dauer in } \\
\text { Sekunden }\end{array}$ & $\begin{array}{l}\text { Mittlere Horizontalver- } \\
\text { schiebung (in } \mu \text { ). }\end{array}$ & $5.10^{-8}$ & N. $10^{-22}$ & Mittel von $\mathrm{N}$ \\
\hline \multicolumn{5}{|c|}{ Erste Gruppe } \\
\hline 30 & 8,9 & 50,2 & 66 & \multirow{4}{*}{$73.10^{22}$} \\
\hline 60 & 13,4 & 113,5 & 59 & \\
\hline 90 & 14,2 & 128 & 78 & \\
\hline 120 & 15,2 & 144 & 89 & \\
\hline \multicolumn{5}{|c|}{ Zweite Gruppe } \\
\hline 30 & 8,4 & 45 & 68 & \multirow{4}{*}{$68 \cdot 10^{22}$} \\
\hline 60 & 11,6 & 86,5 & 70,5 & \\
\hline 90 & 14,8 & 140 & 71 & \\
\hline 120 & 17,5 & 195 & 62 & \\
\hline
\end{tabular}

Endlich wurde in einer dritten Versuchsreihe, immer mit Teilchen von demselben Halbmesser, die intergranuläre Flüssigkeit (Wasser) durch Versetzen mit Zucker fast fünfmal zăher grmacht als reines Wasser. Die mittlere Verschiebung in 30 Seku.' ' $n$, die dann gleich $4,7 \mu$ beträgt, hat sich fast in dem vorausgesehenen Verhältnis verringert und liefert für $\mathrm{N}$ den Wert $56.10^{22}$, welcher geringer ist als die vorhergehenden, ohne daß jedoch der Unterschied die Größe überschreitet, welche infolge der tabellarischen Ungleichheiten und besonders der Fehlerquellen, die durch die gröBere Komplikation der Versuchsanordnung ein wenig vermehrt wurden, möglich ist. Das Mittel aus diesen vier Serien von Messungen, fast gleich dem Mittel der beiden besten Reihen für sich genommen, ist $70.10^{22}$, praktisch identisch mit demjenigen, das ich nach einer ganz verschiedenen Methode, die sich auf die dauernd geordnete Verteilung der Körner gründet, erhielt. 
Die Uebereinstimmung ist so vollkommen als moglich und laßt keinerlei Zweifel aufkommen.

\section{Zweite Bestătigung der Formel von Einstein.}

Es erschien wünschenswert, diese Resultate durch Aenderung der angewendeten Substanz zu prüfen, und ich habe, wie früher für die Verteilung in den Hǒhenlagen, unter der Mitwirkung von Dabrowski die Messungen wiederholt, aber an Stelle von Gummigutti den Mastix genommen.

Die Körner der studierten gleichförmigen Emulsion hatten einen Radius von $0,52 \mu$. Die beleuchtenden Strahlen gingen von einem Auerbrenner aus und durchsetzten, wie bei den vorausgegangenen Versuchen, einen gefüllten Wasserkasten, welcher fast alle die Strahlen zurūckhălt, welche das Wasser des Prăparates erwärmen könnten. Letzteres sowie das Immersionsobjektiv waren in Wasser getaucht; die Temperatur, deren genaue Kenntnis, infolge ihres großen Einflusses auf die Viskosităt, sehr wichtig ist, wurde von Zeit zu Zeit durch Einführung eines Thermometers in den Körper des Mikroskops (ganz gegen das Objektiv zu) festgestellt. Wir haben zunăchst zwei Reihen von Messungen vorgenommen, wobei wir uns beim Mikroskop gegenseitig ablosten und jeder von uns auf die Ansage des andern die Korner von 30 zu 30 Sekunden punktierte. In jeder Serie entspricht dieses Intervall von 30 Sekunden ungefähr 200 Punkten, das Intervall von 60 Sekunden 100 Punkten und so weiter. Die Resultate sind in der folgenden Tabelle zusammengefaBt:

\begin{tabular}{r|c|c}
\hline $\begin{array}{c}\text { Dauer in } \\
\text { Sekunden }\end{array}$ & $\begin{array}{c}\text { N.10-22 } \\
\text { erste Serie }\end{array}$ \\
zweite Serie \\
\hline \hline 30 & 57 & 69 \\
60 & 64 & 65 \\
120 & 67 & 64 \\
240 & 70 & 88
\end{tabular}

Endlich haben wir in einer dritten Gruppe die Größe der Verschiebung in zwei Minuten für 200 verschiedene Körner gemessen. Die 200 Messungen haben für $\mathrm{N}$ den Wert $77.10^{22}$ ergeben.

Diese verschiedenen Bestimmungen liefern für $\mathrm{N}$ einen mittleren Wert von $73.10^{22}$. Wenn man die bereits mit Gummigutti vorgenommenen Messungen berücksichtigt, so kann man sagen, dab die Betrachtung von ungefähr 3000 Verschiebungen für N. 10-22 den Wert 
71,5 1 ibt, welcher mit dem von mir nach einer ganz andern Methode erhaltenen, 70,5 (wahrscheinlich dem wirklichen Wert àngenäherter), gut übereinstimmt.

Die nachstehende Figur (6) gibt drei Zeichnungen wieder, welche durch das Einzeichnen der Segmente, die die im Intervall von 30 Sekunden aufeinanderfolgenden Stellungen eines und desselben Mastixteilchens verbinden, gewonnen wurde. Eine von den Zeichnungen enthalt 50 aufeinanderfolgende Stellungen eines und desselben Teilchens. Die Figuren geben nur eine sehr schwache Vorstellung von der außerordentlichen Kompliziertheit der wirklichen Bahn. Wenn man die

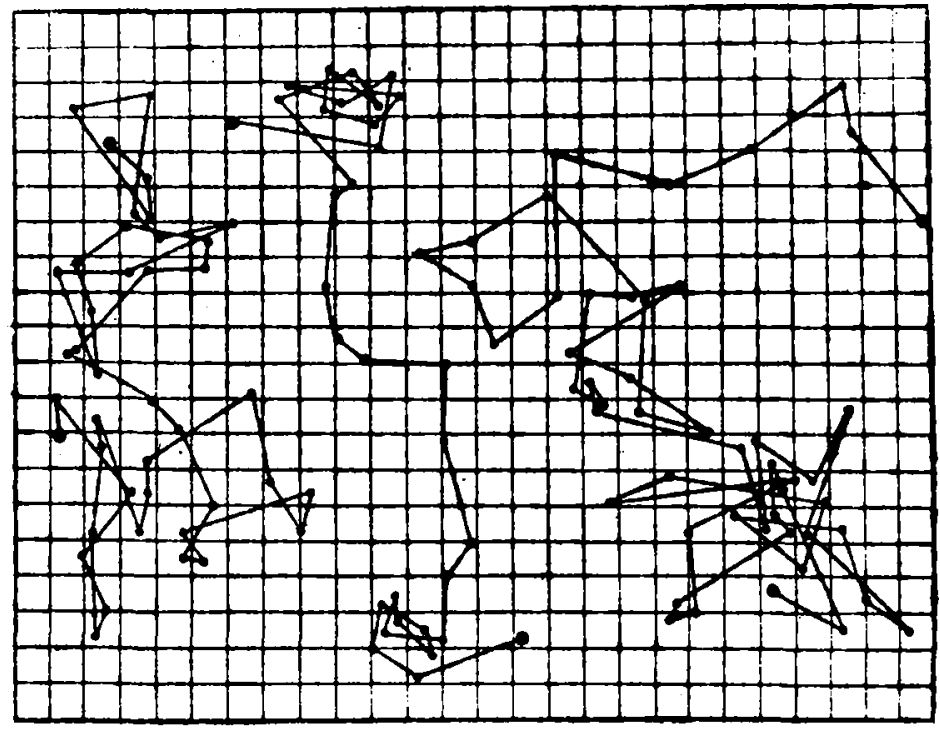

Fig. 6

Punkte von Sekunde zu Sekunde machen würde, dann kăme an die Stelle eines jeden dieser Segmente eine 30 seitige polygonale Kontur von der gleichen Mannigfaltigkeit, wie sie die Zeichnung hier wiedergibt usw. Wir haben da ein Bild der molekularen Bewegungen. Besser, die Bewegungen der Körner sind schon molekulare Bewegungen, sowie ultrarote Strahlen schon Licht sind.

\section{1, Das Gesetz von der Vertellung der Verschiebungen.}

Wir hab en bereits (Nr. 27) gesagt, daß sich bei gleicher Dichte der Körner und der Zwischenflüssigkeit die Verschiebungen in einer gegebenen Zeit um die mittlere Ortsveränderung nach dem Unreger- 
mäBigkeitsgesetz von Maxwell (Nr. 9) verteilen müssen. Fs ist gut, dieses so überaus wichtige Gesetz direkt nachzuweisen. Dies kann auf verschiedene Arten geschehen.

Erstens, die Wahrscheinlichkeit für die Komponente nach $\mathbf{O x}$ zwischen $\mathrm{x}$ und $\mathrm{x}+\mathrm{d} \mathrm{x}$ ist

$$
1_{\xi \sqrt{2} \pi}^{1} e^{\frac{\mathrm{H}^{2}}{2 \xi^{2}}} \mathrm{dx},
$$

wobei man das mittlere Quadrat stets mit $\xi^{2}$ bezeichnet. Dieses Resultat gilt für jede beliebige Horizontalachse auch dann, wenn die Körner nicht dieselbe Dichte haben, als die zwischen denselben sich befindende Flüssigkeit ( Nr. 27).

Aus 12 -Beobachtungen ergibt sich die Zahl derjenigen, welche Komponenten zwischen $\mathrm{H}_{1}$ und $\mathrm{H}_{2}$ geben, durch den Ausdruck

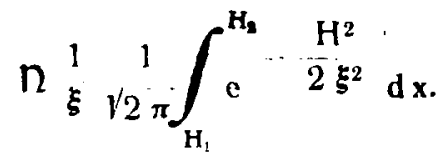

Chaudesaigues hat diese Rechnung, bezogen auf eine willkürliche Achse, für die in 30 Sekunden von Gummiguttiteilchen (Tabellen in Nr. 29) erlittenen Verschiebungen durchgeführt. Die Zahlen n der Verschiebungen, deren Projektion sich zwischen zwei gegebenen Grenzen, Multipla von $1,7 \mu$ (entsprechend den $5 \mathrm{~mm}$ der Quadrillierung), befindet, sind in der folgenden Tabelle angegeben:

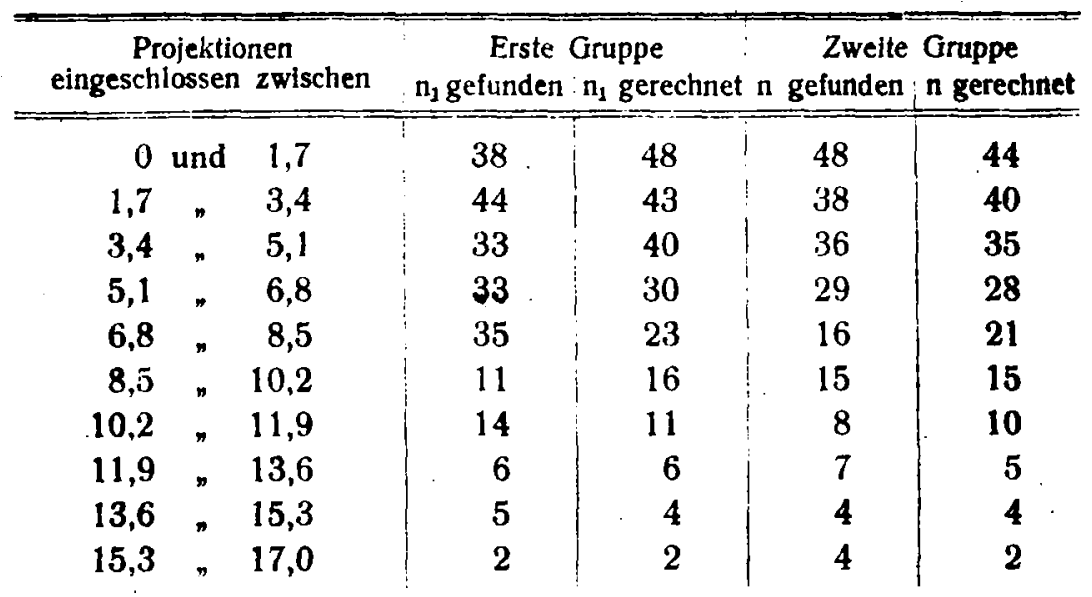

Ein anderer, vielleicht noch frappanterer Beweis, dessen Grundgedanken Ich $\mathrm{Langev}$ in verdanke, besteht darin, daB man die beobachteten horizontalen Verschiebungen parallel zu sich selbst verlegt, so 
daB sie einen gemeinsamen Ursprung erhalten. Die Enden der so erhaltenen Vektoren verteilen sich um diesen Ursprung wie die Treffer auf einer Żielscheibe um ihren Mittelpunkt. Man sieht dies ganz gut

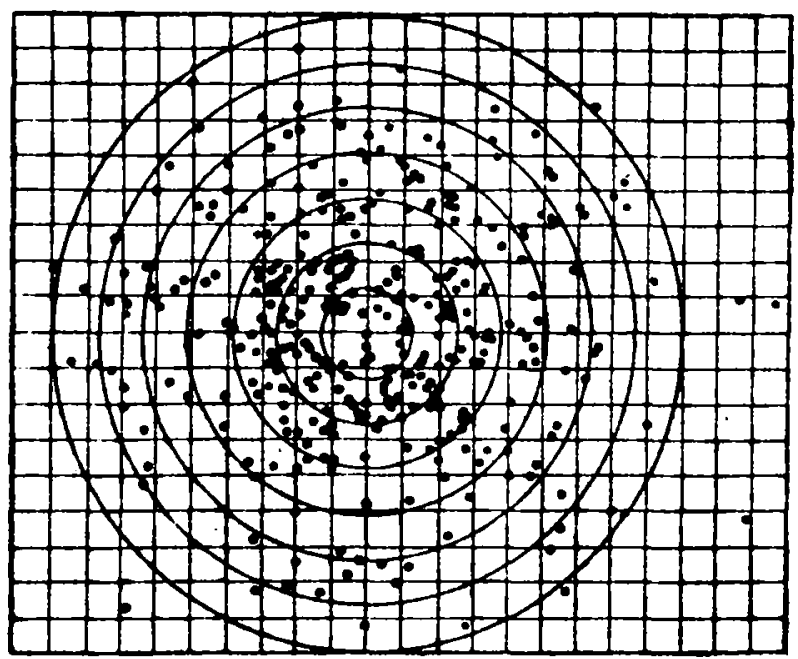

Fig. 7

auf der Fig. 7, wo ich 365 auf Mastix bezogene Beobachtungen, von denen ich im vorhergehenden Paragraphen gesprochen habe, zusammengetragen habe.

In diesem Falle kann man auch das Gesetz von der Verteilung quantitativ prüfen. Wenn man das für eine Komponente $x$ gegebene Gesetz der Wahrscheinlichkeit annimmt, dann ist es leicht einzusehen, daß für eine horizontale Ortsverănderung die Wahrscheinlichkeit einer Ausdehnung $z$ wischen $r$ und $r+d r$ durch den Ausdruck

$$
\frac{1}{2 \pi \xi^{2}} e^{-\frac{r^{2}}{2 \xi^{2}} 2 \pi r d r}
$$

gegeben ist, welcher nach dem Kürzen und Ersetzen von $2 \xi^{2}$ durch das mittlere Quadrat $\rho^{2}$ der horizontalen Verschiebung in

$$
\frac{2}{\rho^{2}} e^{-\frac{r^{2}}{\rho^{2}} r d r}
$$

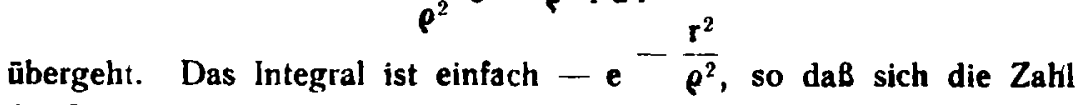
der Verschiebungen $z$ wischen $r_{1}$ und $r_{2}$ unmittelbar ergibt.

ln dem Falle der vorstehenden Figur ist $\rho$ gleich $7,16 \mu$ und ich finde als Zahlen der Verschiebungen zwischen zwei festen Grenzen: 


\begin{tabular}{|c|c|c|c|c|}
\hline \multicolumn{3}{|c|}{$\begin{array}{l}\text { Verschiebungen zwischen } \\
(\text { in } \mu)\end{array}$} & $n_{1}$ beobachtet & $\mathbf{n}_{1}$ gerechnet \\
\hline 0 & und & 2 & 24 & 27 \\
\hline 2 & n & 4 & 76 & 71 \\
\hline 4 & , & 6 & 90 & 84 \\
\hline 6 & $"$ & 8 & 67 & 76 \\
\hline 8 & n & 10 & 45 & 54 \\
\hline 10 & n & 12 & 34 & 30 \\
\hline 12 & & 14 & 20 & 14 \\
\hline 14 & & 16 & 4 & 5 \\
\hline 16 & & $\infty$ & 5 & 4 \\
\hline
\end{tabular}

Ich finde endlich eine dritte Beweisart in der Uebereinstimmung des für das mittlere Quadrat $\varphi^{2}$ der horizontalen Verschiebung wirklich gefundenen Wertes mit demjenigen, welchen man berechnen kann, wenn mán das Mittel e der horizontalen Verschiebungen kennt. Der VernunftschluB ist sehr ahnlich demjenigen, welcher nach dem Maxwellschen Gesetze das mittlere Quadrat $\mathrm{U}^{2}$ der Geschwindigkeit durch Multiplikation des Quadrates $\Omega^{2}$ der mittleren Geschwindigkeit mit $\frac{3 \pi}{8}$ zu rechnen erlaubt (Nr. 9). Wir haben soeben gesehen, dab von $n$ Verschiebungen

$$
n \frac{2}{\rho^{2}} e^{-\frac{r^{2}}{\rho^{2}} r d r}
$$

zwischen $r$ und $r+d r$ fallen. Die Summe ihrer Längen beträgt

$$
n-\frac{2}{\rho^{2}} e^{-\frac{r^{2}}{\rho^{2}} r^{2} d r}
$$

Die Summe aller Lăngen ist demnach

$$
n \int_{\rho^{2}}^{2} \int_{0}^{\infty} e^{-\frac{r^{2}}{\rho^{2}} r^{2} d r}
$$

das heiBt

$$
\mathrm{n} \frac{2}{\rho^{2}} \frac{\sqrt{\pi}}{4} \rho^{3}=n \rho \sqrt{\frac{\pi}{4}}
$$

und die Länge der mittleren Verschiebung $\&$, welche man durch Division dieser Summe durch die Gesamtzahl $\mathbf{n}$ der Verschiebungen erhălt, ist dann $\varepsilon=\rho \sqrt{\pi}$, das heibt, mit grober Annäherung $\rho=\frac{9}{8} \epsilon$. Dieses Resultat findet eine sehr gute Bestătigung. So haben die Verschiebungen, welche zur Anfertigung der vorstehenden Zeichnung 
(Fig. 7) geführt haben, ein Mittel gleich 6,4 $\mu$; der für $\rho$ durch diese Rechnung sich ergebende Wert ist also $7,21 \mu$, welcher mit dem wirklich gefundenen, $7,16 \mu$, gut übereinstimmt.

Kurz, das UnregelmäBigkeitsgesetz von Maxwell bewährt sich in seiner Anwendung auf dic Verschiebungen der Teilchen einer Emulsion zweifellos.

Das zeigt, dab die Wahrscheinlichkeit eines bestimmten Wertes $x$ der Projektion einer Verschiebung auf $O x$ unabhängig ist von den Werten der Komponenten $y$ und $z$ (Nr. 9). Die Unabhängigkeit der drei Komponenten von der Geschwindigkeit ist nun außer Zweifel gesetzt, oder, was auf dasselbe hinauskommt, das Maxwell'sche Gesetz von der Verteilung der Geschwindigkeiten ist als bestehend zu betrachten, obgleich eine direkte Prüfung hierfür, wie sie für die Verschiebungen soeben gebracht worden ist, noch aussteht.

\section{Besonderes Studium von sehr groben Kornern.}

Die vorangegangewen Ausführungen enthaiten keine Beschränkung in bezug auf die Gröbe der Körner und setzen, wie es scheint, einfach voraus, daB die flüssige Masse im Verhältnis zu den Körnern als sehr groß betrachtet werden kann, der Einfluß der Wände also zu vernachlässigen ist. Nach unseren bisherigen Annahmen führen Objekte von bereits grober Gestalt noch immer eine wahrnehmbare B row n'sche Bewegung aus, denn nach der Formel von Einstein würde eine Kugel von $1 \mathrm{~mm}$ Durchmesser in Wasser von $20^{\circ}$ eine Bewegung machen, welche in der Minute einer durchschnittlichen Verschiebung von $1 \mu$ entspricht.

Ohne gerade mit derart großen Körnern experimentieren zu können, habe ich doch das Gebiet beträchtlich erweitert, wo die vorhin behandelten Gesetze noch sicher gelten.

Zunächst war es notwendig, nach Belieben Körner herstellen zu können, die viel größer sind als diejenigen der bisher untersuchten Emulsionen. Dies gelang mir auf eine Art, die ich durch die nachstehenden Betrachtungen verständlich machen will:

Beim EingieBen von viel Wasser in eine alkoholische Harzlösung erhult man eine in allen Teilen an Harz stark übersăttigte wăsserige Lobsung. Wenn man sich an das erinnert, was man von früher her von der spontanen Trennung einer instabilen Phase in zwei Phasen weiB (Bildung von Tropfchen, Absetzen von Kristallen usw.), dann wird es gar nicht überraschend wirken, wenn die Keime, um die herum die unlosliche Phase wachsen soll, in grober Anzahl erscheinen. 
Jeder dieser Keime wird also, da er nur einen sehr kleinen Raum ausfüllen kann, ein sehr kleines Korn liefern, das im allgemeinen einen Durchmesser von weniger als $1 \mu$ besitzt. Wenn man jedoch an Stelle von reinem Wasser der alkoholischen Lösung ein viel Alkohol haltiges Wasser zusetzt, dessen Lösungsvermögen für Harz zwar schwach, aber doch nennenswert ist, dann kann der Fall eintreten, daB die Keime in viel geringerer Zahl auftreten und daher die Harzkügeichen, welche sich immer nur um solche Zentren bilden können, viel großer ausfallen als in dem vorhergehenden Fall.

Ich lieB nun unter eine ungefähr zehnprozentige alkoholische Gurnmigutti- oder Mastixlösung durch einen Trichter mit ausgezogener Spitze reines Wasser langsam einfließen. Zwischen beiden Flüssigkeiten entsteht eine kontinuierliche Mischungszone; sobald eine Schichte so viel Wasser enthält, dab eine beträchtliche Uebersättigung vorliegt, hilden sich daselbst Keime, welche auf Kosten des aus den höheren Schichten ankommenden Harzes wachsen, ohne dak jedoch jene Uebersättigung so groß werden kann, daß sie das Erscheinen einer sehr großen Anzahl von Keimen zur Folge haben könnte. Endlich werden die Korner infolge ihres Wachstums bald so schwer, daB sie trotz ihrer B rown'schen Bewegung, die. Schichten reinen Wassers durchsetzend (wobei sie sich waschen), zu Boden fallen und durch einfache Dekantation gewonnen werden können. Ich habe so das ganze Harz der alkoholischen Gummigutti- oder Mastixlösungen in Form von.Kugein gefallt, deren Durchmesser praktisch nie unter $2 \mu$, gewöhnlich nahe bei $10 \mu$, aber auch bis $50 \mu$ betrug. Diese groben Körner haben das Aussehen von gelben (heim Gummigutti) oder farblosen (beim Mastix) Glaskugeln, die leicht zerbrechlich sind und dabei unregelmaBige Bruchstücke liefern. Sie erscheinen oft vollkommen und geben wie Linsen ein erkennbares reelles Bild der das Präparat beleuchtenden Lichtquelle (z. B. des Auerstrumpfes), ein Bild, auf das man leicht das Mikroskop einstellen kann. Aber fast ebenso häufig enthalten die Kugeln Einschlüsse von ein wenig verschiedener Brechbarkeit. Ich konnte mich jedoch mit der Natur und dem Ursprung dieser Einschlüsse ${ }^{1}$ ), welche die Beobachtung der unregelmäßigen Rotations-

1) Diese Eínschlüsse können, da sie die Dichte des Kornes kaum vetändern (Bestimmung der Dichte in einer wässerigen Harnstofflösung nach der Schwebemethode von Retgers) eine von diesen nur wenig verschiedene Zusammenseizung haben. Ich meine, daB sie ats einer sehr zähen, noch ein wenig Alkohol einschliebenden Masse bestelien, ähnlich dem Gemisch, das sich langsain abscheidet, wenn man eine alkoholische, schon schwach gewässerte und an Harz gesuttigte 
bewegungen der Kugeln sehr erleichtern, nicht näher befassen. Endlich kommt es ausnahmsweise vor, dab ein Korn aus zwei längs eines ganzen kleinen Kreises zusammenhängenden Kugeln besteht, was augenscheinlich auf einer Zusammenklebung derselben während ihres Wachstums um ihre bezüglichen Keime beruht. Vom doppelten Standpunkte der Entstehung der Keime und ihrer Wachstumsgeschwindigkeit bieten diese verschiedenen Erscieinungen ein Interesse das außerhalb des hier verfolgten Zieles liegt.

Wir sind also, abgesehen von diesen neuen aufgerollten Problemen, jetzt in der Lage, große runde Körner herstellen zu kơnnen. Man kann sie nach ihrer Größe durch ein Trennungsverfahren, das dem sehr ähnlich ist, womit wir die kleinen Körner getrennt haben (Nr. 16), scheiden, indem man, ohne seine Zuflucht zur Zentrifuge nehmen zu brauchen, einfach die Tatsache benützt, daß die gröbten Körner am schnellsten fallen. Sehen wir nun zu, wie wir mit solchen Körnern, deren Durchmesser 10 bis $12 \mu$ betrăgt, die Fundamentalgesetze der B row n'schen Bewegung verfolgen können.

Man kann nicht leicht mehr daran-denken, ihre zunehmende Verdünnung als Funktion der Hőhe in Wasser zu studieren. Die einfache Anwendung der Verdünnungsformel (Nr. 24) zeigt, daB eine Erhohung um nur $1 \mu$ genügt, um die Konzentration der Körner auf ein 60000 stel ihres Betrages herabzudrücken (beim Gummigutti wăre diese Verdünnung eine noch raschere). Das heiBt mit anderen Worten, daB sämtliche Teilchen sich in der unmittelbaren Nähe des Bodens befinden. - Andererseits würden sich die Körner durch die ganze Dicke des Präparates hin verteilen, wenn man durch Auflösen eines passenden Stoffes der intergranularren Flüssigkeit eine Dichte erteilen würde, welche der der Körner beinahe gleich ist. Die quantitative Bestätigung des Gesetzes von der Verteilung ist praktisch zwar noch immer unmöglich, aber die Messung der mittleren Verschiebungen scheint wenigstens a priori mit keinen ernsten Schwierigkeiten verbunden zu sein, und wir wollen nun untersuchen, ob die Einste in'sche Fonnel sich noch anwenden läBt.

Losung mit sehr wenig Wasser verdünnt (am folgenden Tag findet man am Boden des GefäBes eine dünne, sehr zăhe, fast aus reinem Harz bestehende Schicht). Tropptchen dieser Art können, wenn sie durch die B row n'sche Bewegung in eine Sct.:-ht gelangen, wo sich das sogenannte glasarlige Harz abscheidet, bei dem rascheren GröBerwerden (dessen Ursache mir unbekannt ist) dieser reinen Harzkugeln leicht eingeschlossen werden. 
Ich habe also, um die Dichte der intergranulären Flüssigkeit gleich derjenigen der Teilchen zu machen, jener verschiedene Stoffe zugesetzt. Störend, aber für das Studium des Gerinnungsvorganges sehr instruktiv, wirkte hier das Agglutinieren der Körner aneinander. Man sieht, daß sich unter dem Einfluß der koagulierenden Substanz die betrachteten großen Körner in Haufen von zusammenhängenden Körnern, Weintrauben vergleichbar, oder wie regelmäßige Aufeinanderschichtungen von Kugeln anordnen.

Die Mengen der für gewöhnlich als schwach koagulierend betrachteten Salze und selbst des Zuckers, welche notwendig waren, um die Körner im Innern der Flüssigkeit schweben zu machen, haben alle meine großen Mastixkörner zum Gerinnen gebracht. Der Harnstoff allein hat eine genug schwache koagulierende Kraft gehabt, um die Verfolgung der Bewegungen der isolierten Körner zu gestatten.

Die intergranuläre Flüssigkeit von der passenden Dichte enthielt ungefähr 27 Proz. Harnstoff, und ihre Viskosität betrug 1,28 mal mehr als jene des reinen Wassers. Ein Teil der Körner schwamm dann im Innern umher und konnte gut beobachtet werden; ibre Zahl war stets sehr klein, da diese Körner so groß sind, daß schon ganz kleine Unterschiede in der Dichte genügen, um die Körner ganz nahe an die Oberfläche oder den Boden des Gefäßes zu bringen. Bestimmte Messungen sind in einer Küvette von $1 \mathrm{~mm}$ Höhe gemacht worden; die Höhe ist also für die großen Körner im. Verhältnis der oben genannten Höhen zu den kleinen Körnern größer gewesen. Wie der Versuch zeigt, sind jedoch die Bewegungen in diesem hohen GefäBe die gleichen, wie die in einem riur $100 \mu$ hohen, und man sieht leicht ein, daB in der Tat die Verteilung der Molekularbewegungen um das seine Bewegung ausführende Korn seine normale Art in einer Entfernung von den Wänden erreicht, welche mit der Größe der Körner nichts zu tun hat.

Ich habe in der Hellkammer zwei dieser beinahe gleichgroßen (Durchmesser gleich 11,5 ) Körner verfolgt und ungefähr 100 Verschiebungen gemessen. Sie geben für. $N$ nach der Einste in'schen Formel den Wert 78.1022. In anderen Ausdrücken, die mittlere horizontale Verschiebung in der Minute bei $25^{\circ}$ wurde zu $2,35 \mu$ gefunden, während die aus $N=70,5 \cdot 10^{22}$ gerechnete $2,5 \mu$ betragen würde.

Wenn man die sich entgegenstellenden Schwierigkeiten, sowie die kleine Anzahl von Punktierungen berücksichtigt, so ist die Uebereinstimmung eine unverhofft gute, und man kann nicht daran $z$ weifeln, daB die Theorie von Einstein ihre Gültigkeit bewahit hat. 
Nun ist das Fundament dieser Theorie das Theorem von der gleichen Verteilung der kinetischen Theorie. Es ist also durch die vorangegangenen Versuche festgestellt, dab ein Mastixkorn von 11,5 $\mu$ Durchmesser dieselbe mittlere kinetische Energie besitzt, als das kleinste in meinen anderen Versuchen studierte Korn, welches ungefahr $60000 \mathrm{mal}$ weniger wog. Es ist diese Tatsache bis jetzt die weitgehendste Bestätigung von der gleichen Verteilung der kinetischen Translationsenergie.

\section{Die Brown'schen Rotationsbewegungen und die Rotationsenergie.}

Endlich habe ich dank der Einschlüsse, weiche die spontane und unregelmäBige Rotation der groben runden Körner offenbaren, eine der wichtigsten Beziehungen der kinetischen Theorie feststellen können, und zwar die mittlere Gleichheit der Energien der Rotation und der Translation. Diese Beziehung erlaubt in der Tat, die von Einstein aufgestellte Formel für die Rotationen zu benützen:

$$
\alpha^{2}=\tau \frac{R T}{N} \frac{1}{4 \pi \zeta a^{3}}
$$

Wir wollen nun sehen, ob diese Gleichung sich bewăhrt. - Wenn man bedenkt, daß diese Formel, wenn sie richtig ist, für Körner von $1 \boldsymbol{\alpha}$ Durchmesser eine mittlere Rotation von $100^{\circ}$ pro Sekunde angibt, so wird man einsehen, daß man diese Rotationsbewegung kaum messend verfolgen kann. Für meine Korner von 10 bis $15 \mu$ Durchmesser betragt die voraussichtliche Rotation nur etliche Grade pro Minute und ist leicht meBbar. Ich habe in der Tat von Minute zu Minute die Lage von in einer Harnstofflosung suspendierten Mastixkugeln (die einen Durchmesser von beilaufig $13 \mu$ hatten) bestimmt; es genügte zu diesem Ende, die aufeinanderfolgenden Stellungen der kleinen Einschlüsse, deren Entfernung vom Mittelpunkt gemessen worden war, zu punktieren. Man hat nun die notwendigen Elemente, um die Komponente der Rotation um eine willkürliche Achse zu berechnen. Die ziffernmåBigen Rechnungen, deren Einzelheiten interesselos sind, geben für $\mathbf{N}$ durch Benützung von ungefähr 200 Winkelmessungen den Wert 65.1022, wăhrend der wahrscheinliche genaue Wert 70,5.1022 ist. Mit anderen Worten, wenn man von dem für $\mathbf{N}$ erhaltenen Wert ausgeht, erhält man in Graden für $\sqrt{\alpha^{2}}$ pro Minute den Wert $14^{\circ}$ und experimentell wurde $14,5^{\circ}$ gefunden.

Die Uebereinstimmung ist so gut, wie sie das nur Annähernde der Messungen und Rechnungen gestatten kann, sie ist um so über- 
raschender, als man a priori selbst die Grobenordnung der untersuchten Erscheinung nicht kannte. Die bei diesen - Messungen gebrauchten Körner sind ungefähr $100000 \mathrm{mal}$ schwerer als die kleinen zuerst studierten Gummiguttikorner.

So findet man die gleiche Energieverteilung in diesem sehr großen Intervall bestätigt. Es ist ihr Nachweis für die Rotationen eine experimentelle Befestigung der theoretisch kinetischen Ausdricke, welche das Verhältnis $\frac{C}{c}$ der spezifischen Wärmen eines vollkommenen Gases vorauszuberechnen erlaubt haben.

\section{Zusammenfassung.}

Immer mehr und mehr scheint es, daß für alle wesentlichen Punkte die kinetische Molekularhypothese eine feste experimentelle Basis in dem Studium der Brown'schen Bewegung gewinnt. An zweiter Stelle führt das quantitative Studium des Gesetzes von der Verteilung der Kơrner einer Emulsion einerseits und der Tätigkeit der Brown'schen Bewegung andererseits auf zwei verschiedenen Wegen zu dem gleichen genauen Werte der Konstante von Avogadro, der wesentlichen Unveränderlichen der kinetischen Theorie.

. Es ist interessant, diesen Wert mit den von anderen Gesichtspunkten aus erhaltenen zu vergleichen. Obgleich die meisten derselben noch nicht mit der gleichen Genauigkeit bestimmt sind, hat ihre Uebereinstimmung infolge der auBerordentlich verschiedenen Mittel, welche dazu führen, eine hervorragende Bedeutung.

Ohne diese Mittel in ihren Einzelheiten erklären zu können, will ich sie wenigstens aufzählen, um einen Ueberblick über die Fragen zu erleichtern, wo sich die Wirklichkeit der Moleküle am zwingendsten aufdrängt.

\section{TEIL.}

35. Durch die Diffusion gegebene Mittel:-

Da dieser Gesichtspunkt unmittelbar mit der Theorie von A.Ein s te in zusammenhängt, will ich zunächst einige Worte über dịe ziemlich urbestimmten Folgerungen sagen, welche man aus der Messung der Diffusionskoeffizienten ziehen kann.

Nach einer der Einstein'schen Formeln ist der Diffusions-

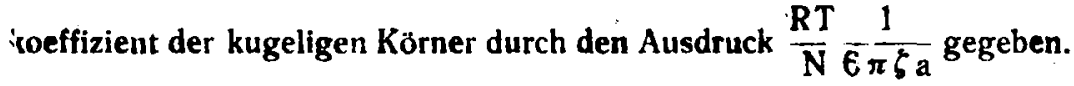


Man kann hoffen, dab diese Formel auch noch in dem Falle von etwas großen Molekülen, wie die des Zuckers oder des Phenols, oberflächlich gültig ist, und sehen, ob die so angenommene Formel zu annehmbaren Werten für $\mathrm{N}$ führt. E in ste in versuchte dies natülich, sobald er in den Besitz dieser Gleichung gelangt war ${ }^{1}$ ).

Pür den Fall des Zuckers würde inan also bei $18^{\circ}$ annathernd $\frac{0,33}{86400}=\frac{83,2 \cdot 10^{6} \cdot 291}{6 \pi \cdot 0,0105} \frac{1}{\mathrm{Na}}$ bekommen, oder $\mathrm{Na}=3 \cdot 10^{-16}$.

Es bleibt uns noch der Halbmesser (?) des Zuckermoleküls zu bestimmen übrig. Das einfachste ist, ihn als durch das spezifische Volumen des festen Zuckers gegeben zu betrachten (Langevin), oder nach einer etwas weniger genauen Art $z u$ beobachten, daB in diesem festen Stoff die Moleküle nicht năher aneinander liegen kőnnen als es bei Kugeln, die einen Haufen bilden, der Fall ist (Nr. 11) und wahrscheinlich weniger voneinander entfernt sind als in einer gewöhnlichen Flüssigkeit (wo, nach van der Waals, das scheinbare Volumen das Vierfache des wahren Volumens der Molekïle ausmacht).

Es resultiert daraus für $\mathrm{N}$ ein Wert, welcher zwischen $85.10^{22}$ und $150.10^{22}$ gelegen ist.

Dieselben Rechnungen für das Phenol durchgeführt, dessen Strukturformel auf eine dichtere Ansammlung der Moleküle deutet, liefern für $\mathrm{N}$ einen besseren Wert, und zwar zwischen $60.10^{22}$ und $100.10^{22}$.

In Wirklichkeit erhielt Einste in die Radien nach einer komplizierteren nnd unsichereren Methode, aus der Differenz der Viskosităten des reinen Wassers und der Lösung (Ann. d. Phys. . 9 .,., Er fand so für den Zucker $\mathrm{N}$ gleich $40.10^{22}$.

Alle diese Werte stimmen untereinander grob überein, man kann aber auch keine bessere Uebereinstimmung hoffen, da in den verwendeten Ausdrücken die Zuckermoleküle als Kugeln gedacht werden (die viel wahrscheinlicher die Gestalt von langen Zylindern haben). Für das zyklische Molekül des Phenols ist das Resultat schon viel besser und beinahe ebenso angenähert als das durch die Anwendung der Theorie von van der Waals (Nr. 11) erhaltene.

Nun setzt die Theorie von Einstein die Gültigkeit des Gesetzes ron Stokes voraus. Es ist also wahrscheinlich, daB dieses Gesetz, dessen genaue Einhaltung ich bis zur GröBenordnung der Zehntel der $\mu$ (Nr. 21) direkt nachgewicsen habe, auch noch für die großen Mole-

l) Ann. d. Phys. 19, 289 (1906). 
küle, deren Durchmesser unter einem Tausendstel eines $\mu$ liegen, vollkommene Gültigkeit hat. Dieses ist offenbar das interessanteste Ergebnis, das wir dieser Betrachtung der Diffusionskoeffizienten zu verdanken haben. Es gestattet uns, für den Fall der in einem Crase sich bewegenden Ionen das Gesetz von Stokes mindestens als annähernd zu betrachten.

\section{Aus der Beweglichkeit der Ionen resultierende Mittel.}

Eine noch kühnere Erweiterung des $S$ to $\mathrm{k}$ es'schen Gesetzes bildet die Grundlage einer sinnreichen von Herrn Pellat1) entwickelten Idee. Es sei $\nu$ die mittlere elektrische Ueberführungsgeschwindigkeit eines einwertigen Ions (vom Radius a und der Ladung e), in einem elektrischen Felde II. Vorausgesetzt, dab sich das Stokes'sche Gesetz anwenden läßt, erhält man dann $6 \pi \xi \mathrm{a} v=\mathrm{He}$, welche Gleichung wenigstens eine teilweise Bestätigung in der bekannten Tatsache findet, dah die Geschwindigkeit $\nu$ dem elektrischen Felde proportioniert ist. Multiplizieren wir beide Glieder dièser Gleichung mit $\mathrm{N}$, der Konstanten ron Avogadro, dann erhalten wir, wenn wir uns erinnern. daB $\mathrm{Ne}$ in elektrostatischen Einheiten $29.10^{13}$ gilt, $6 \pi 5_{\mathrm{H}}^{\nu}$ a N $=29.10^{13}$.

Wenn wir andererseits annehmen, daB man das Volumen des geladenen lons annähernd bestimmen kann, wenn man vom Volumen O des Grammatoms im festen Zustande ausgeht, so erhalten wir nahezu das, was wir im . vorhergehenden Abschnitt angekündigt haben, $0,250<\frac{4}{3} \pi a^{3} \mathrm{~N}<0,730$, zwei Beziehungen, welche eine Größenordnung für a und $\mathrm{N}$ geben werden.

Betrachten wir nun, nicht wie es Herr Pellat getan hat, das Quecksilber (denn die unbekannte Beweglichkeit des Quecksilberions kann mur hypothetisch festgestellt werden), sondern einwertige lonen, welche die beststudierten sind.

Für das Silber, das ein kleines Atomvolumen besitzt, findet man $63.10^{22}<\mathrm{N}<108.10^{22}$, so daB ein mittlerer Wert $85.10^{22}$ beiläufig ebenso angenähert ist als die von van der Waals erhaltenen.

Abcr die Alkalimetalle, besonders das Cäsium, welche, ohne im ionisierten Zustand eine vom Silber sehr verschiedene Beweglichkeit zu besitzen, ein viel höheres Atomvolumen (das übrigens genau bekannt ist ) haben, geben für $\mathbf{N}$ weniger gute Werte. So gibt das Kalium

1) Traité đ'Electricité $3,56$. 
den Wert $30.10^{22}$ und das Cäsium den fast dreimal zu kleinen $25.10^{22}$. Vor einigen Jahren noch hätte man einen solchen Unterschied nicht allzu groß genannt, aber jetzt haben wir das Recht, zu sagen, daB dieses Resultat entweder zeigt, daß die Gültigkeit des S tokes'schen Gesetzes bei diesen außerordentlich kleinen Atomen schwankend zu werden beginnt (ohne daB der Unterschied schon zu groß werdell würde), oder aber, dat das Kaliumatom im Wasser in lonenform einen zweieinhalbmal kleineren Halbmesser hat als im elementaren Zustand des Metalles.

Es ist noch eine weitere Beziehung, welche man ohne Zuhilfenahme des Stokes'schen Gesetzes erhält, nötig, um diese Frage zu erläutern.

\section{Aus der blauen Farbe des Himmels gezogene Folgerungen.}

Eine sehr merkwürdige und ganz verschiedene, Lord Rayleigh zu verdankende Methode bedient sich der Diffraktion des Sonnenlichtes durch die Moleküle der Atmosphäre.

Dringt ein Bündel weißen Lichtes durch ein feine Staubteilchen enthaltendes Mittel, so "ist infolge des durch diese Staubteilchen zerstreuten oder gebeugten Lichtes die Bahn der Strahlen seitlich sichtbar. Das Phänomen dauert noch an, wenn die Staubteilchen kleiner und kleiner werden (worauf die Ultramikroskopie beruht), aber das gebeugte Licht verändert sich in Blau, und das kurzwellige Licht erleidet nun eine noch stärkere Beugung. AuBerdem ist das so zerstreute Licht zur Ebene, welche durch den einfallenden Lichtstrahl und das Auge des Beobachters geht, polarisiert.

Die lichtbeugenden Teilchen haben a priori keine untere Grenze. Lord Rayleigh nimmt an, dab selbst die Moleküle gleich den im Mikroskop noch wahrnchmbaren Staubteilchen wirken und dadurch die blaue Himmelsfarbe verursachen. In Uebereinstimmung mit dieser Hypothese erweist sich das blaue Himmelslicht, wenn man es normal zur Strahlenrichtung untersucht, als stark polarisiert. Es ist im übrigen schwer anzunehmen, dak es sich hier um eine Diffraktion durch sogenannte Staubteilchen handelt, denn das Blau des Himmels wird nur wenig geschwåcht, wenn man sich 2000 bis 3000 Meter in die reinste Atmosphäre erhebt, hoch über die Mehrzahl der Staubteilchen, welche die Luft in unmittelbarer Năhe des Bodens erfüllen.

Sich mit dieser qualitativen Erklärung nicht begnügend, hat Lord Rayleigh die elastische Theorie des Lichtes entwickelt und das Verhältnis ausgerechnet, welches in seiner Hypothese zwischen der Intensität 
der direkten Sonnenstrahlung und derjenigen des blauen Lichtes bestehen muB. Nehmen wir an, dab man den Himmel in einer Richtung betrachtet, welche mit der Vertikalen einẹn Winkel $\varphi$ und mit den Sonnenstrahlen einen Winkel $\beta$ bildet; die Lichtstărken e und $\mathrm{E}$, welche man im Brennpunkt eines abwechselnd auf diese Himmelsrichtung und auf die Sonne eingestellten Objektivs erhalt, sind dann in einem Verhältnis $\frac{\mathrm{e}}{\mathrm{E}}=\left(9 \pi^{3} \omega^{2} \frac{1+\cos ^{2} \beta}{2 \cos \varphi}\right) \frac{p}{M} g \frac{R}{\lambda^{4}} \mathrm{~N}^{\prime}$ wobei w den halben scheinbaren Durchmesser der Sonne, $p$ den Luftdruck am Orte der Beobachtung, $g$ die Akzelaration der Schwere, $M$ die Masse des Ciramm-Moleküls Luft, $\mathscr{R}$ das molekulare Brečhungsvermögen der Luft (gleich dem Ausdruck $\frac{M n^{2}-1}{d} \frac{n^{2}+2}{n^{2}}$ und $N$. die Konstante von Avogadro bedeuten und letztere somit durch diese Gleichung unter Voraussetzung ihrer Exaktheit bestimmt erscheint. Die Wahrscheinlichkeit der Richtigkeit der vorstehenden Gleichung wird übrigens durch die Tatsache vermehrt, daB $L$ a n g e vi n, von einer elektromagnetischen Theorie ausgehend, genau dieselbe Gleichung findet (an Stelle von $\mathrm{n}^{2}$ hat er die Dielektrizitätskonstante). Man sieht, daß das äußerste sichtbare Violett des Spektrums eine ungefăhr $16 \mathrm{mal}$ stärkere Diffraktion erleidet als das äuberste Rot, was die beobachtete Farbe gut erklărt.

Der Genauigkeit halber soll eine Prüfung dieser Theorie in einer Höhe durchgeführt werden, wo die durch die Staubteilchen (Rauch, Tropfchen, große Ionen usw.) verursachten Störungen nicht mehr in Betracht konımen. Ueberdies sollen die Messungen spektrophotometrische sein. Diese letztere Bedingung ist in den bis jetzt einzigen brauchbaren Werten, deren Bestimmung wir Herrn Sella verdanken, leider nicht verwirklicht. Sella hat vom Gipfel des Monte Rosa aus die Helligkeit der Sonne für eine Höhe von $40^{\circ}$ über dem Horizont und die Helligkeit des Himmels im Zenith gleichzeitig bestimmt. Aus diesem Verhältnis erhält man durch Berührung der obigen Gleichung für $\mathrm{N}$ einen Wert, der zwischen $30.12^{22}$ und $150.10^{22}$ liegt.

So findet im Hinblick auf die Größenordnung die so interessante Theorie von Lord Rayleigh ihre Bestätigung, und es ist zu erwarten, dab man in diesem Sinne durch vollkommenere Versuche eine genaue Bestimmung von $\mathbf{N}$ wird durchführen konnen.

\section{Direkte Messung der Ladung eines lons in einem Gase.}

Anstatt sich auf die Bestimmung der Konstante von Avogadro der der Malekularenergie zu verlegen, kann man sich bemüben, das 
Elektrizitätsatom, welches mit jenen Größen, wie wir gesehen haben, in einfacher Weise zusammenhängt, direkt zu ermitteln. Dies ist den Physikem der $\mathrm{Cambridger} \mathrm{Schule} \mathrm{gelungen,} \mathrm{indem} \mathrm{sie} \mathrm{die} \mathrm{Ladung}$ der Ionen in einem Gase bestimmten.

Man kann nicht im vorhinein wissen, ob zum Beispiel die Ladung $e^{*}$ eines durch das Passieren von X-Strahlen in einem Gase hervorgerufenen lons mit der Ladung e, weiche ein einwertiges elektriscines Ion überträgt, in einem einfachen Verhältnis steht. Selbstverständlich wirrden genaue Messungen von $e$ und $e^{\prime}$ diese Frage entscheiden; aber diese Bestimmungen sind überflüssig geworden, da Townsend i i Jahre 1900 in seiner experimentell sowie theoretisch genialen Arbeit ') gezeigt hat, daB beide Arten von lonen die gleiche Ladung besitzen, deren gemeinsamen Wert $e$ anderweitig zu bestimmen übrig bleibt.

Betrachten wir die gleichsinnigen, angenommenen identischen lonen, welche in einem Gase nach dessen Bestrahlung durch X-Strahlen anwesend sind; sie werden ganz unabhängig von ihrer Größe dieselbe mittlere kinetische Energie besitzen als die Moleküle des Gases und werden sich infolge der molekularen Bewegung in diesem Gase verbreiten.

D sei ihr Diffusionskoeffizient, u die gleichformige Geschwindigkeit, welche die unter der Einwirkung eines elektrischen Peldes $H$ mit der Ladung $e^{\prime}$ behafteten Ionen in demselben Gase annehmen. Wenn nun $\mathbf{N}$ wieder die Konstante von Avogadro bezeichnet, dann kann man die Gleichung $\mathrm{Ne}^{\prime}=\frac{\mathrm{RT}}{\mathrm{D}} \underset{\mathrm{H}}{\mathrm{H}}$ aufstellen.

Ohne auf die Untersuchungen von Town send năher einzugehen, will ich nur bemerken, dab man die obige Gleichung sehr leicht erhalten kann, wenn man die von A. Einste in für die Diffusionskoeffizienten aufgestellte Formel auf die betrachteten lonen anwender, das heiBt $D=\frac{R T}{N} \frac{1}{6 \pi} \bar{\zeta}$; wenn man ferner das Gesetz vou Stokes auf die Bewegung in elektrischen Felde bezieht, kann man schreiben $\mathrm{He}^{\prime}=6 \pi \mathrm{a} \zeta \boldsymbol{y}$. Durch Multiplikation der auf derselben Seite der beiden Gleichungen befindlichen Glieder ergibt sich genau der Townsend'sche Ausdruck.

Man mulb also, um das Produkt $\mathrm{Ne}^{\prime}$ zu erfahren, noch das Verhältnis $\frac{u}{H}$ (oder die Beweglichkeit des lons) und den Diffusions-

1) Phil. Trans. of the Royal Soc. 1900, 129; tra luit dans lons, Elektroms Corpuscules 2, 920 (Gauthier-Villars, éditeur). 
koeffizienten D kennen lernen. Tow risend selbst hat diesen Koeffizienten in verschiedenen Gasen gemessen (Luft, Sauerstoff, Wasserstoff, Kohlensäuregas); die älteren für die genannten Gase vorgenommenen Bestimmungen der lonenbeweglichkeit benutzend, hat er sodann für $\mathrm{Ne}^{*}$ Werte gefunden, deren mittlerer mit den durch die Elektrolyse für das Produkt Ne gefundenen, 29.10 ${ }^{13}$, bis auf 1 Proz. genau übereinstimmt. Dieses Resultat ist in ganz besonderer Weise geeignet, die Begriffe, welche uns die Elektrolyse betreffs der Existenz eines Elektrizitătsatoms geben kann, außerordentlich zu erweitern.

Aber, weun auch Townscnd der erste genaue Nachweis der Unveränderlichkeit der Atomladung zu verdanken ist, so war es doch J. J. Thomson, welcher als erster durch die Messung der Ladung ' ${ }^{\prime}$ gezeigt hat, daB die beiden Ladungen von der gieichen Größenordnung sind). Er benutzt hierzu die von $C . T, R$. Wils on beobachtete Tatsache, dab sich die Wassertropfchen in einenı staubfreien, feuchten und durch Abkühlung (bedingt durch eine Ausdehnung) stark übersăttigten Gase um die in dem Gase anwesenden Ionen herum bilden. Die Methode kann zusammengefaBt werden, wie foigt:

Man miBt durch irgendeines der gebräuchlichen Mittel die Ladung $\mathrm{E}$, welche sich in Form von Ionen in einem Kubikzentimeter Gases vorfindet, weiches nuf einem konstanten Grad der lonisierung erhalten wird; das gibt das Produkt $\mathrm{n}^{\mathbf{t}}$, das ist die Anzahl der in diesem Volumen anwesenden Ionen mit der gesuchten Ladung $e^{\prime}$. Wenn man nun das Volumen um einen bedeutenden bekannten Betrag vergröbert, kann man die Kondensation einer Wassermenge hestimmen. welche man durch Anwendung der bekannten Gesetze von den adiabatischen Zustandsănderungen. rechnen kann. Sei m diese Wassermasse pro Kubrkzentimeter des ursprünglichen Gases. Wenn jedes lon als Keim gedient hat, dann ist diese Masse in $\mathbf{n}$ Tröpfchen geteilt, und man hat, wenn a der Halbmesser jedes Tropfens ist, $n=n \frac{4}{3} \pi a^{3}$.

Nun kann man den Radius a aber auch du. I $A$ wendung des S t okes'schen Gesetzes erhalten, indem man die $\mathrm{F}$ !lg schwindigkeit der unter der Wirkung der Schwere sinkenden Wolke mißt. Man kann also $n$ und, weil das Produkt $n \mathrm{e}^{\prime}$ schon bekannt ist, auch $\mathrm{c}^{\prime}$ rechnen.

J. J. Thomson hat in dieser Weise für $e^{d}$ in dem Falle der durch die X-Strahlen bewirkten Ionen Werte gefunden, welche zwischen $6,5 \cdot 10^{-10}$ und $3,4 \cdot 10^{-10}$ gelegen sind, wobei ihm der letztgenannte

ग) Phil. Mag. 46, 528 (1898); traduit dans lons, Étectrons, Corpuscules 2, 802. 
Wert als der wahrscheinlichere schien (1903). In dem Fall der negativen lonen, welche durch das ultraviolette Licht auf einer Zinkoberflăche entstehen, hatte er den fast doppelt so groBen Wert $6,8 \cdot 10^{-10}$ gefunden. Es folgt daraus, daB die Konstante von Avogadro zwischen $42.10^{22}$ und $85.10^{22}$ gelegen sein muk, wobei die Unsicherheit des mittleren Wertes wenigstens 30 Proz. betrăgt. Das ist der Genauigkeitsgrad der Bestimmung nach van der Wa als.

Wie interessant und belehrend diese Methode auch sein mag, so tragt sie doch Ursachen von Irrtümern in sich; so wird angenommen. dab jedes lon als Keim dient, dab jeder Keim nur ein Ion enthält und $\mathrm{daB}$ die ganze berechnete Wassermenge in Wirklichkeit kondensiert worden ist. Diese Unsicherheiten sind durch eine H. A. Wils on'l zu verdankende Vervollkommnung beseitigt worden, welcher das Verhăltnis der Geschwindigkeiten mißt, mit denen die Tropfen unter dem alleinigen Einflusse der Schwere und dem Einflusse der Schwere und einem vertikalen elektrischen Feld $H z u$ Boden sinken. Man hat

$$
\begin{aligned}
& V_{1}=\frac{4}{3} \pi a^{3} g \\
& \hat{V}_{:}=\frac{4}{3 a^{3} g+H e}
\end{aligned},
$$

wobei a stets durch das Stoke s'sche Gesetz gegeben ist:

$$
{ }_{3}^{4} \pi a^{3} g=6 \pi 5 a V_{1} \text {. }
$$

H. A. Wilson hat auf diese Weisc gefunden, daB sich die geladene Wolke unter dem EinfluB des elektrischen Peldes in zwei oder drei Wolken von verschiedenen Geschwindigkeiten teilt, entsprechend den Ladungen, die sich zwischen ihnen befinden. Ein Tropfen kann metirere lonen eingeschlossen enthalten, besonders wenn in dem Gase mehrwertige lonen vorkommen. Der mit der schwächstgeladenen Wolke für e gefundene Wert schwankt übrigens unter. den. scheinbar sich gleichbleibenden Bedingungen der einzelnen Versuche nicht unbedeutend, und zwar zwischen $2,7 \cdot 10^{-10}$ und 4,4.10-10. Die Gesamtheit der Versuche lieferte für e den Wert $3,2.10^{-30}$ und folglich für $\mathrm{N}$ den Betrag $90.10^{-22}$.

Trotz der von H. A. Wils on durchgeführten Vervollkommnung würde doch noch eine vielleicht ( $R$ u the rford) auf der Verdunstung der Wassertropfen während ihres Fallens beruhende ziemlich grobe Ungenauigkeit bestehon.

Indessen scheinen in neuester Zeit von Millikan und Bege$m$ an $n^{2}$ ) ausgeführțe Untersuchungen von gröBerer Genauigkeit zu

1) Phil. Mag. 1903; traduit dans Ions, Électrons, Corpuscules 2, 1107.

9) Phys. Rev., Pebruar 1908, 197: 
sein. Sie geben für e den Wert 4,05.10-10 und daher für $N 72 \cdot 10^{22}$ an, wobei sich die Unsicherheit vielleicht nur in den Hundertsteln bewegt.

\section{Ladung der in den Gasen anwesenden ,ggroben lonen".}

Den vorstehenden Rechnungen kann man die Versuche anreihen, welchè man gemacht hiat, um die Ladung zu bestimmen, welche nach einem von Langevin erlăuterten Mechanismus ein in einem ionisierten Gase befindhiches ultramikroskopisches Teilchen annimmt.

Es ist leicht einzusehen, daß jedes Ion, das durch die Molekularbewegung in die Nähe eines solchen Staubteilchens gelangt, elektrische Anziehung erleidet und sich an das betreffende Teilchen anlagert; dieses bleibt elektrisch neutral, wenn es gleichviel positive und negative lonen an sich nimmt, erscheint aber geladen, wenn es von dem einen oder dem andern einen Ueberschub aufgenommen hat. Diese Gesamtladung wird demnach eine ganze Anzahl Elektronen repräsentieren, jedoch selten viel inehr als eines, da die bereits angenommene Ladung die gleichsinnig geladenen lonen zurückstöBt.

Ehrenhaft und de Broglie haben durch sehr hübsche Experimente diese Annahmen bestätigt, indem sie nicht nur die Ortsveränderung der Teilchenansammlung als solche verfolgten, sondem auch die Verschiebungen der Teilchen für sich maken ${ }^{1}$ ). In ihren Versuchen wird die mit Staubteilchen (Tabakrauch zum Beispiel) beladene Luft in ein durchsichtiges Behältnis eingeblasen, welches auf konstatiter Temperatur erhalten wird, und wo die Strahlen einer krăftigen Lichtquelle konvergieren. Im rechten Winkel von diesen Strahlen befindet, sich das Mikroskopr. welches die Rauchteilchen in der Gestalt von stark glänzenden, von einer lebhaften Brown'schen Bewegung ergriffenen Pünktchen wahrnehmen läßt. Wenn man dann im rechten Winkel zur Richtung der Schwerkraft und des Mikroskops ein elektrisches Kraftfeld wirken laBt, dann hemerkt man sogleich drei verschiedene Gruppen von Körnern: Die einen wandern im Sinne des Feldes, dadurch ihre positive Ladung bekundend; die anderen gehen im entgegengesetzten Sinne und sind negativ geladen; die Körner der dritten Gruppe endlich bewegen sich in kurzen Strecken hin und her und sind daher neutral.

1) Ehrenhaft, Akad. der Wiss. in Wien, März 1909, und Physik. Zeitschr. 1909, 308; de Broglie, Compt. rend., Mai 1909, und Radium 1909, 203. 
Genaue Messungen sind leider nicht möglich, da die Teilchen an Größe (und zweifellos auch an Gestalt) sehr verschieden sind. Wenn man sich durch ihren Gianz leiten lätst, so wird man durch Anwendung des Stokes'schen Gesetzes von der Fallgeschwindigkeit im vertikalen Sinne dennoch einen Durchmesser ableiten können, der von einem gewissen mittleren Wert nicht gar zu sehr abweicht"). Man hat nur die mittlere Verschiebungsgeschwindigkeit in der Richtung des elektrischen Feldes zu messen, um durch eine zweite Anwendung des Stokes'schen Gesetzes, nach der Gleichung $6 \pi 5$ a $\nu=\mathrm{He}$ die elektrische Ladung zu erfahren.

Man findet auf diese Art, daß der genaue Wert von e von 4,6 $10^{-10}$ (Ehrenhaft) oder 4,5 $10^{-10}$ (nach de Broglie) nicht sehr verschieden ist. Für $\mathrm{N}$ ergibt sich daraus der Wert 64.1022.

Trotz der hervorgehobenen Unsicherheit halte ich diese Methode für sicherer und leichter durchführbar als die auf der Kondensation von Wassertröpfchen beruhende.

\section{Aus den radioaktiven Phănomenen gefundene Werte.}

Endlich gestattet eine bewunderungswürdige, den Begriff des elektrischen. Atoms noch erweiternde Arbeit Rutherford's ${ }^{2}$, ausgehend von auf die radioaktiven Körper bezüglichen Beobachtungen, die Größe jener Atome auf mehrere Arten zu ermitteln.

Man weiB, daB die von diesen Körpern ausgehenden $\alpha$-Strahlen positive Elektrizität mit sich führen; auferdem rufen sie beim Auffallen auf Schwefelzink Szintillationen hervor, die alsbald wieder verschwinden. Diese zwei Phänomene haben Rutherford zwei voneinander ganz. verschiedene Mittel in die Hand gegeben, un die Anzahl p der von 1 Gramm Radium pro Sekunde ausgestrahlten positiven Körperchen zu erhalten, welche für sich imstande sind, ihre Exislenz entweder durch einen Impuls in einem Elektrometer oder durch eine Szintillation zu bekunden. Diese beiden Mittel stimmen auf 1 oder 2 Proz. überein und liefern für die gesuchte Anzahl $p=3,4 \cdot 10^{10}$.

1) Herr de Broglie hat sich gleichzeitig durch photographische Messungen der Verschiebungen überzeugt, daB die Einstein'sche Formel wenigstens annăhernd noch anwendbar bleibt. Diese Bestătigung ist interessant, obgleich sie nicht von der Schürfe ist als die früher beim Gummigutti gezeigte; die Ursache hier /on liegt il' der auBerordentli h groBe , Differenz der Bedingungen, namentlich was die Viskosität betrifft, we'che in der Luft fast fünfzignal schwacher ist als Im Wasser.

2) Ru therford und Geiger, Royal Soc., juin 1908; Le Radium 6, 257 (1908). 
Wenn man andercrseits die gesamte positive elektrische Ladung, welche von einem gegebenen Quantum Radium in der Sekunde ausgestrahlt wird, messen kann, so wird eine einfache Division die Ladung $\mathbf{e}_{0}$ des Korperchens (projectile) \& geben. Diese Messung ist in der Tat schwer durchführbar, und $R$ utherford hat für $e_{0}$ je nach den Bedingungen Werte gefunden, welche zwischen $8,3 \cdot 10^{-10}$ und $10 \cdot 10^{-10}$ liegen, das ist ungefăhr das Doppelte des Elektrizitätsatoms. Das Projektil a wïrde demnach ein zweiwertiges Ion sein ( $R$ utherford hat in genauerer Weise gezeigt, dab dies ein zweiwertiges Atom Helium ist).

Die elementare Ladung e würde deminach die Halfte von $e_{11}$ sein, das heiBt, wenn inan das Mittel der gefundenen Werte nimmt $4,65 \cdot 10^{-10}$, was für $\mathrm{N}$ den Wert $62 \cdot 10^{22}$ ergeben würde.

Dieser Wert ist etwas kleiner als der von mir durch das Studium der Brown'schen Bewegung erhaltene.

Aber Ru t h e rf ord selbst führt noch andere auf der Radioaktivität beruhende Tatsachen an, welche ebenfalls die Bestimmung von $N$ aus der Anzahl $p$ der von den a-Strahlen von $1 \mathrm{~g}$ Radium weggeschleuderten Körperchen $a$ gestatten und zu praktisch denselben Werten führen, ais es die meinigen sind.

Eine der genannten Fakten bezieht sich auf eine Arbeit von Boltwood, aus welcher hervorgeht, dab die Umwandlungsperiode des Radiums sehr leicht gemessen werden kann und daB die Umwandlung in 2000 Jahren zur Hälte vor sich gegangen ist. Wenn $\mathbf{N}$ wieder die Konstante von Avog ad ro und 226,5 das Gramm-Atom Radium bezeichnen, so beträgt die Anzahl der Radium-Atome. welche pro Gramm Radium in der Sekunde zerfallen, 3,4.10'0, gleich der Anzahl der während der gleichen Zeit fortgeschleuderten Körperchen $*$. also auch gleich $\frac{1,09 \cdot 10^{-10}}{226,5}$, woraus für $\mathrm{N}$ der Wert $70,6 \cdot 10^{22}$ folgt, welcher genau der gleiche ist, auf welchen ich gekommen bin.

Andererseits, wenn man für $p$ stets die Zahl 3,4.10 10 annimmt, wird man mit Rutherford gelten lassen, daB die Anzahl HeliumAtome, welche pro Sekunde durch $1 \mathrm{~g}$ Radium produziert werden, viermal $3,4.10^{10}$ beträgt, weil in dein Radium vier Produkte vorkommen, von denen ein jedes pro Sekunde die gleiche Anzahl von Korperchen $\alpha$, das ist Helium-Atome, fortschleudert. Wenn man demnach das Volumen des in der Sekunde entstandenen Heliums kennt, weiB man, wieviel Atome dieses Volumen enthălt, und erhalt folglich direkt die Anzahl $\mathbf{N}$ der in einem Gramm-Atom Helium enthaltenen 
Atome. Nun gibt es sehr sorgfältig ausgeführte; Dewar zu ve. dankende Bestimmungen des Volumens des in einem Tage aus $1 \mathbf{g}$ Radium entstandenen Heliums (das ist $0,37 \mathrm{cmm}^{3}$ ). Und wie M ouli $\mathrm{n}^{1}$ ) beobachtete, führt dies für $\mathrm{N}$ zu dem Wert $71.10^{22}$, welcher noch immer den von mit durch das Studium der Brown'schen Bewegung erhaltenen sehr nahe liegt.

Die auferordentliche Uebereinstimmung der auf so grundverschiedenen Wegen erhaltenen Resultate ist um so überraschender, als dieselben keinen, selbst unbewuBten Einflub aufeinander ausüben konnten; so hat zum Beispiel Moulin seine Berechnung erst nach Vollendung und Publikation meiner Untersuchungen durchgeführt.

\section{Aus den Gesetzen der "schwarzen" Strahlung ermittelte Werte.}

Endlich wird man es nicht minder überraschend finden, fast die gieichen Zahlen mittelbar durch Messungen zu erhalten, welche sich auf die infrarote Partie des Spektrums beziehen. Die betreffenden Untersuchungen sind von Lorentz und Planck angestellt worden.

Die-kinetische Theorie der Metalle, wie sie von J.J.Thomson und $\mathrm{Drude}^{2}$ ) aufgestellt wurde, enthält die Grundannahme, daB in den .Metallen elektrische Korpuskeln enthalten sind, weiche mit denjenigen, welche die Kathodenstrahlen bilden, identisch sind, und die sich in dem Metall wie die Moleküle eines Gases nach allen Richtungen bewegen. Jede Bewegung der Elektrizităt in dem Leiter ist eine Bewegung aller dieser Korpuskeln; weiter wächst ihre mittlere Bewegungsenergie mit der Temperatur. Lebhafter bewegt in den heileren Regionen des Metalls, übertragen sie durch ihre StöBe die stärkere Bewegung nach und nach und das ist, was wir als die Wärmeleitung der Metalle bezeichnen. Diesen Gedanken drückt Drude genauer aus, indem er annimmt, daß die mittlere Korpuskelenergie gleich ist der mittleren Molekularenergie, und er zeigte, daB die thermische Leitfăhigkeit daher der elektrischen proportioniert sein muB, was das bekannte Gesetz von Wiedemann-Franz ist; er konnte weiter a priori den Proportionalitătskoeffizienten rechnen, und dieser so erhaitene Wert stimmt mit den Werten, welche die verschiedenen Metalle geben, gut überein.

Diese bemerkenswerte gute Uebereinstimmung rechtfertigt die Hypothese von Drude (und erweitert noch, diesmal in der Richtung

1) La valeur la plus probable de la charge atomique (Le Radium 6, 164, 1909).

a) Ihre Abhandlungen siad in den ,Ions, Électrons et Corpuscules" (GauthierVillars) abersetzt. 
gege. das unendlich Kleine, das, was wir von der gleichen Energieverteilung wissen).

Lorentz beobachtet, daB diese Korpuskeln, die sich nach allen Richtungen bewegen, nach einem bekannten elektromagnetischen Gesetze jedesmal Energie ausstrahlen, wenn sich ihre Geschwindigkeit an Richtung und Grobe andert und daf diese Strahlung dem Lichte entspricht, welches das Metall bei der betreffenden Temperatur aussendet ${ }^{1}$ ).

Lorentz rechnet diese Strahlung," entwickelt behufs ihrer Zerlegung in Strahlen von verschiedener. Wellenlänge Fourier'sche Reihen und besçhrānkt sich dann auf diejenigen Strahlen, deren Wellenlănge im Verhältnis zur mittleren Wegstrecke der Korpuskeln eine sehr große ist. Ebenso rechnet er für diese gróßen Wellenlängen das Absorptionsvermögen des Metalis und erhălt (nach dem Gesetze von Kirchh of f) durch Division des Ausstrahlungsvermögens durch das Absorptionsvermögen den Ausdruck für die schwarze Strahlung ${ }^{2}$. Das Resultat ist, daB die Strahlungsenergie für die Volumseinheit d A. entsprechend den Wellenlängen zwischen $\lambda$ und $\lambda+d \lambda$, gleich ist $\frac{16 \pi}{3} W \frac{d \lambda}{\lambda^{4}}$, wobei $W$ die Energie der Korpuskeln (oder der Moleküle) bei der betrachteten Temperatur bedeutet. Diesen Ausdruck kann man daher eben so gut auch schreiben $8 \pi \frac{R T}{N}-\frac{d \lambda}{\lambda^{4}}$, und, um $N$ zu bekommen, braucht man nur diese Energie zu messen (was in den zahlreichen Messungen, die sich auf die Energieverteilung im Spektrum de? schwarzen Korpers beziehen, wenigstens annähernd geschehen ist). Aus den Bestimmungen von Lummer und N. Pringsheim ethalt Lorentz auf diese Art für $\mathrm{N}$ den Wert 77.1022.

Unabhängig von Lorentz und mittels einer komplizierteren Theorie war Max Planck schon früher zu derselben Formel gelangt. Durch die experimentell gefundenen Resultate erhălt er für $\mathrm{N}$ den etwas abweichenden Wert $61.10^{22}$. Das Mittel aus den beiden letzten Zahlen ist $69.10^{22}$, also den vorangegangen sehr nahegelegen.

Man sieht, dab man ohne $Z$ weifel in diesem Sinne eine genaile Bestimmung vòn $\mathrm{N}$ wird durchführen können, sobald man der Strahlungskonstanten sicherer sein wird.

1) Ich glaube auf Orund verschiedener Betrachtungen annehmen zu konnen, daB wir in dieser Strahlung eine Art Brown'scher Bewegung des Aethers vor uns haben.

7) Diese durch Langevin vereinfachten Rechnungen sind im ersten Bande ter It as, Étectrons, Corpuseules, S. 500 enthalten. 


\section{Vergleich aller erhaltenen Werte.}

In dếr nachfolgenden Tubelle sind die verschiedenen Phänomenen, welche .zur Bestimmung von $\mathrm{N}$ gedicnt haben, übersichtlich zusammengestellt. Die im allgemeinen gute Uebereinstimmung der Resultate kann als cier Beweis der realen Existenz der Moleküle betrachtet werden.

$$
\text { Studierte Phänomene. } \quad \text { N.10-23 }
$$

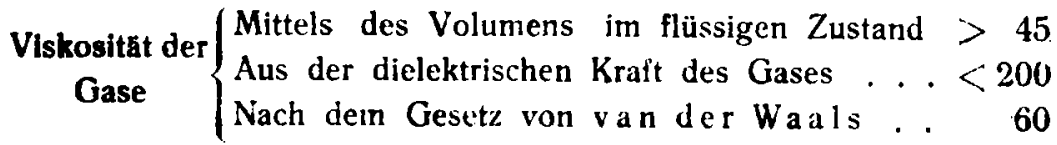

Brown'sche $\begin{cases}\text { aus d.Verteilung einer gleichförnigen Suspension } & \mathbf{7 0 , 5} \\ \text { aus der mittlerenVerschiebung in einergegeb. Zeit } & \mathbf{7 1 , 5} \\ \text { aus der mittleren Rotation in einer gegeb. Zeit } & \mathbf{6 5}\end{cases}$

Diffusion der gelösten Körper . . . . . . . . . . . 40-90

Beweglichkeit der lonen in Wasser . . . . . . . 60-150

Glanz des Himmelsblaus . . . . . . . . . . . . . . . 30-150

Direkte Messung der $\{$ Auf den lonen kondensierte Tröpfchen 60--90

atomaren Ladung Auf fein. Staubteilchen angelagerte lonen 64

Aussendung von (Gesamte ausgestrahlte Ladung . . . 62

Korperchen $\propto$ Zeitkonstante des Radiums . . . . 70,5

Durch das Radium produziertes Helium 71

Energie des infraroten Spektrums ........... 60-80

Der wahrscheinlichste Wert scheint mir stets $70,5.10^{22}$; die entsprechenden anderen molekularen Gröfen sind in den Paragraphen 26 und 27 angegeben.

\section{Die Wirklichkeit der Moleküle.}

Angesichts der Tatsache, daB so außerordentlich verschiedene Erscheinungen zu fast demselben Werte führen, ist es schwer, wenn nicht unmöglich, ein Gegner der Molekularhypothese zu sein.

Wir sollen endlich auch in der Lage sein, die verschiedenen realen Zahlen der Masse oder der Ladung, deren Größe wir bestimmen konnten, stets durch sichtbare Elemente auszudrücken, ohne zu unsichtbaren unsere Zuflucht nehmen zu müssen. Es ist in der Tat leicht zu zeigen, daß dies bei allen in Laufe dieser Abhandlung besprochenen Erscheinungen gelingt.

Was zunächst jede's cinzelne Gesetz betrifft, ist die Konstante $\mathrm{N}$ einfach ein numerischer Faktor in dem vollkommen bekannten A isdruck des Gesetzes. So wird zum Beispiel das von A. Einste in 
aufgestellte und im Laufe dieser Arbeit besprochene Bewegungsgesetz

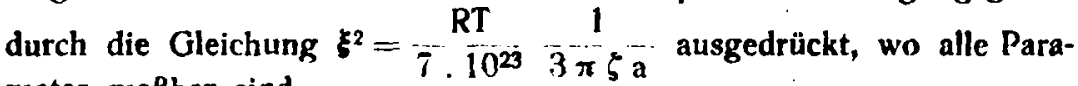
meter meBbar sind.

Ein vielleicht interessanteres Ergebnis erhălt man durch Vergleichung zweier Gesetze, in denen die Konstante von Avogadro figuriert. Das eine dieser Gesetze drückt die Konstante als Funktion bestimmter verănderlicher Parameter, $a, a^{\prime}, a^{\prime \prime}, \ldots$ aus : $\dot{N}=f\left[a, a^{\prime}, a^{\prime \prime}, \ldots .,\right]$; Das andere drückt sie als Funktion anderer veränderlicher Parameter h, $\mathbf{b}^{\prime}, \mathbf{b}^{\prime \prime}, \ldots$ aus: $N=\mathbf{g}\left[\mathbf{b}, \mathbf{b}^{\prime}, b^{\prime \prime}, \ldots\right]$.

Wenn man diese beiden Ausdrücke gleichsetzt, so ergibt sich eine Beziehung $f\left[a, a^{\prime}, a^{\prime \prime}, \ldots\right]=g\left[b, b^{\prime}, b^{\prime \prime}, \ldots\right]$, die nur reale Größen enthält, und welche einen tiefen Zusammenhang zweier Phănomene ausdrückt, welche im ersten Anblick voneinander vollkommen unabhängig schienen (z. B. Umwandlung des Radiums und Brown'sche Bewegung). Wenn wir zum Exempel das Verteilungsgesetz der Energie A der schwarzen Strahlung als Funktion der Wellenlănge (Nr. 41) und das Verdünnungsgesetz einer gleichförmigen Suspension ais Funktion der Schwere (Nr. 14) vergleichen, so finden wir, dab sie voneinander keineswegs unabhängig sind, sondern durch die Gleichung

$$
\frac{1}{\mathrm{dA}} \cdot \frac{\mathrm{d} \lambda}{\lambda^{4}}=\frac{1}{8 \pi} \log \frac{n_{0}}{\mathrm{n}} \frac{1}{\left(\Delta-\frac{1}{\sigma}\right)}-\frac{\mathrm{gh}}{\mathrm{g}}
$$

zueinander in Beziehung stehen, in welcher alle Größen durch Messung zugänglich sind.

\section{SchluB.}

Ich glaute in der vorliegenden Abiandlung den gegenwärtigen Zustand unserer Kenntnisse über die Brown'sche Bewegung sowie über die molekularen Groben entwickelt zu haben. Was ich personlich durch Vernunftschlüsse oder Experimente zu diesen Kenntnissen beizutragen versucht habe, wird, wie ich hoffe, klarmachen, dab die Beobachtung der Suspensionen den Molekulartheorien eine feste experimentelle Basis gibt. Die wichtigsten im Laufe dieser Arbeit aufgestellten Resultate sind, kurz zusammengefabt, folgende:

Die Bereitung von Suspensionen mit gleichen runden Körnern von genau gemessenem und beliebig gewăhltem Halbmesser.

Erweiterung des Stokes'schen Gesetzes auf das Gebiet der mikroskopischen Gröten.

Der Beweis, daB die Gasgesetze sich auch auf die gleichförmigen Suspensionen anwenden lassen. 
Die genaue Bestimmung der verochicienen molekularen Groben und der Ladung des Elektrons.

Die experimentelle Bestatigung der Rotationen und Translationen, der gleichen Energieteilung als auch der schönen theoretischen Untersuchungen A. Einstein's.

Und endlich davon ausgehend, eine zweite, mit der ersten äbereinstimmende Resultate gebende, genaue Bestimmung der verschiedenen molekularen GröBen.

Wie ersichtlich, wurde ich in diesem letzteren Teil von Herrn Chaudesaigues unterstutzt, welcher mit viel Geschicklichkeit die meisten Punktierungen der Verschiebungen für das Gummigutti vorgenommen hat. Ferner bin ich Herm Dabrowski zu vielem Dank verpflichtet, der mir half, die mit dem Gummigutti gemachten Experimente mit einer zweiten Substanz, dem Mastix, zu wiederholen.

(Ann. de Chim. et de Phys., 8. Serie, 18, Sept. 1909.) 